\title{
ECKARD LEFÈVRE
}

\author{
Versuch einer Typologie des römischen Dramas
}




\title{
VERSUCH EINER TYPOLOGIE DES ROOMISCHEN DRAMAS *
}

\author{
Von Eckard Lefèvre
}

Inhalt : Einleitung: Die Eigenständigkeit des römischen Dramas S. 1. I. Das Weltbild des römischen Dramas S. 4. 1. Die Tragödie S. 4. 2. Die Komödie S. 24. II. Die Struktur des römischen Dramas S. 41. 1. Die Tragödie S. 41. 2. Die Komödie S. 66. Ausblick: Die Einheit des römischen Dramas S. 85. Nachbemerkung S. 89.

\section{EINLEITUNG:}

\section{Die Eigenständigkeit des römischen Dramas}

Während in der langen Geschichte der Rezeption und Erforschung der Literatur der Antike erst unser Jahrhundert zu erkennen und auch nachzuweisen vermochte, daß die römische Literatur unbeschadet des entscheidenden Einflusses der griechischen Vorbilder in nahezu allen Genera eine ausgeprägte Eigenart entwickelt hat, die nur aus dem Denken und den geschichtlichen Bedingungen dieses Volkes zu erklären ist, wird der künstlerische Wert des römischen Dramas noch immer relativ gering eingeschätzt. Dieses ist um so erstaunlicher, als gerade aus der Nachahmung und Nachgestaltung der römischen Komödien und der Tragödien Senecas im 15. bis 17. Jahrhundert das europäische Drama nicht nur entstanden ist, sondern sich darüberhinaus in steter Rezeption zu seiner charakteristischen Form ausgebildet hat. Kaum ein Zweig der römischen Literatur hat in den ersten Jahrhunderten der europäischen Neuzeit einen solchen Anklang gefunden wie das römische Drama, ja bei der Komödie darf von einer gewissen Popularität gesprochen werden. Aus diesem Umstand mag es sich erklären, daß in der Zeit des erwachenden Griechenenthusiasmus am

* Vgl. die Nachbemerkung S. 89. 
Ende des 18. Jahrhunderts das römische Drama wie kaum ein anderes Gebiet der römischen Literatur getroffen wurde. Das Drama wurde nicht nur als Depravierung der attischen Vorbilder betrachtet, es wurde seinen Dichtern sogar eine eigene künstlerische Absicht bestritten. Das Urteil August Wilhelm Schlegels über Plautus und Terenz in der 14. >Vorlesung über dramatische Kunst und Litteratur< ist hierfür bezeichnend:

Im Einzelnen haben [...] die griechischen Dichter gewiß immer durch die lateinische Nachbildung verloren. Man muß diese in Gedanken in jene sorgfältige Zierlichkeit, die wir an den Bruchstücken wahrnehmen, zurückübertragen. Indessen haben Plautus und Terenz auch an der Anordnung des Ganzen manches verändert und schwerlich verbessert. Jener ließ zuweilen Szenen und Charaktere weg, dieser fügte hinzu und verschmolz zwei Stücke in eins. Taten sie dies in einer künstlerischen Absicht und wollten wirklich ihre griechischen Vorgänger in dem vollkommenen Bau der Stücke übertreffen? Ich zweifle.

Und über Senecas Tragödien in der 15. Vorlesung:

Mit den alten Tragödien, jenen höchsten Schöpfungen des poetischen Genius der Griechen, haben diese nichts weiter gemein als den Namen, die äußre Form und die mythologischen Stoffe; und doch stellen sie sich neben jene, sichtbar in der Absicht, sie zu überbieten, was sie ungefähr so leisten, wie eine hohle Hyperbel gegen die innigste Wahrheit.

Es ist wohl kaum zu bestreiten, daß sich die Wertschätzung des römischen Dramas bis heute nicht von den Verdikten dieser Epoche freimachen konnte, scheint doch der Vergleich mit den griechischen Vorbildern die römischen Stücke stets nur als sekundäre Produkte zu erweisen. Dieses Urteil mag freilich insofern entschuldbar sein, als die Römer selbst das Drama nicht unter die bedeutenden Leistungen ihrer Dichter gerechnet zu haben scheinen. Von der republikanischen Tragödie ist kein Stück überliefert, und auch Senecas Dramen haben offenbar keinen besonderen Anklang gefunden; über die Komödie schließlich hatte der Antiquar Gellius im zweiten nachchristlichen Jahrhundert geurteilt, man lese die römischen Stücke besser ohne die griechischen Originale; denn wenn man diese vergleichend danebenhalte und Einzelheiten mit Überlegung in abwechselnder Lektüre betrachte, begännen die römischen Nachbildungen kraftlos und ohne Reiz zu werden und gegenüber dem griechischen Witz und Glanz zu verblassen $(2,23,3)$ :

sed enim si conferas et componas Graeca ipsa, unde illa venerunt, ac singula considerate atque apte iunctis et alternis lectionibus committas, oppido quam 
iacere atque sordere incipiunt, quae Latina sunt; ita Graecarum, quas aemulari nequiverunt, facetiis atque luminibus obsolescunt.

Mangelnde Originalität und minderen künstlerischen Wert der drei erhaltenen römischen Szeniker Plautus, Terenz und Seneca glaubt man schon daraus erklären zu können, daß man die Eigenart der ersten beiden auf das noch 'primitive' Kunstwollen der archaischen Zeit, die des letzten auf das nicht minder 'primitive' Kunstwollen der Verfallsperiode zurückzuführen pflegt. Man wäre gewiß erstaunt, wären der 'Thyestes von Lucius Varius Rufus aus dem Jahre 29 v. Chr. oder die >Medea< Ovids von der Zeitenwende erhalten, Zeugen der klassischen und der Übergangs-Periode vor sich zu haben, die in vielen Zügen nicht weniger 'archaisch' oder 'kaiserzeitlich' anmuteten als die archaischen oder kaiserzeitlichen Stücke.

Der Grundfehler bei der Würdigung des römischen Dramas ist es, die einzelnen Stücke jeweils neben die erhaltenen griechischen Vorbilder bzw. neben entsprechende Originale zu stellen oder an diesen zu messen. Die klassische griechische Tragödie drängt sich auf einen kleinen Zeitraum im 5. Jahrhundert zusammen, die griechische Neue Komödie - die allein für Rom wichtig geworden ist - auf eine ebenso kurze Periode an der Wende des 4. zum 3. Jahrhundert. Sowenig es die künstlerische Entwicklung dieser Genera in Athen gestattete, sich ad libitum fortzusetzen, konnte es möglich sein, sie in einer ganz anderen Kultur - in Rom - unter völlig verschiedenen Bedingungen zu neuem Leben $\mathrm{zu}$ erwecken oder gar folgerichtig weiterzuentwickeln. Es wäre höchstens eine strenge Adaption oder gar eine Ubersetzung in Frage gekommen. In der Tat hat man, wenigstens bei der Komödie und der republikanischen Tragödie, früher weitgehend mit einer mehr oder weniger freien Ubersetzertätigkeit der römischen Dichter gerechnet und überall da, wo kein griechisches Original vorliegen konnte, Mißverständnisse des Bearbeiters, sei es einzelner Stellen der Vorbilder, sei es der Intentionen ganzer Stücke angenommen. Daß man Terenz vielfach als den bedeutendsten römischen Szeniker schätzt, weil er am engsten - wie man meint: am verständnisvollsten - die griechischen Vorbilder nachgestaltet habe, ist noch heute eine Folge dieser Betrachtungsweise. Eine eigene 'künstlerische Absicht' hat nicht nur August Wilhelm Schlegel, sondern weitgehend auch die Forschung dem republikanischen Drama abgesprochen. Da dies bei Senecas Tragödien wegen der überragenden Persönlichkeit des Autors nicht ebenso möglich war, schob man sie lange Zeit kurzerhand beiseite. 
Schon aus dem Umstand, daß die Römer die griechischen Vorbilder nicht einfach übersetzten, ergibt sich, daß die römischen Stücke in dem Selbstverständnis ihrer Dichter nicht 'sekundär' waren. Zielten die römischen Dichter aber auf etwas anderes als die griechischen, sind ihre Stücke notwendig mit anderen Maßstäben zu messen als jene. Da aus einem verschiedenen Weltbild auch eine andersartige Struktur der Stücke folgt, bilden diese beiden wesentlichen Komponenten des römischen Dramas den Gegenstand der folgenden Betrachtungen.

\section{Das Weltbild Des Römischen Dramas}

\section{Die Tragödie}

In der Geschichte der Literatur pflegt die Tragödie einen Höhepunkt innerhalb der Ausbildung der literarischen Genera darzustellen und zumeist Epochen zuzugehören, die als klassisch gelten. Jedenfalls setzt ihr Auftreten einen hohen Grad an Bewußtwerdung des menschlichen Geistes und dementsprechend seiner literarischen Ausdrucksformen voraus. Während der Epiker in seinem Gedicht Leben und Wirken des Menschen in der Welt beschreibt und damit indirekt auch deutet, empfindet der Tragiker die Lebensbedingungen des Menschen als Problem. Er stellt nicht mehr einfach nur dar, sondern argumentiert, ihm geht es nicht mehr um das So-Sein des Menschen, sondern um die Begründung dieses So-Seins. Hegels Bemerkungen in der >Aesthetik treffen vor allem auf die Tragödie $\mathrm{zu}$ :

Das Drama ist das Produkt eines schon in sich ausgebildeten nationalen Lebens. Denn es setzt wesentlich sowohl die ursprünglich poetischen Tage des eigentlichen Epos als auch die selbständige Subjektivität des lyrischen Ergusses als vergangen voraus, da es sich, beide zusammenfassend, in keiner dieser für sich gesonderten Sphären genügt. $Z u$ dieser poetischen Verknüpfung muß das freie Selbstbewußtsein menschlicher $Z$ wecke, Verwicklungen und Schicksale schon vollkommen erwacht und in einer Weise gebildet sein, wie es nur in den mittleren und späteren Entwicklungsepochen des nationalen Daseins möglich wird. So sind auch die ersten großen Taten und Begebnisse der Völker gemeinhin mehr epischer als dramatischer Natur [...], und erst später treten jene selbständigeren einsamen Helden auf, welche aus sich heraus selbständig $Z$ wecke fassen und Unternehmungen ausführen. 
Je weiter der Tragiker fragt, desto notwendiger stößt er an die Grenze - um sie später zu überschreiten -, innerhalb deren die Lebensbedingungen des Menschen noch als geordnet, als sinnvoll, als im Transzendenten gründend erklärt werden können. Die Tragödie trifft in ihrer konsequenten Ausrichtung auf Erhellung des Metaphysischen schließlich ins Dunkel, indem sie erkennen muß, daß der Mensch ganz auf sich gestellt ist und sein Leben nur insoweit einen Sinn hat, als er ihm einen solchen zu verleihen imstande ist. Den Vorgang, "wie sich die noch glaubende und vertrauende Seele immer stärker in die Unentrinnbarkeit des Unglaubens, in das Wagnis des Zweifels und in die Verzweiflung hineingerissen sieht", zeigt die Entwicklung der deutschen Tragödie von Lessing bis Hebbel nach B. v. Wiese ebenso wie die griechische Tragödie von Aischylos bis Euripides. Von der Konzeption einer von außen an den Menschen herantretenden Zwangslage bei Aischylos schreitet die attische Tragödie zu der Darstellung des erst im Innern des Menschen entstehenden Konflikts bei Sophokles fort, um bei Euripides eine Kollision sittlicher Normen kaum noch zuzulassen. Es versteht sich, daß es von dem durch die Götter unverdient geschlagenen Oidipus nur ein Schritt zu der Infragestellung des Transzendenten bei Euripides war. Doch ist Euripides weit davon entfernt, eine einheitliche Weltdeutung zu geben. Vielmehr spiegelt die Mannigfaltigkeit seiner Lösungen die Krise seiner Zeit wider. Resignieren und Experimentieren sind stets Zeichen, daß die Tragödie

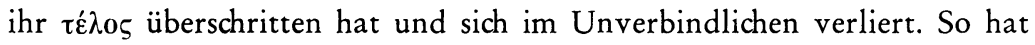
Euripides eine Reihe von untragischen Stücken wie die >Helena oder den Ion geschrieben, die am ehesten als Schauspiele zu bezeichnen sind und mit ihrer Tyche-Konzeption eine direkte Vorstufe der späteren Neuen Komödie bedeuten. Auf der anderen Seite ist es klar, daß der Zweifel am Transzendenten meist aus einem $Z$ weifel am Menschen resultiert. Bei Euripides scheint der Orestes diesen Prozeß am deutlichsten zu zeigen. Jedenfalls hat W. Burkert ihn als 'Gangsterstück' gedeutet, das die „Katastrophe der Tragödie selbst“ bedeute, insofern „einer kriminalisierten Gesellschaft [...] auch die Tragödie abhanden" gekommen sei.

Obschon die folgenden Jahrhunderte ein Übermaß an tragischer Produktion brachten, war mit Euripides die große Zeit der griechischen Tragödie vorbei. Dem ruhigen demokratischen und bürgerlichen Weltbild des vierten Jahrhunderts konnte die eigentliche Tragödie keine adäquate Ausdrucksform mehr sein. Typisch für diese Zeit ist der unter Euripides' Namen überlieferte, Rhesos`, in dem an die Stelle wesentlicher Ausein- 
andersetzungen nach A. Lesky kleine 'Teilkonflikte' getreten sind und ein Aspekt echter Tragik gar nicht sichtbar wird. Daher ist es kein Wunder, daß man seit etwa 386 Stücke alter Meister wiederaufführte und sich deutlich bewußt war, an ihre Leistungen nicht mehr heranzureichen. So sind uns Verse des jüngeren Astydamas erhalten, in denen er bekennt, daß er mit den alten Dichtern nicht wetteifern könne. Wurden zunächst die traditionellen Stoffe immer wieder neu gestaltet, so brachte die Tendenz der hellenistischen Dichter, sich gerade entlegener Stoffe anzunehmen, auch für die Tragödie neue Themen auf die Bühne. Wieweit damit neue Problemstellungen verbunden waren, läßt sich schwer beurteilen, doch dürfte das Gewicht vor allem auf rhetorisch-pathetischer Ausgestaltung gelegen haben - was fast stets ein Symptom für Sinnentleerung ist. Die verrätselte Sprache der erhaltenen >Alexandra< Lykophrons dürfte freilich auch für jene Zeit einen Extremfall bedeutet haben. Andererseits hat sich die nachklassische Tragödie, wie schon Aischylos in den >Persai<, vereinzelt geschichtlichen und zeitgenössischen Themen zugewandt; Lykophrons 'Kassandreis` etwa ist diesen, Theodektes' >Maussolos` und Philikos' >Themistokles jenen zuzurechnen. Doch scheint diese Thematik nur eine untergeordnete Rolle gespielt zu haben. Ganz vereinzelt steht schließlich die 'Exagoger des Juden Ezechiel, ein Mosesdrama aus der jüdischen Heilsgeschichte, das um 200 v. Chr. entstanden ist und von dem 269 Verse erhalten sind.

Dieser kurze Uberblick über die Entwicklung der griechischen Tragödie zeigt, daß der einst einheitliche kraftvolle Strom der attischen Tragödie in mannigfaltige, doch im ganzen spärliche Rinnsale auseinandergeflossen war, als man im Jahre 240 v. Chr. in Rom beschloß, an den Festen auch Tragödien nach griechischem Brauch aufzuführen. In der griechischsprachigen Welt Süditaliens und Siziliens waren römische Soldaten bereits mit der zeitgenössischen auf Repräsentation und Unterhaltung zielenden griechischen Tragödie in Berührung gekommen, und es war naheliegend, daß sie auch in der Heimat nach unterhaltsamen Spektakeln verlangten. Jedenfalls war es von vornherein vorgezeichnet, daß die römische Tragödie nicht an die klassische griechische Tragödie anknüpfen konnte, da Weltbild und Weltdeutung im 5. Jahrhundert in Athen und im 3. Jahrhundert in Rom wegen der anderen geschichtlichen und gesellschaftlichen Voraussetzungen grundverschieden waren. Die veräußerlichte Sehweise des hellenistischen Publikums dürfte auch der römische Dichter gehabt haben. Bekannt ist, daß Horaz die römische Tragödie nicht sonderlich 
hoch geschätzt hat; und wenn sich seine Charakteristik, die er in der Augustus-Epistel 2, 1 gibt, auch auf Eindrücke aus seiner Zeit beziehen mag, so steht sie doch immerhin innerhalb einer längeren Betrachtung, die der gesamten Tragödie gilt und von der Zeit nach dem Ersten Punischen Kriege ihren Ausgangspunkt nimmt. Verlagert habe sich, stellt Horaz fest, das Vergnügen von den Ohren zu den unstet schweifenden Augen und nichtigem, inhaltslosem Genuß, ad incertos oculos et gaudia vana (V. 188). Vier oder mehr Stunden bleibe der Vorhang geöffnet, während Scharen von Reitern und Haufen von Fußvolk über die Bühne eilten; darauf würden gefesselte Könige in ihrem 'Glück' über die Bühne geschleppt; Streitwagen, Kutschen, Kaleschen und Schiffe zögen vorüber; aus Korinth erbeutetes Elfenbein werde dahergetragen. Wäre Demokrit der lachende Philosoph - auf Erden, er würde es belächeln, wenn eine Giraffe, die Mischung aus Kamel und Panther, oder ein weißer Elefant die Aufmerksamkeit der Menge auf sich lenke; er würde das Volk aufmerksamer als das Spiel betrachten, weil es ihm mehr 'Theater' als die Bühne böte. Die Dichter aber, müßte er glauben, erzählten ihr Stück einem tauben Esel. Denn welche Stimmen vermöchten die Geräuschkulisse römischer Theater zu übertönen? Man müsse glauben, das GarganusGebirge oder das Tyrrhenische Meer heulen zu hören: mit solchem Lärm würden die Spiele betrachtet sowie die Kunst und Schätze der Fremde:

190

quattuor aut pluris aulaea premuntur in horas,

dum fugiunt equitum turmae peditumque catervae;

mox trahitur manibus regum fortuna retortis,

esseda festinant, pilenta, petorrita, naves,

captivum portatur ebur, captiva Corinthus.

si foret in terris, rideret Democritus, seu

195

diversum confusa genus panthera camelo

sive elephans albus volgi converteret ora;

spectaret populum ludis attentius ipsis,

ut sibi praebentem nimio spectacula plura;

scriptores autem narrare putaret asello

200

fabellam surdo. nam quae pervincere voces

evaluere sonum, referunt quem nostra theatra?

Garganum mugire putes nemus aut mare Tuscum:

tanto cum strepitu ludi spectantur et artes

divitiaeque peregrinae.

Es ist kaum anzunehmen, daß das Publikum in dem Jahrhundert der Punischen Kriege weniger schaulustig, ja gebildeter gewesen wäre als in 
der Blütezeit der römischen Literatur unter Augustus. Im Gegenteil: ein zeitgenössischer Text, der noch zur Sprache kommen wird, zeigt dasselbe Bild für die Komödie. Es stellt sich daher die Frage, wie die Tragödiendichter in einer Zeit, für die echte Tragödie kein adäquates literarisches Ausdrucksmittel war, das Publikum für ihre Stücke zu gewinnen vermochten. Denn daß die Thematik neben der szenischen Zurschaustellung nicht ganz bedeutungslos war, wird man ja nicht annehmen können.

Es versteht sich, daß in diesem Zusammenhang gerade die Anfangsphase der römischen Tragödie in Betracht zu ziehen ist, die durch die drei Dichter Livius Andronicus, Naevius und Ennius repräsentiert wird. Bei ihren Tragödien ist die überraschende Beobachtung zu machen, daß diese Dichter offenbar versucht haben, mit der in Rom neuartigen Dichtung vor allem den historischen Sinn der Römer anzusprechen, und zwar, wie noch deutlich erkennbar ist, auf zweierlei Weise: einerseits entnahmen sie ihre Stoffe der für Rom besonders wichtigen Troia-Sage, zum anderen wählten sie aus dem griechischen Mythos mit Vorliebe solche Helden aus, die in irgendeiner Beziehung zu Italien, meist Latium oder gar Rom, gestanden hatten. Man darf in den historischen und aitiologischen Tendenzen der frührömischen Tragödie den Grund für ihre Entstehung in Rom überhaupt vermuten.

Die Troia-Sage ist schon in alter Zeit mit der römischen Frühgeschichte in Verbindung gebracht worden. So soll Odysseus auf seinen Irrfahrten, wie bereits die Griechen zu berichten wußten, auch zu der an der südlichen Küste Latiums lokalisierten Kirke gelangt sein. Der Historiker Hellanikos von Lesbos vom Ende des 5. Jahrhunderts überlieferte sogar, daß Odysseus mit Aeneas in Latium zusammengetroffen sei und beide Rom gegründet hätten. Wenn man sich auch später für Aeneas als Nationalheros entschied, darf nicht vergessen werden, daß sich auch Odysseus als Ktistes eines guten Renommées in Rom erfreute. Es ist von hohem Interesse, daß die troische Abstammung der Römer gerade in der Zeit, als die Tragödie in Rom Fuß faßte, besondere Aktualität gewann, insofern sie politischer Argumentation nutzbar gemacht wurde. Als 281 die Tarentiner König Pyrrhus von Epirus um Hilfe gegen die Römer baten, gab dieser der Hoffnung Ausdruck, wie Pausanias 1, 12, 1 berichtet, er werde als Nachkomme Achills gegen die Nachkommen der Troer erfolg-

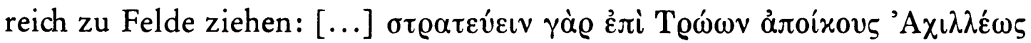

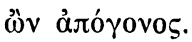


Umgekehrt wurde das Argument im Sinne der Römer verwendet, als bald nach 240 die Akarnanen die Römer um Hilfe gegen die Aetoler mit der Begründung baten, wie der Geograph Strabo 10, 2, 25 überliefert, sie seien die einzigen Griechen, deren Vorfahren nicht am Kampf gegen Troia teilgenommen hätten. Es bedarf kaum der Anführung weiterer Zeugnisse, um zu erkennen, daß im Jahre 240 und in der Folgezeit Tragödien mit Themen aus dem troischen Sagenkreis sowohl aufgrund der mythologischen Überlieferung als auch aufgrund des aktuellen politischen Geschehens auf besonderes Interesse bei den Zuschauern in Rom stoßen mußten. So ist es nicht verwunderlich, daß sechs der zehn bekannten Tragödientitel des ersten Tragödiendichters in Rom, des Griechen Livius Andronicus, der Sage um Troia und die Troia-Kämpfer entstammen:

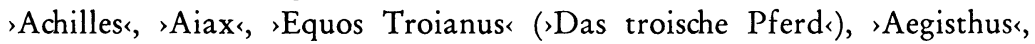
'Hermiona<, ,Teucer،. Noch eindeutiger als bei Livius ist das Verhältnis der Troia-Titel zu anderen Stoffen bei dem ersten römischen Tragödiendichter, dem aus Kampanien stammenden Naevius, der von sieben bekannten Stücken fünf diesem Themenkreis widmete: 'Hector proficiscens (`Der zum Kampf aufbrechende Hektor`), 'Equos Troianus`, ,Andromache‘, ’Hesiona‘, ’Iphigenia‘. Noch Ennius, der schon auf eine längere Tradition der römischen Tragödie zurückblicken konnte, hat die Hälfte seiner tragischen Stoffe - soweit wir sehen können: zehn von zwanzig dem troischen Sagenkreis entnommen.

Die Beliebtheit der Aeneas-Sage gründete sich darauf, daß ein Held aus einem berühmten Geschlecht und einer traditionsreichen Stadt aus dem Osten nach Italien kam und hier zum (Mit)begründer des römischen Volks wurde. Eben diese Verbindung bestimmt die Struktur vieler anderer Stoffe, die die frühen römischen Tragödiendichter auf die Bühne brachten. So schrieben Livius und Naevius eine >Danae،. Die Königstochter wurde von ihrem Vater Akrisios ausgesetzt, weil sie ein Kind bekommen hatte (dessen Vater Zeus selbst war, der sich ihr in Gestalt eines goldenen Regens genaht hatte, was aber Akrisios nicht wissen konnte). Nach griechischer Tradition trieb sie auf der Insel Seriphos an, nach römischer aber in Latium, wo sie Ardea gründete und somit Stammutter des Rutulerfürsten Turnus wurde. Livius schrieb auch eine >Ino،. Diese - auch sie eine Königstochter - wurde aus Theben vertrieben, weil sie gegen Heras Willen dem kleinen Dionysos beigestanden hatte. Während sie nach griechischer Tradition zur Meergöttin Leukothea wurde, kam sie nach römischer ausgerechnet nach Latium in die Gegend des späteren Rom. Ihr Sohn Palai- 
mon wurde dem römischen Hafengott Portunus gleichgesetzt. Ja, selbst von Medea, deren Schicksal zu allen Zeiten an Kolchis und Korinth gebunden war, wußte man zu berichten, daß sie in die Nähe Roms gelangt war und die Marruvier Heilmittel gegen Schlangengift gelehrt hatte. Man sieht: alle diese Stoffe haben dieselbe Wurzel. Helden kommen aus dem Osten nach Latium, von denen sich viele dort ansiedeln - wobei die Blickrichtung der Römer natürlich umgekehrt ist: mit Hilfe solcher aitiologischen Konstruktionen konnten sie ihre Herkunft auf berühmte troische und griechische Heroen zurückführen, ein Bemühen, das für das noch immer aufstrebende Rom bezeichnend war. Gewiß konnten spätere Dichter wie Pacuvius und Accius aufgrund der zunehmenden literarischen Bildung des römischen Publikums einerseits und des im 2. Jahrhundert wachsenden Verständnisses für die griechische Geisteswelt andererseits auch anspruchsvollere Probleme - so möchte man jedenfalls vermuten auf der römischen Bühne gestalten. Aber es ist bezeichnend, daß auch sie nicht auf aitiologisch-historische Verklammerungen verzichten mochten. So berichtet der spätantike Vergilkommentator Servius, daß Accius in seinem >Atreus`, der das gräßliche Mahl des Thyestes zum Inhalt hatte, ausführlich darauf hingewiesen habe, daß Atreus ebenso von Atlas abstamme wie Euander. Dieser aber war der bekannte Arkaderkönig, der am Palatin die Stadt Pallanteum gegründet hatte, die Keimzelle des späteren Rom, wie es auch Vergil im 8. Buch der >Aeneis dargestellt hat. Servius' Nachricht lehrt, daß der letzte bedeutende republikanische, bis in Ciceros Zeit reichende Tragödiendichter Roms nur mit Hilfe eines aitiologischen Exkurses den auf ihre eigene Geschichte fixierten römischen Zuschauern ein Geschehen aus dem griechischen Mythos interessant machen konnte. Auch in dieser letzten Phase der republikanischen Tragödie dürfte das alte Motiv, daß ein Held aus dem Osten nach Latium gekommen war, noch immer die Darstellung des griechischen Mythos gerechtfertigt haben. In welchem Umfang solche 'Verklammerungen' eine Rolle gespielt hatten, läßt sich nicht mehr feststellen, doch scheint es, daß die mythologische Tragödie der Römer nicht nur in ihrer frühen Phase zu einem wesentlichen Teil von aitiologisch-historischen Tendenzen bestimmt war.

Lenkte das aitiologische Interesse der Römer ihre Aufmerksamkeit primär auf den Inhalt der Stücke, so verstand es sich von selbst, daß die Sympathie mit den in diesen Stücken agierenden Vorfahren auch eine Identifizierung mit den von ihnen repräsentierten Haltungen einschloß. Auf diese Weise wurde der Römer, der nach Horaz von Natur aus zu 
Pathos und Erhabenheit neigte: er sei natura sublimis et acer (epist. 2, 1, 165), von den großen Haltungen der tragischen Personen gefesselt - ohne wiederum die Probleme und Fragestellungen dieser Personen, die erst zu diesen Haltungen führten, als Deutung des eigenen Daseins zu begreifen. So hielten neben den troischen Helden auch andere traditionelle Gestalten der tragischen Bühne in Rom Einzug. Wie sehr es dabei aber nur auf die Darstellung erhabener Haltungen ankam, zeigt etwa Ciceros Bemerkung, Pacuvius habe in den $>$ Niptra ( $>$ Die Waschung) die große Sterbeszene von Odysseus 'besser', melius, als Sophokles gestaltet, weil der Held nicht so weine und jammere wie in dem Vorbild; seine Seele gehorche der Vernunft wie ein gehorsamer Soldat seinem gestrengen Feldherrn, rationi sic paruit ut severo imperatori miles pudens (Tusc. 2, 51). Auch in der mythologischen Tragödie stand die virtus-Ideologie im Vordergrund, nicht die tragische Situation, daß der Sohn unwissentlich den eigenen Vater tödlich verwundet hatte. Man vergleiche etwa die Veräußerlichung, daß Ennius in der IIphigeniar statt des Jungfrauenchors des Originals einen rauhen Soldatenchor einführte, der in einem Lied über Langeweile klagte und sich nach Taten sehnte: Das entsprach römischer Mentalität!

Es ist daher nicht verwunderlich, daß diese Tendenzen in der einzigen genuin römischen Dramenform, der nach der purpurgesäumten Toga der curulischen Würdenträger und Feldherrn benannten Praetexta, ihren angemessenen Ausdruck fanden. Schöpfer dieses nationalrömischen Schauspiels war Naevius, der erste italische Dichter, der mit dem >Bellum Poenicum (`Der Punische Krieg`), dem Epos über die römische Frühgeschichte unter besonderer Berücksichtigung des Ersten Punischen Kriegs, zugleich der Schöpfer des römischen Nationalepos war. Gerade diese Species, die ohne jegliche Vorbilder entstand, vermag eindeutiger als jede adaptierte Form der griechischen Tragödie zu demonstrieren, worauf es den Römern in dieser frühen Phase des Bühnenspiels ankam. Unter den noch kenntlichen Praetexten heben sich zwei Stoffkreise heraus: einmal die Sagen aus der Frühzeit Roms - >Lupus` (`Die Wölfin`) und `Romulus` von Naevius, 'Sabinaer (’Die Sabinerinnen ) von Ennius, >Brutus von Accius -, zum anderen historische oder zeitgenössische außenpolitische Ereignisse - >Clastidium` von Naevius, ,Ambraciar von Ennius, ,Paullus und 'Aeneadae vel Decius von Accius. Bei Clastidium hatte der römische Konsul Marcus Marcellus im Jahre 222 den Gallierhäuptling Virdumarus besiegt; Ambracia in Aetolien hatte der römische Konsul Marcus Fulvius Nobilior im Jahre 189 belagert; im >Paullus von Pacu- 
vius handelt es sich um den entscheidenden Sieg des römischen Konsuls Aemilius Paullus über den Makedonenkönig Perseus bei Pydna im Jahre 168 , der die endgültige Unterwerfung Griechenlands bedeutete. In diesen Stücken ging es keineswegs um die Vergegenwärtigung dramatischer Kriegshandlungen; der um die Erforschung der republikanischen Tragödie hochverdiente Gelehrte O. Ribbeck hat aus der Uberlieferung stets nur Episoden rekonstruieren können, die sich zu einem mehr oder weniger gleichförmigen Kontinuum reihten. Vielmehr waren die Historien, wie man diese Stücke am ehesten bezeichnen könnte, einerseits panegyrische Darstellungen der Leistungen einzelner - Romulus, Marcellus, Fulvius Nobilior, Aemilius Paullus, Decius Mus -, zum anderen aber, da gemäß der Ideologie des römischen Volks der einzelne stets hinter der res publica zurücktrat, eine Selbstdarstellung der römischen virtutes. Im >Paullus، von Pacuvius etwa dürfte die Gegenüberstellung des verzweifelnden und kleinmütigen Perseus mit der eindrucksvollen Erscheinung des siegreichen, die Römertugenden überlegen personifizierenden Konsuls den Höhepunkt gebildet haben, während in Accius' >Aeneadae` ('Die Nachkommen von Aeneass) die Selbstaufopferung des jüngeren Publius Decius Mus ihre Wirkung nicht verfehlen konnte. Wie sehr Panegyrik des Individuums mit der Darstellung altrömischer Art Hand in Hand ging, zeigt der >Brutus« von Accius, der die heroische Tat des älteren Brutus, des Befreiers des römischen Volks von den Königen im Jahre 510, zum Inhalt hatte, zugleich aber zum Ruhm des Nachkommen Decimus Iunius Brutus, des Konsuls von 138, beitragen sollte, der ein Freund des Dichters war.

Während es in den begrenzten Möglichkeiten der Bühne begründet ist, daß die äußere Dramatik des Kriegsgeschehens nicht dargestellt werden konnte, ist es um so auffallender, daß sich in keiner der Praetexten auch nur Ansätze zur Gestaltung eines tragischen Geschehens erkennen lassen. In den $>$ Sabinae< von Ennius stiften die geraubten Sabinerinnen zwischen ihren Vätern und ihren Gatten Frieden, wobei eine der Frauen eine entscheidende Rede zwischen den kämpfenden Männern hielt. Wenn F. Leo meinte, diese stünde zwischen Romulus und Titus Tatius wie Iokaste in Euripides' 'Phoinissai< ('Die Phönizierinnen`) zwischen ihren streitenden Söhnen, so zeigt dieser Vergleich, der auf die äußere Struktur der Szene zutreffen mag, gerade den erheblichen Abstand. Denn wie die entsprechenden Reden bei Livius und Ovid lehren, kam es bei dem Konflikt weder wie in dem griechischen Stück auf die Position der einzelnen Parteien noch auf eine Diskussion über Recht und Macht an, sondern einzig 
und allein auf den Opfermut der tapferen Römerinnen, der sowohl die Menge als auch die Führer 'rührt' - movet res cum multitudinem tum duces (Liv. 1, 13,4) -, auf ihre pietas, ihr Pflichtgefühl gegen die Verwandten und die res publica. Die tragische Situation, zwischen zwei gleichwertigen Polen zu stehen, wird durch den Primat der Ideologie der römischen Seite überspielt. Ganz deutlich wird das im `Decius` von Accius, in dem der jüngere Publius Decius Mus sich in der Schlacht von Sentinum 295 als stellvertretendes Opfer freiwillig den Göttern weihte, um sein Heer zu retten. Opfer für die Allgemeinheit hatten auch die Helden der griechischen Tragödie zu bringen. Agamemnon bekam von den Göttern den Befehl, seine Tochter zu opfern, damit das Heer zum Feldzug gegen Troia aus Aulis auslaufen konnte. Er stieß seinen Herrscherstab auf den Boden und konnte die Tränen nicht halten: 'Schwer ist mein Los, wenn

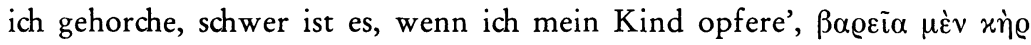

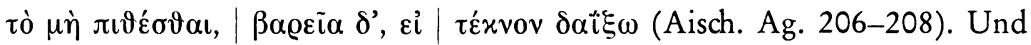
wenn in Euripides' >Phoinissai< Kreons Sohn, Menoikeus, von den Göttern als Opfer für die Errettung Thebens gefordert wird, so weicht dieser, im Gegensatz zum Vater, nicht aus, er stellt sich dem Gebot der Götter zunächst aus persönlichem Grunde, um seine Ehre zu wahren, sodann um die Heimatstadt zu erretten. Von diesen mythologischen Beispielen grundsätzlich verschieden ist die Devotion der römischen Feldherrn, die $\mathrm{f}$ re i w ill ig geschieht, wie im >Decius von Accius. Während der Menoikeus des aufgeklärten Euripides in einem langen Entscheidungsmonolog die Rechte und Pflichten abwägt und über den Sinn des Opfers reflektiert, gibt es für den römischen Konsul nur die bedingungslose Darbringung des Selbstopfers, wie schon für seinen Vater in der Schlacht gegen die Latiner im Jahre 340. Er bittet den Priester, ihm die Worte der Devotionsformel vorzusprechen, mit denen sein Vater den Staat einst gerettet hatte, quibus rem summam et patriam nostram quondam adauctavit pater (frg. 15 W.). Er geht wissentlich in den Tod: 'Nach dem Beispiel meines Vaters will ich mich darbringen und mein Leben den Feinden opfern', patrio exemplo et me dicabo atque animam devoro hostibus (frg. $14 \mathrm{~W}$.). Hier geht es nicht um das Schicksal des Individuums wie in der griechischen Tragödie, sondern um den bedingungslosen Anspruch der Allgemeinheit, der res publica. So sagt Decius bei Livius von seinem Vater und sich, sie seien Opfer, die Bedrohungen der Allgemeinheit zu bannen, luendis periculis $p u-$ $b l i c$ is piacula $(10,28,13)$, und sein Opfer ist ein ungeheurer Ansporn für die anderen, alles für die Allgemeinheit $\mathrm{zu}$ wagen, ingens hortamen 
ad omnia pro re publica audenda $(10,29,5)$ - gemeinsame Sache und Staat, das ist im römischen Denken dieser Zeit dasselbe. Hier wird die Staatsideologie in die Weihe der religiösen Sphäre gehoben.

Es dürfte deutlich sein, daß die Praetexta am ehesten dem entspricht, was Schlegel in seiner 15. Vorlesung das 'Ideal einer ursprünglich römischen Tragödie' nennt, das nie verwirklicht sei:

Mir schwebt das Ideal einer ursprünglich römischen Tragödie vor, dunkel freilich, im Hintergrunde der Zeiten, wie man ein Wesen erkennen mag, das aus dem Schoße des Möglichen nie zur Wirklichkeit geboren worden. Sie hätte von der griechischen an Bedeutung und Gestalt durchaus verschieden, und im altrömischen Sinne religiös und patriotisch sein müssen. Alle wahrhaft schöpferische Poesie kann nur aus dem innern Leben eines Volkes und aus der Wurzel dieses Lebens, der Religion, hervorgehen. Der Geist der römischen Religion war aber ursprünglich, ehe sie nach Einbuße des Gehalts die Oberfläche nach fremder Sitte ausschmückten, ein ganz andrer als der Geist der griechischen. Diese war künstlerisch bildsam, jene priesterlich unwandelbar. Der römische Glaube und die darauf gegründeten Gebräuche waren ernster, sittlicher, frommer, naturdurchschauender, magischer und geheimnisvoller als wenigstens derjenige Teil der griechischen Religion, der außerhalb der Mysterien gelehrt ward. Wie die griechische Tragödie den Kampf des freien Menschen mit dem Schicksal darstellt, so hätte der Sinn einer römischen die Unterwerfung der menschlichen Triebe unter die heiligende, bindende Gewalt, religio, und deren offenbarte Allgegenwart in allen irdischen Dingen sein müssen.

Als Abglanz dieses Ideals darf die Praetexta gelten, wie sie uns heute kenntlich ist. Denn „im altrömischen Sinne religiös und patriotisch“, wie Schlegel das nennt, ist die Praetexta gewiß gewesen. Und in welchem Maße „die Unterwerfung der menschlichen Triebe unter die heiligende, bindende Gewalt, religio" der Sinn einer römischen Tragödie sein kann, lehrt Vergils Darstellung des Aeneas-Schicksals.

Die mythologische Tragödie wurde von den Römern in der Frühphase ihrer tragischen Produktion in derselben Art wie die nationale Praetexta verwendet: als poetisches Gefäß zur Gestaltung nationaler Stoffe. Die mythologische Tragödie brachte die Verbindung der römischen Frühgeschichte mit der griechischen und troischen Welt, die Praetexta sowohl die frührömische Sage als auch im besonderen die Zeitgeschichte zur Darstellung. In beiden Genera steht die Panegyrik nationaler Tugenden, in der Praetexta zudem einzelner Personen aus Sage, Geschichte und Gegenwart im Mittelpunkt. Die frühe römische Tragödie stellt daher nicht eine 
Erscheinungsform dieser Gattung im eigentlichen Sinne dar, sondern ist vom literarhistorischen Standpunkt aus ein atypisches Phänomen. Der Überblick über die Gedankenwelt dieser Stücke macht deutlich, daß es sich bei ihnen um ein Weltbild handelt, das der Welt des Epos entspricht, die im eigentlichen Sinne untragisch ist, da sich das Individuum noch in Ubereinstimmung mit der Gesellschaft befindet. Insofern steht in Rom die Tragödie in ihrer ersten Phase auf der Stufe des Epos, das einer so frühen Zeit eher angemessen ist. Dementsprechend sind manche Stoffe der Praetexten zugleich auch in der zeitgenössischen Epik dargestellt worden. So hat Ennius, der Schöpfer des bekanntesten Epos dieser Zeit, der >Annales ( Jahrbücher ), den Raub der Sabinerinnen und die Belagerung von Ambracia ebenso dramatisch wie episch gestaltet. Wenn daher von einer gewissen Auswechselbarkeit dieser beiden Gattungen gesprochen werden kann, ist gleichwohl nicht zu übersehen, daß die römische Tragödie nicht einfach ein dramatisiertes Epos darstellt. Historisches Argumentieren mit Hilfe des ganzen Werks und Einbindung des Gehalts in ein Heilsgeschehen ist der ursprünglichen Form sowohl des Epos als auch der Tragödie unangemessen: Epos und Tragödie sind somit in Rom in gleicher Weise atypische literarische Phänomene.

Es war bisher vorwiegend von der ersten Phase der republikanischen Tragödie die Rede, weil sich aus ihr die Bedingungen für die Rezeption der tragischen Gattung in Rom besonders deutlich ableiten ließen. Mit den das 2. Jahrhundert beherrschenden Tragikern Pacuvius und Accius begann eine entscheidende Entwicklung der Tragödie, die schließlich zu ihrem Untergang führte. Mit einer Spezialisierung, der auch die abgelegensten Themen verdankt wurden, ging eine gewisse Literarisierung Hand in Hand, die nun auch anspruchsvolle Probleme auf die römische Bühne

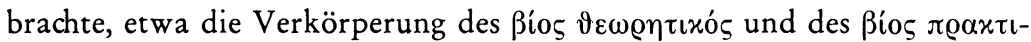
xó $\varsigma$ in Pacuvius' >Antiopa nach dem euripideischen Vorbild, wobei Euripides dem ersten, Pacuvius bezeichnenderweise wohl dem zweiten den Vorrang gab. Während sich die griechische Tragödie zu Euripides hinentwickelte, hatte man in Rom gleich mit Euripides begonnen - freilich in depravierter Form. Es bedurfte erst einer reiferen Stufe der römischen Kultur - Pacuvius gehörte zu den Freunden des jüngeren Scipio und Laelius -, um Euripides überhaupt adäquat wiedergeben zu können. So läuft in Rom die Entwicklung der Tragödie in umgekehrter Richtung als in Athen auf Euripides zu. Damit waren aber nicht nur die Stoffe, sondern auch die Möglichkeiten dieser Gattung erschöpft, so daß sie mit Accius, 
dem letzten bedeutenden Vertreter, um die Wende vom 2. zum 1. vorchristlichen Jahrhundert abstarb.

Nach dem überraschenden Auftreten der Tragödie in republikanischer Zeit hat diese Gattung in der augusteischen Epoche keine besondere Bedeutung erlangt. Dennoch stammen aus ihr zwei Außerungen der Tragödie, die höchstes Interesse beanspruchen. Sie verkörpern zugleich die beiden Erscheinungsformen der republikanischen Tragödie: einerseits die aitiologisch-national ausgewertete mythologische Tragödie, andererseits die panegyrisch-zeitbezogene Praetexta.

Im Jahre 29 v. Chr. wurde aus Anlaß der Siegesfeier für die Schlacht bei Actium, die für die Begründung des augusteischen Imperium entscheidend war, ein Stück aufgeführt, das als die berühmteste römische Tragödie galt und seinem Verfasser die höchste Summe eintrug, die jemals in Rom für ein Bühnenwerk gezahlt worden war: eine Million Sesterzen erhielt Lucius Varius Rufus von Octavian für seinen >Thyestes‘. Sowohl der Anlaß für die Aufführung als auch die Belohnung durch den Herrscher lassen vermuten, daß sich der Charakter des Stücks ganz aus der Tradition der altrepublikanischen Tragödie herleitete. In ihm dürfte nicht wie in Senecas >Thyestes das gräßliche Geschehen im Mittelpunkt gestanden haben, bei dem Atreus seinem Bruder Thyestes aus Rache dessen eigene Kinder zum Mahl vorsetzte, sondern die Fortsetzung des Mythos, nach der Aegisthus seinen Vater Thyestes an Atreus gerächt und den sich über Generationen erstreckenden Streit des Geschlechts zur Ruhe gebracht hatte - so wie Octavian den sich über Generationen erstreckenden Bürgerkrieg beendet hatte. Ein Teil der Handlung dürfte wie im ennianischen 'Thyestes von 169 in Thesprotien gespielt haben, eben jener Landschaft, in der Actium, der Ort der Entscheidungsschlacht lag. Und wenn eine Person in jenem Stück ausrief et me Apollo ipse delectat ductat Delphicus (353 W.), so wird das ebenso der Wahlspruch des varianischen Aegisthus gewesen sein, wie er auf den zu feiernden Sieger Octavian zutraf, der nicht nur bei Actium, sondern zeitlebens Apollo als seinen besonderen Schutzgott betrachtet hatte. Bei diesem Stück dürfte in einem der tragischsten Stoffe der griechischen Bühne zeitgenössische Panegyrik auf der Basis der römischen Herschaftsideologie demselben untragischen Weltbild entsprochen haben wie in der gleichzeitig entstandenen >Aeneis«.

Auch Vergils Werk darf in einer Betrachtung der römischen Tragödie, zumal in Hinsicht auf das vierte Buch, nicht übergangen werden. Eine 
ganze Reihe struktureller Kriterien und Entsprechungen zeigt, daß Vergil die Begegnung zwischen Dido und Aeneas auch formal als Tragödie gestaltet hat. Die Verwandtschaft der beiden Gattungen kann nach den bisherigen Beobachtungen kaum überraschen. Die Thematik des vierten Buchs ist als der vollendete Ausdruck des Weltbilds der epischen Tragödie der republikanischen Zeit anzusprechen. Aeneas hat auf der Flucht von Troia den Auftrag der Götter erhalten, in Italien ein neues Reich zu gründen. Seiner Sendung vergißt er anläßlich eines längeren Aufenthalts bei der Karthagerfürstin Dido. Erst nach einer Mahnung der Götter unterzieht er sich von neuem dem Auftrag und fährt nach Italien. Dido gibt sich in unnennbarer Enttäuschung den Tod. Aeneas gerät, wie R. G. Austin gesagt hat, in einen Konflikt von Pflicht und Neigung, "conflict between duty and desire" - doch zerbricht ihn dieser Konflikt nicht wie den Helden der Tragödie. Das ist ungewöhnlich.

Wenn man bei dem vergilischen Aeneas in Rechnung stellt, daß der Götterauftrag von außen an ihn herantritt, so steht bei ihm - auf den ersten Blick hin - in der Tat Pflicht gegen Neigung. Aber im Grunde genommen - und darin liegt das Außergewöhnliche der römischen Konzeption steht bei Aeneas, richtig verstanden, Neigung gegen Neigung. Denn Aeneas bejaht seine Pflicht. Er legt zwar immer wieder Säumen an den Tag, ja zuweilen Kleinmut - aber echten Zweifel an seiner Bestimmung kennt er nicht, er bejaht sie im tiefsten Grunde seines Herzens. Er würde trotz aller Enttäuschung niemals ernsthaft erwägen, den fata den Dienst aufzusagen. Mag uns seine Entscheidung in Karthago befremden - kein Römer jener Zeit hätte eine andere verstanden. $\mathrm{Zu}$ erklären ist dieser 'Konflikt', der im Grunde kein solcher ist, aus der römischen Sendungsideologie, die jeden Konflikt und damit die Voraussetzungen jeglicher Tragik aufhebt. Wenn man mit Aeneas jedoch eine Gestalt aus einer anderen Epoche vergleicht, von der ebenfalls die absolute Erfüllung einer göttlichen Sendung gefordert wird, offenbart sich die ganze Rigorosität der römischen Ideologie. Schillers Johanna schwankt einmal wie Aeneas, dem Auftrag zu willfahren: wie Dido in sein, tritt Lionel in ihr Leben, doch ist der Unterschied der Konsequenzen bezeichnend. Während Johanna nur ihrer Sendung gegenüber schuldig wird, wird Aeneas darüberhinaus seiner Umgebung gegenüber schuldig. Während Johanna an ihrer Sendung, an ihrer Auserwähltheit zu zweifeln beginnt, so daß sie von allen verlassen wird, kennt Aeneas keinen echten Zweifel. Während sich Johanna strengster Buße unterwirft, wird Aeneas für sein Zaudern über- 
haupt nicht zur Rechenschaft gezogen. Während Johanna erst im Tode mit den Göttern versöhnt wird, genügt bei Aeneas die bloße Befolgung des Auftrags. Dieser ist zu erhaben, als daß an ihm überhaupt $Z$ weifel erlaubt wären. Und vor allem: Er ist so rigoros in seinem Anspruch, daß er nicht gestattet, Aeneas für seine Schuld gegenüber der Umwelt zur Verantwortung zu ziehen. Die römische Sendungsideologie überhebt ihren Auserwählten einem Konflikt, an dem der tragische Held gewöhnlich zerbricht - den antiken Gottheiten vergleichbar, die in einer kritischen Situation auf dem Schlachtfeld eine Wolke um ihre Schützlinge hüllen, um sie unversehrt auf einem anderen Schauplatz wieder agieren zu lassen, als wäre nichts geschehen. Insofern erinnert die römische Konzeption an die Stücke Corneilles, deren Personen zwar auch äußerlich zwischen 'passion' und 'devoir' stehen, bei denen aber die Erringung der 'gloire' diesen Konflikt, wie K. Heitmann gesagt hat, „in den absolut untragischen zwischen einer Glücksaussicht und einer anderen Glücksaussicht" verwandelt. J. Maurens hat daher von einer 'tragédie sans tragique' gesprochen. Corneilles Bezeichnung einiger seiner Stücke als 'comédies héroïques' läßt sich gut auch auf die römischen Stücke übertragen.

Die Tragödie des vergilischen Aeneas ist ebenso untragisch wie die republikanische Tragödie. Das bis in die augusteische Zeit unveränderte Vorherrschen der Ideologie erklärt zwei literarhistorische Merkwürdigkeiten zugleich: erstens, daß in Rom die Tragödie bereits am Beginn der Literatur in Blüte steht und ein Substitut des Epos darstellt; und zweitens, daß die augusteische Zeit keine eigentliche Tragödie hervorgebracht hat, wie man es von einer sogenannten klassischen Literatur hätte erwarten können.

Die republikanische und die spärliche augusteische Tragödie ist bis zu einem gewissen Grade politische Dichtung, die von der Anerkennung der offiziellen Staatsideologie durch den Dichter und sein Publikum bestimmt wird. Mit dem Ende des augusteischen Staats verlor jedoch seine Ideologie an Verbindlichkeit: res privata und res publica traten auseinander. $\mathrm{Da}$ dieser Wechsel so abrupt vonstatten ging, lag darin begründet, daß der augusteische Staat nicht ein gewachsenes, sondern ein restauratives Gebilde und dementsprechend seine Ideologie nicht von natürlicher Evidenz, sondern zu einem guten Teil Postulat war. Oppositionelle Strömungen aus der voraugusteischen Zeit, die latent vorhanden waren, brachen unvermindert auf. Die Tragödie spiegelt diese Entwicklung beispielhaft wider, wozu sie in Rom aufgrund ihres von Hause aus politi- 
schen Charakters in der Lage war. Atypisch wie sie in Rom eingesetzt hatte, ist auch ihre Erscheinungsform in der Kaiserzeit. Waren sowohl die mythologische Tragödie als auch die Praetexta bisher patriotisch-panegyrisch gewesen, wurde der Geist beider jetzt antipatriotisch-antipanegyrisch. Die Tragödie und mit ihr die Praetexta wurden eine bevorzugte Gattung der Oppositionsliteratur.

Von der Hauptperson des taciteischen >Dialogusı, dem Dichter Curiatius Maternus, heißt es, er habe mit seinem ,Cato die Gesinnung der Mächtigen verletzt, offendisse potentium animos, was das Tagesgespräch der ganzen Stadt sei $(2,1)$. Ebenso dichtete er eine Praetexta 'Domitius<, deren Titelheld der Vater Domitius Ahenobarbus, ein scharfer Gegner Caesars, oder dessen Sohn, ein Gegner Octavians, gewesen ist. Er und Cato wurden in Maternus' Praetexten wegen ihrer Haltung ge ge n den Princeps verherrlicht. Der jüngere Cato - der im Jahre 46 aus Protest gegen Caesars Regime Selbstmord begangen hatte - war überhaupt die Idealfigur der stoischen Opposition im ersten nachchristlichen Jahrhundert in Rom und die Hauptfigur des bedeutendsten Epos dieser Epoche, des $>$ Bellum civile von Lucan. Doch nicht nur die Praetexta, sondern auch die mythologische Tragödie wurde zum 'Widerstandsdrama'. Von Maternus wird berichtet, er habe einen 'Thyestes` von eben der politischen Gesinnung des , Cato konzipiert, und von Tacitus und Sueton wird bezeugt, daß Mamercus Scaurus einen >Atreusı geschrieben habe, der Partien enthielt, die gegen Tiberius gerichtet waren, weshalb dieser das Stück verbrennen ließ.

Unter diesen Gegebenheiten sind zu einem wesentlichen Teil auch die acht mythologischen Dramen des bedeutendsten Tragikers dieser Zeit, des stoischen Philosophen Lucius Annaeus Seneca, zu würdigen. Zwar wissen wir, daß die Stoiker gerade die Gestalten der Tragödie im Sinne ihrer Lehre zu interpretieren und als Beispiele menschlichen Verhaltens zu zitieren pflegten, doch ist eine stoische Tragödie vor Seneca nicht faßbar. Andererseits soll Diogenes von Sinope in sieben Tragödien die kynische Lehre für breitere Kreise populär zu machen versucht haben. Ihm diente das gräßliche Mahl des Thyestes dazu, das Essen von Menschenfleisch schmackhaft zu machen, der Stoff des Oedipus, den Inzest als natürlich zu erweisen. Doch reichen solche vereinzelten bzw. abstrusen Versuche dichtender Philosophen nicht aus, Senecas Tragödien aus griechischer Tradition zu erklären; die Herkunft der stoischen Philosophie aus Griechenland jedenfalls darf dafür am wenigsten in Anspruch genommen werden, 
da sie im ersten nachchristlichen Jahrhundert in Rom eine überragende Rolle gespielt hat, die durch die dem Individuum feindlichen politischen Verhältnisse begünstigt wurde. Auch die Werke der beiden bedeutendsten zeitgenössischen Dichter, Persius und Lucan, sind von ihr geprägt, ohne daß sich entscheidende griechische Einflüsse auf ihre Entstehung geltend machen ließen. Im Gegenteil: Senecas Tragödien, Persius' Satiren und Lucans Epos vom Bürgerkrieg setzen innerhalb ihrer Gattungen eindeutig römische Traditionen fort.

Senecas Tragödie ist immer wieder als philosophische Tragödie angesprochen worden - was zweifellos zutrifft: sie ist aber bis zu einem gewissen Grade auch eine politische Tragödie. Es genügt, die Atreus- und Thyestesdramen von Scaurus und Maternus, die die animos potentium offenderunt, neben Senecas >Thyestes zu stellen, dessen Held der Tyrann $\chi \alpha \tau^{\prime} \mathfrak{\varepsilon} \xi o \chi \eta^{\prime} v$ Atreus ist, um die gemeinsame Wurzel zu erkennen - ja Senecas sämtliche Stücke sind in einer nur wenig variierenden Weise in tyrannos gerichtet. Gewiß eignen sich große Stellungen dazu, große Wahrheiten zu sagen, gewiß ist der Mächtige moralisch besonders gefährdet, doch erklärt das nicht allein, warum sich Seneca im Gegensatz zu seinem philosophischen Euvre in den Tragödien vorwiegend mit dem tyrannus beschäftigt, den er in seiner Schrift ’De clementia` (`Uber die Milde`) als entarteten Herrschertyp scharf von dem rex stoischer Prägung abhebt. $\mathrm{Zu}$ welchem Zwecke Seneca seine Stücke bestimmt hatte, wissen wir nicht; aber es verdient in diesem Zusammenhang Beachtung, daß uns keine eindeutige Nachricht über eine tatsächlich erfolgte Rezitation überliefert ist. Auf der anderen Seite hat sich Seneca jeglicher direkten Anspielungen auf seine Zeit enthalten, was gewiß dazu beigetragen hat, daß man seine Stücke der Überlieferung für wert erachtete, die seiner sich allzu direkt äußernden Kollegen nicht. Eine Ausnahme macht die Praetexta ১Octavia<, die Nero als vollendeten Tyrannen, als Bruder des Prototyps Atreus, zeichnet. In Senecas Tragödien begegnen zwei grundsätzlich verschiedene Personenkreise: der dem stoischen Ideal nahe kommende und der nach Ansicht dieser Lehre in verdammenswerter Weise den Affekten unterliegende Mensch. Dieser letzte interessiert den Stoiker freilich nicht nur in seinem politischen, sondern auch - und vor allem - in seinem rein menschlichen Verhalten. Als eindrucksvollster Vertreter der politischen pravitas kann Atreus gelten, der bei seinem ersten Auftritt programmatisch seine Herrschaftsmaximen verkündet, die in pointiertester Weise in einer auf den Kopf gestellten politischen Moral begründet sind. Daneben hat Seneca 
die im persönlichen Bereich von ihren Affekten überwältigten Personen wie etwa die bekannten Frauengestalten Medea und Phaedra vorgeführt, ohne jedoch auch hier die ausdrücklichen Hinweise auf ihre hohe Stellung zu unterlassen. Demgegenüber tritt der stoisch Gebildete, auf den es Seneca am meisten ankam, etwas zurück, so wie er selbst sagt, daß es ihn im Leben nur selten gebe. Mehrfach hat Seneca ihn jedoch in wirkungsvoller Weise als Kontrastfigur eingeführt: Die besonnene Iocasta steht neben dem rasenden Oedipus, die gefaßte Cassandra neben dem leidenschaftlichen Agamemnon. Es ist nur folgerichtig, daß der stoisch Gebildete, der seiner Umgebung gänzlich unerschütterlich gegenübersteht, den weder ein körperlicher Schmerz noch ein Angriff auf sein moralisches Empfinden rührt, eine im Grunde vollkommen untragische Gestalt ist, an der die Probleme der griechischen Tragödie - Seneca hat sich offenbar vor allem Stücke des klassischen 5. Jahrhunderts zum Vorbild genommen - zuschanden werden. Wieder wird die Tragik durch eine Ideologie überwunden, durch die absolute $\alpha \dot{\tau} \alpha \varrho \alpha \xi i \alpha$ der Stoiker, die auch für den äußersten Fall gerüstet ist, indem sie den als Wohltat angesehenen Freitod jederzeit parat hat: 'Ach, welch süßes Ubel ist den Sterblichen gegeben: die unheilvolle Liebe zum Leben, obwohl ihnen doch ein Ausweg aus den Leiden offensteht und der freiheitbringende Tod die Elenden ruft, ein sanfter Hafen in ewiger Ruhe. Kein Schrecken und kein Schlag der übermächtigen Fortuna bewegt ihn, auch nicht der Blitz des feindlichen Donnergotts':

heu quam dulce malum mortalibus additum
vitae dirus amor, cum pateat malis
effugium et miseros libera mors vocet
portus aeterna placidus quiete.
nullus hunc terror nec impotentis
procella Fortunae movet aut iniqui
flamma Tonantis.

So bekennen die gefangenen Troerinnen bei ihrer Ankunft in Mycenae im >Agamemnon< V. 589-595. Und sie fahren fort: 'Brechen wird jede Knechtschaft, wer die leichten Götter verachtet, wer das Antlitz des schwarzen Acheron, wer den traurigen Styx nicht traurig erblickt und es wagt, seinem Leben ein Ende zu setzen. Gleich wird er einem König, gleich wird er den Uberirdischen sein. $\mathrm{O}$ wie kläglich ist es, nicht sterben zu wissen' (605-611):

perrumpet omne servitium

contemptor levium deorum, 
qui vultus Acherontis atri, qui Styga tristem non tristis videt audetque vitae ponere finem. par ille regi, par superis erit. o quam miserum est nescire mori!

Sind diese Frauen stoisch gebildet und angesichts ihrer aussichtslosen Lage geradezu bewunderungswürdig gefaßt, so können sie wenig später doch nicht umhin, gewisse Regungen des Gemüts zu zeigen und Troias Geschick $\mathrm{zu}$ beweinen (654-655), ja in fast unstoischer Weise zuzugeben, daß es erleichtere, bei Unglücksschlägen gemeinsam Tränen zu vergießen (664 bis 667). Der w a h r e stoische Charakter kennt solche kleinlichen Regungen freilich nicht. Und so ist diesen stoischen Laien mit Cassandra, der harschen Jungfrau, des Leidens gewohnt, dura virago patiensque mali (668), eine stoische Professionelle gegenübergestellt, die sich jegliches Mitleid kurzerhand verbittet: 'Mein Leid braucht keinen Gefährten, aerumnae meae socium recusant. Laßt bitte die Klagen von meinen Schicksalsschlägen fern, cladibus questus meis removete. Mit meinen eigenen Leiden werde ich schon selbst fertig, nostris ipsa sufficiam malis' (661-663). In dieser erschreckenden Autarkie und absoluten Inperturbabilität zeigt sich die Rigorosität dieser Ideologie auf das deutlichste. Doch ist es verständlich, weshalb die stoische Philosophie im kaiserzeitlichen Rom eine so überragende Rolle spielen konnte. Disziplin, Sittenstrenge, virtus waren die Ideale des alten Rom gewesen, und es wird im Rückblick deutlich, welches Maß an stoischem Tugendstreben und stoischer Selbstdisziplin schon diesen Idealen zugrundelag. Der sich dem Fatum willig unterwerfende Aeneas ist daher auch schon in der Antike als stoischer Charakter gedeutet worden. Seneca hat seine Worte an die Sibylle als beispielhaft angeführt: 'Keine Gestalt einer Gefahr begegnet mir, Jungfrau, neu oder unvermutet; alles habe ich im Geist vorweggenommen und erwogen' (Aen. 6, 103-105):

non ulla laborum,

o virgo, nova mi facies inopinave surgit;

omnia praecepi atque animo mecum ante peregi.

Die alten Römerideale erhielten jedoch ihren vollen Sinn erst in der uneingeschränkten Unterordnung der res privata des Individuums unter die res publica der Allgemeinheit. Als zunächst unter Caesar, vollends aber unter den Nachfolgern von Augustus die res publica zerfiel, d. h. das, was bis dahin von allen getragen wurde, nunmehr von der Willkür eines 
einzelnen abhing, wurde das Individuum plötzlich auf sich selbst zurückgeworfen; durch die Entwicklung der politischen Verhältnisse wurde es gezwungen, seine Tugenden nicht mehr im Einsatz $f \ddot{u} r$, sondern im Einsatz gege $n$ den Staat unter Beweis zu stellen. Die Ideologie der Selbstaufopferung für den Staat wurde durch die Ideologie der Selbstbehauptung gegen den Staat abgelöst. Selbst-Behauptung - dieser Begriff bestimmt sich sowohl in dem Anspruch auf die Bewahrung der virtus als auch in der Willensstärke der disciplina: keine andere Philosophie als die stoische vermochte die Basis einer solchen Ideologie zu werden. Politiker wie Literaten wurden Vertreter der sogenannten stoischen Opposition. Hegel hat in der ,Geschichte der Philosophie über die Rezeption der stoischen Philosophie durch die Römer gesagt:

Im Unglück der Wirklichkeit wird der Mensch in sich hineingetrieben und hat da die Einigkeit zu suchen, die in der Welt nicht mehr zu finden ist. Die römische Welt ist die abstrakte Welt [...]; eine fremde Gewalt, abstraktes Allgemeines hat auf den Einzelnen gelastet. In solchem Zustande der Zerrissenheit war es Bedürfnis, Befriedigung zu suchen und zu finden. Wie, was gegolten hat, ein abstrakter Wille war, [...] hat das innere Prinzip des Denkens auch ein abstraktes sein müssen, das nur formelle, subjektive Versöhnung hervorbringen konnte. Rom hat nur das Prinzip der abstrakten Herrschaft; dem römischen Geiste konnte so nur ein Dogmatismus zusagen, der auf ein Prinzip gebaut war, welches durch die Form des Verstandes aufgebaut und geltend gemacht wurde. Die Philosophie ist so in engem Zusammenhang mit der Weltvorstellung.

Es wurde bemerkt, Zeiten des Übergangs - daß bei der augusteischen Zeit nur bedingt von einem natürlichen Höhepunkt der römischen Kultur zu sprechen ist, klang schon an - mündeten in verschiedene Versuche der Weltinterpretation: Von diesen treffen auf die hier besprochene Zeit derjenige der Philosophie und derjenige der Offenbarungsreligion zu. Senecas Denken ist zu einem wesentlichen Teil der Versuch, mit Hilfe einer philosophisch begründeten Ideologie gegen das Chaos zu bestehen, so wie das bei dem etwa gleichzeitig aufkommenden Christentum der Fall ist: Indem beide Ideologien die Tragik zu überwinden versuchen, machen sie eine eigentliche Tragödie unmöglich. Für Seneca ist das deutlich, für die Offenbarungsreligion demonstriert es bereits Ezechiels Moses-Drama >Exagoger. B. Snell hat gezeigt, wie in ihm die Idee der Heilsgeschichte jegliche Tragik aufhebt, und diese Interpretation der Geschichte derjenigen der römischen Epiker Naevius, Ennius, Vergil verglichen: Er hätte ebensogut auf die republikanische Praetexta und einen guten Teil der mythologischen 
Tragödie verweisen können, die von derselben Ideologie bestimmt sind. Im Gegensatz zu seinem Neffen Lucan hat Seneca jedoch darauf verzichtet, politische Stoffe zu gestalten, sondern sein Interesse vor allem auf die Darstellung menschlicher Verhaltensweisen konzentriert. Ob es sich um den Tyrannen handelt (Atreus, Oedipus) oder den von Affekten Uberwältigten (Phaedra, Medea) oder den stoisch Gebildeten (Iocasta, Cassandra): In allen Fällen bot der Mythos Personen, die Seneca mit Hilfe der stoischen Psychologie neu deuten konnte.

Wie am Beginn der römischen Literatur war die Tragödie auch in der Kaiserzeit nicht ein gewachsenes Gebilde, sondern ein atypisches Phänomen. Kam sie zunächst durch einen ganz äußerlichen Anlaß nach Rom und fungierte sie dementsprechend als Substitut des Epos, so haftet ihrer Erscheinungsform in der Kaiserzeit nicht minder etwas Künstliches an. Sie ist das Produkt kleiner literarischer Zirkel, die meist der Opposition angehören; sie wird nicht mehr an den offiziellen staatlichen Festen aufgeführt, sondern - darin liegt das entscheidend Neue - in beschränkten Kreisen rezitiert. Wieder erweist sie sich als eine uneigentliche Erscheinungsform, die dem Epos nahesteht. Auch die >Aeneis` ist ein Beispiel für die Verwandtschaft, oder besser: Vermischung, ja Austauschbarkeit dieser beiden Gattungen in der römischen Literatur. Ebenso macht das die Gedankenwelt und die Struktur des in Senecas Zeit gehörenden Epos Lucans deutlich, das wie Maternus' Praetexta den stoischen Idealhelden Cato von Utica verherrlicht. Stoisches Rezitationsdrama - stoisches Rezitationsepos in gleicher Funktion: In Rom entstanden die literarischen Gattungen nicht aufgrund natürlicher Gegebenheiten, sie waren vielmehr frei verfügbar. Und sie nahmen deshalb notwendig in jeder Epoche und in jedem Stadium ihre eigenen, fast stets atypischen, jedoch stets charakteristischen Züge an.

\section{Die Komödie}

Ebenso atypisch, jedoch ebenso charakteristisch wie die Tragödie ist in Rom die Erscheinungsform der Komödie gewesen. Wenn die Tragödie eine reife Gattung darstellt, die einen hohen Grad an Bewußtwerdung des Menschen voraussetzt und demgemäß im fortgeschrittenen Stadium einer Kultur aufzutreten pflegt, so gilt das in noch größerem Maße für die Komödie. Den höheren 'ästhetischen Wert' der Komödie hat Schiller in seiner Schrift , Uber naive und sentimentalische Dichtung betont: 
Es ist mehrmals darüber gestritten worden, welche von beiden, die Tragödie oder die Komödie, vor der andern den Rang verdiene. Wird damit bloß gefragt, welche von beiden das wichtigere Objekt behandle, so ist kein Zweifel, daß die erstere den Vorzug behauptet; will man aber wissen, welche von beiden das wichtigere Subjekt erfordere, so möchte der Ausspruch eher für die letztere ausfallen. - In der Tragödie geschieht schon durch den Gegenstand sehr viel, in der Komödie geschieht durch den Gegenstand nichts und alles durch den Dichter. $\mathrm{Da}$ nun bei Urteilen des Geschmacks der Stoff nie in Betrachtung kommt, so muß natürlicherweise der ästhetische Wert dieser beiden Kunstgattungen in umgekehrtem Verhältnis zu ihrer materiellen Wichtigkeit stehen. Den tragischen Dichter trägt sein Objekt, der komische hingegen muß durch sein Subjekt das seinige in der ästhetischen Höhe erhalten. [...] Der Tragiker muß sich vor dem ruhigen Räsonnement in acht nehmen und immer das Herz interessieren; der Komiker muß sich vor dem Pathos hüten und immer den Verstand unterhalten. [...] Wenn also die Tragödie von einem wichtigern Punkt ausgeht, so muß man auf der andern Seite gestehen, daß die Komödie einem wichtigern Ziel entgegengeht, und sie würde, wenn sie es erreichte, alle Tragödie überflüssig und unmöglich machen. Ihr Ziel ist einerlei mit dem Höchsten, wornach der Mensch zu ringen hat, frei von Leidenschaft zu sein, immer klar, immer ruhig um sich und in sich zu schauen, überall mehr Zufall als Schicksal zu finden und mehr über Ungereimtheit zu lachen als über Bosheit zu zürnen oder zu weinen.

Die Tragödie tritt in Zeiten des Übergangs auf und ist der literarische Ausdruck für den Vorgang, nach dem Sinn des Transzendenten und der Weltordnung zu forschen und sie schließlich in Frage zu stellen. Wenn hierauf nach Jaspers ein Stadium philosophischer Weltinterpretation folgt, so handelt es sich um den Boden, auf dem auch die echte Komödie gedeiht. An die Stelle der Konzeption eines Kosmos tritt die Erkenntnis des Zufälligen als obersten Prinzips - eine Entwicklung, die nicht zu Resignation führen muß, sondern durchaus eine ausgeglichene, ja heitere Lebensdeutung erlaubt. Jedenfalls bedeutet das Leugnen einer planvollen Weltordnung noch nicht das Eingestehen eines totalen Chaos. Wenn der Zufall als allgültiges Prinzip anerkannt wird, wenn die $\tau u ́ \chi \eta$ den Platz der

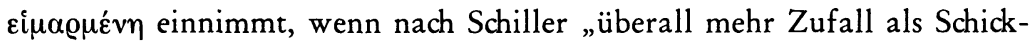
sal zu finden“ ist, wenn, wie Hegel in der >Aesthetik sagt, "die äußere Zufälligkeit sich zum Meister aller Verhältnisse und Zwecke macht", kann gleichwohl der Weltenlauf akzeptiert werden. Ja, für die Entstehung der Komödie sind das Postulat einer gewissen Ordnung und die Gültigkeit von Normen notwendige Voraussetzungen. Es ist daher nur natürlich, daß in der Neuen Komödie Athens, die beispielgebend für die gesamte 
abendländische Komödie geworden ist, die 'gute' Tyche, ả $\alpha \alpha \vartheta \grave{\eta}$ Túxๆ,

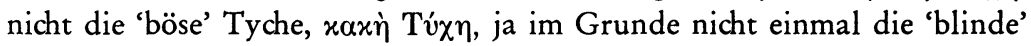

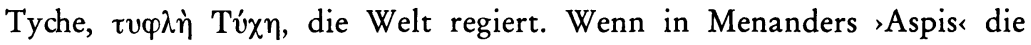
Göttin selbst auftrat und erklärte, daß sie, Tyche, bevollmächtigt sei, das

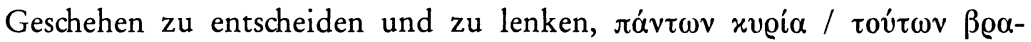

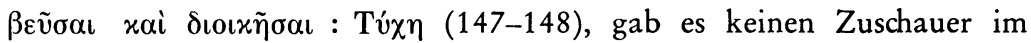
Theater, der ihre Worte nicht als Ausdruck eines sanften höheren Waltens empfunden hätte, in dem er sich nicht trotz aller seiner Unberechenbarkeit letztlich geborgen fühlte, das er zwar nicht als 'Ordnung', aber doch als 'in Ordnung' anerkannte. In ihrer Tyche-Konzeption war die Neue Komödie der Ausdruck hellenistischer Weltanschauung, wie sie sich auch in anderen Genera, der Geschichtsschreibung oder dem Roman, nieder-

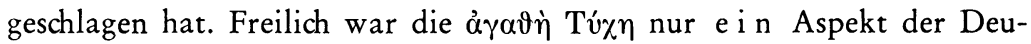
tungsskala dieser Zeit.

Die Alte Komödie, die durch Aristophanes repräsentiert wird, war ebenso wie die Tragödie auf dem politischen Boden der Polis erwachsen. Mit dem Ende der politischen Bedeutung Athens starben beide Formen ab. Das Erbe der Tragödie übernahm die unpolitische Neue Komödie, an die Stelle des mythischen Gleichnisses trat das bürgerliche Schauspiel. Bezeichnenderweise hatte Tyche auch schon in dem Spätstadium der Tragödie eine wichtige Rolle gespielt, wie etwa im >Ion sie aufgrund des für die Menschen nicht durchschaubaren Geschehens als Gottheit apostrophiert wurde, die das Geschick Tausender 'ändere' - zum

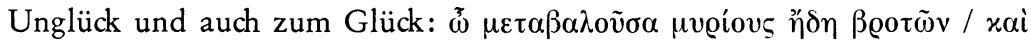

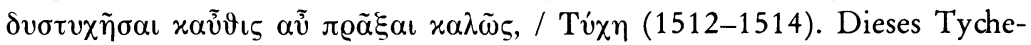
Verständnis war eine entscheidende Grundlage für die Ausbildung des komödienhaften, jedoch keineswegs schlechthin komischen Bühnengeschehens des bürgerlichen Schauspiels der Neuen Komödie. Entsprach der unpolitische Charakter dieses Genus der unpolitischen Zeit - Athen war in Abhängigkeit von Makedonien geraten -, so war wie bei jeder echten Komödie eine festgefügte Gesellschaft der Nährboden für die Neue Komödie. Denn darin bestimmt sich der soziale Charakter dieses Genus, daß es gleichgesinnte Mitglieder einer Gesellschaft voraussetzt, die sowohl die dargestellten Normen als auch die Abweichungen von den Normen beurteilen und aufgrund eines geordneten Weltbilds als komisch empfinden können.

Aus der typischen Ausprägung der athenischen Gesellschaft leiten sich die eingeschränkten, stereotypen Handlungsschemata der Neuen Komödie 
her. Mittelpunkt des Geschehens ist fast stets der Hausvater, den entweder der Sohn oder der Sklave im Interesse des Sohns, selten die Ehefrau, zu hintergehen versuchen. Anlaß ist vorwiegend die Liebschaft des Sohns, sei es mit einem Bürgermädchen, sei es mit einer Hetäre. Wenn bei dieser Thematik die verschiedensten Konstellationen stets von neuem durchge-

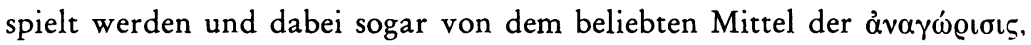
der Wiedererkennung eines verlorenen oder ausgesetzten Kinds, Gebrauch gemacht wird, wäre es jedoch verfehlt, von einer Lebensunwirklichkeit der Neuen Komödie zu sprechen. Jede einzelne Person - der gutmütige oder engstirnige Hausvater, die strenge Ehefrau, der liberaler als der Vater denkende Sohn, der listige Sklave, Hetäre und Kuppler - entsprach der athenischen Lebenswirklichkeit. Nur repräsentieren diese Personen nicht in der Konzentration, wie sie die Komödie bietet, die ga n ze Lebenswirklichkeit. Aber das ist auch nicht der Sinn der Komödie. Diese will vielmehr in einem Ausschnitt ä u $ß$ e r e n Geschehens die in n e r e $n$ Probleme der ganzen Gesellschaft vorführen. Ihr Thema ist der Widerspruch von Sein und Schein, von Plan und Erfolg, die stets neue Erfahrung, daß der Mensch, je schlauer er zu sein glaubt, desto sicherer sein Ziel verfehlt. Die stereotypen Handlungsschemata sind dabei ebenso wie die manchmal seltsamen Fügungen Tyches nur äußere Mittel zum Zweck der Sichtbarmachung der inneren Probleme.

Es bedarf keiner Betonung, daß im Rom des dritten vorchristlichen Jahrhunderts gänzlich andere Voraussetzungen als in Athen bestanden und weder der Oberbau der Neuen Komödie, das von der Tyche-Konzeption geprägte Weltbild, noch der Unterbau, das Bild einer unpolitischen von bestimmten bürgerlichen Interessen geleiteten Gesellschaft, der römischen Wirklichkeit entsprachen. Waren aber Weltbild und Abbild der Gesellschaft unverbindlich, ergab sich zwangsläufig, daß die Komödie nur in einer denkbar veräußerlichten Form rezipiert werden konnte. In der Tat sank die Neue Komödie in Rom auf die Ebene der reinen Belustigung der Zuschauer herab - dies freilich in einer so genial-komischen Weise, daß sie in ihrer Art ebenfalls etwas Einzigartiges darstellt. Wie es in einem römischen 'Theater' zuging, in welcher Weise das Publikum auf den Genuß eines Kunstwerks eingestimmt war, geht schön aus der Rede des Prologsprechers des plautinischen >Poenulus` ('Der Punier`) hervor: Keine Dirne möge im Proszenium Platz nehmen, kein Liktor schwatzen oder die Amtsruten mucksen lassen, kein Platzanweiser vor den Schauspielern herumlaufen und Zuschauer zum Platz führen, wenn das Spiel begonnen habe. 
Wer zu Hause faul die Zeit verschlafen habe, müsse mit Recht den Gleichmut besitzen zu stehen oder aber vorher nicht so lange schlafen. Auch die Sklaven sollten nicht sitzen, damit die Freien Platz hätten, oder aber sie sollten sich gefälligst freikaufen. Wenn sie das nicht könnten, sollten sie nach Hause gehen und zweifaches Unglück vermeiden, damit sie nicht im Theater von Amtsruten und zu Hause von der Peitsche gebläut würden, wenn etwas nicht erledigt sei und der Herr heimkehre. Die Ammen sollten die Wickelkinder lieber zu Hause versorgen, damit sie selbst nicht Durst und die Kinder Hunger erlitten und mit leerem Magen wie die Böcklein blökten. Die Matronen sollten still zuschauen, still lachen, sich ihrer 'wohltönenden' Stimmen hier enthalten und nur zu Hause schwatzen, damit sie nicht auch im Theater wie daheim die Männer belästigten:

scortum exoletum ne quis in proscaenio sedeat, neu lictor verbum aut virgae muttiant, neu dissignator praeter os obambulet neu sessum ducat, dum histrio in scaena siet. diu qui domi otiosi dormierunt, decet animo aequo nunc stent vel dormire temperent. servi ne opsideant, liberis ut sit locus, vel aes pro capite dent; si id facere non queunt, domum abeant, vitent ancipiti infortunio, ne et hic varientur virgis et loris domi, si minus curassint, quom eri reveniant domum. nutrices pueros infantis minutulos domi ut procurent neu quae spectatum adferat, ne et ipsae sitiant et pueri pereant fame neve essurientes hic quasi haedi obvagiant. matronae tacitae spectent, tacitae rideant, canora hic voce sua tinnire temperent, domum sermones fabulandi conferant, ne et hic viris sint et domi molestiae.

Wenn man auch annehmen möchte, daß es nicht in jeder Vorstellung so zugegangen war, so spricht doch der Umstand, daß ein Dichter sein Publikum überhaupt in dieser Weise anredete, deutlich genug: er war sich dessen bewußt, daß er in erster Linie Unterhaltung bot, ja wohl auch bieten mußte. Denn noch Terenz widerfuhr das doppelte Mißgeschick, daß bei der ersten Aufführung seiner Hecyrar das Publikum mitten in der Vorstellung zu Boxern und Seiltänzern, bei der zweiten zu Fechtern davonlief! 
Bei der Transplantation der Neuen Komödie von Athen nach Rom ist zweifellos der Verlust der metaphysischen Komponente am folgenreichsten gewesen. Dieses zeigt eindrücklich Plautus' ,Casina،, ein burleskes, ja obszönes Stück, das Macchiavelli für würdig erachtete, seiner ,Cliziar von 1525 als Vorlage zu dienen. Bei Plautus lieben Vater (Lysidamus) und Sohn (Euthynicus) ein in ihrer Familie als Sklavin aufwachsendes Findelkind (Casina). Um sich ihrer ungestört erfreuen zu können, betreibt jeder von ihnen die Verheiratung Casinas mit einem ergebenen Mittelsmann, Lysidamus mit seinem Gutsverwalter Olympio, Euthynicus, den seine Mutter Cleostrata verständlicherweise unterstützt, mit seinem Reitknecht Chalinus. Während Euthynicus' Abwesenheit schmiedet Cleostrata ein Komplott gegen ihren ungetreuen Ehemann, indem der als Braut verkleidete Reitknecht dem Gutsverwalter verheiratet wird und diesem sowie dem lüsternen Alten bei dem Vollzug der Hochzeitsnacht übel mitspielt. Lysidamus ist bloßgestellt und gelobt Besserung. Das ist eine Farce schwer überbietbaren Grades. Ganz anders war der Gehalt des Originals, obwohl sich die Handlung nicht wesentlich unterschied. In Diphilos' 'Klerumenoi< ('Die Losenden ), die nach einer auch von Plautus nachgebildeten Szene

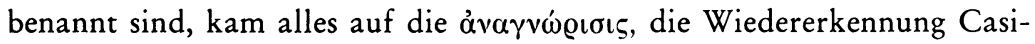
nas als Athenerin und freier Bürgerin, an - einen Handlungsstrang, den Plautus weggeschnitten hat, wie er selbst witzig andeutet. Denn von dem Sklaven, der Casina gefunden hat und die Wiedererkennung herbeiführt, heißt es im Prolog, er liege 'in einer Krankheit', doch um nicht zu lügen, er liege vielmehr 'im Bett', in morbo cubat, / immo hercle vero in lecto, ne quid mentiar (37-38). Der Zuschauer wird darauf vorbereitet, daß etwas mit dem Sklaven nicht stimme und er demzufolge nicht unbedingt mit der Wiedererkennung rechnen dürfe. Und damit auch die letzte Hoffnung auf eine bevorstehende Hochzeit zwischen Casina und Euthynicus ausgeräumt wird, warnt der Prologsprecher, die Zuschauer möchten nicht darauf warten, daß der abwesende Euthynicus heute zurückkehre; Plautus habe das nicht gewollt und die Brücke abgebrochen, die auf seinem Wege war - eine Wendung, die ebenso wörtlich wie metaphorisch zu verstehen ist (64-66):

$$
\begin{aligned}
& \text { is, ne exspectetis, hodie in hac comoedia } \\
& \text { in urbem non redibit: Plautus noluit, } \\
& \text { pontem interrupit, qui erat ei in itinere. }
\end{aligned}
$$

Im Original wendet sich Casinas Schicksal zum guten, indem sie Euthynicus heiratet, wie es Plautus noch am Ende kurz andeutet (1014). Die 
Wiedererkennung ist in der Neuen Komödie das vorzügliche Mittel, durch

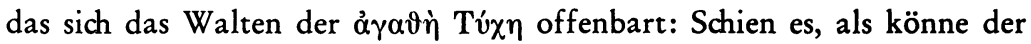
Sohn des Hauses die Sklavin aus Standesgründen nicht ehelichen, als würde sie zum Heiratsobjekt eines Sklaven und zum Lustobjekt eines Alten herabgewürdigt, so fügt Tyche alles zum besten, sie hat, wie auch sonst, einen Ausweg aus dem Wirrsal der Menschen gezeigt. Casina und Euthynicus sind ihr zu Dank verpflichtet - aber auch Cleostrata, die ihr Mann Lysidamus hintergehen wollte. Führt Tyche die guten Absichten der Menschen trotz allen Bedrängnissen zum Ziel, so vereitelt sie ihre schlechten Wünsche. Sosehr sich Lysidamus in immer neuen Anläufen bemüht, seine Pläne durchzuführen, sowenig gelingt es ihm. Und da die Welt der Komödie keinen echten Bösewicht kennt, sondern nur durchschnittliches Fehlverhalten und Abweichen von der Norm, toleriert sie auch einen Lysidamus: Mit wenigen Worten ist alles in die rechte Ordnung gebracht. Bei Plautus aber fehlt der metaphysische Úberbau, der nicht dem Denken der Zeit entsprach; bei ihm sind Spiel und Personen nicht mehr eingebunden in ein zwar nicht starres, aber doch fest umrissenes Weltbild - sie sind frei und verfügbar geworden: Das abgewogene Spiel wird zur Posse, seine Personen zu Marionetten der Phantasie des Dichters. Plautus interessiert im Grunde nur e in Thema: der gefoppte Alte, der unter dem Pantoffel der resoluten Ehefrau steht. Auf ihn ist die burleske Szene mit der falschen Braut zugeschnitten, er ist ihm ein Nichts, eine grauhaarige Mücke, cana culex (239), der am Ende 'nackt und bloß' dasteht, expalliatus (945), der es nicht wagt, seiner Frau in die Augen zu sehen (939), der überhaupt nicht nur auf die Stufe von Sklaven, sondern gar schlechter Sklaven abgesunken ist (ut / improbos famulos imiter, 953 bis 954) - er, der freie Bürger und pater familias.

Cleostrata nennt ihren Mann einen Bigamisten mit einem hybride gebildeten, aber deshalb um so witzigeren Wort: dismaritus (974). Die Bigamie eines ansonsten angesehenen Bürgers und Familienoberhaupts mußte in Rom in ihrer Unmöglichkeit grotesk erscheinen. Eben sie ist auch das Hauptthema eines Terenz-Stücks, des >Phormio<, der nach dem $>$ Epidikazomenos، Apollodors von Karystos (dessen Titel auf eine attische $\mathrm{Ge}-$ richtspraxis anspielt) gestaltet ist. In ihm bemüht sich der alte Chremes, eine außereheliche Tochter, die in Lemnos aufwächst, dem Sohn seines Nachbarn Demipho zu verheiraten. Als er aus Lemnos, wo er seine Tochter nicht antrifft, nach Athen zurückkehrt, muß er feststellen, daß der Nachbarssohn inzwischen geheiratet hat. Beide Väter bemühen sich in 
stets neuen Anläufen um die Auflösung der Ehe, bis sie endlich einsehen, daß der Sohn unwissentlich das Mädchen geheiratet hat, das ihm die Väter zugedacht hatten. Das, worum die Alten gekämpft haben, ist trotz allen Rückschlägen eingetreten, das, wogegen sie sich mit allen Mitteln zur Wehr gesetzt haben, war das, was sie selber wünschten. Wieder hat sich

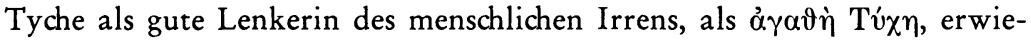
sen. Das erkennt schließlich auch Chremes, wenn er ausruft, wie oft geschehe durch Zufall, was man nicht zu hoffen wage! Bei seiner Rückkehr habe er die Tochter dem vermählt gefunden, mit dem er es wünschte. Das, worum sich die beiden Alten mit größter Anstrengung bemüht hätten, habe der Sohn ohne ihr Zutun, nur mit seinem Tun vollendet (757-761):

di vostram fidem, quam saepe forte temere eveniunt quae non audeas optare! offendi adveniens quicum volebam et ut volebam conlocatam amari: quod nos ambo opere maxumo dabamus operam ut fieret, sine nostra cura, maxuma sua cura solus fecit.

Hier scheint die Tyche-Konzeption des griechischen Originals deutlich durch, doch ist sie nicht das Thema des römischen Stücks. In ihm geht es vielmehr um den lysidamischen Charakter des an sich ehrbaren Chremes. Während sich dieser bei Apollodor um die angemessene Verheiratung seiner Tochter kümmert und um dieses Ziels willen keine Anstrengungen scheut, hat Terenz das ganze Gewicht auf seine Beziehungen zu der Frau in Lemnos gelegt. Während es sich bei Apollodor um ein einmaliges anderthalb Dezennien zurückliegendes Verhältnis handelt, kam Terenz auf den grotesken Einfall, das Verhältnis zu perpetuieren und Chremes nicht nur in Athen, sondern auch in Lemnos verheiratet sein zu lassen. Was bei Plautus Vorwurf war, ist bei Terenz Faktum: Chremes ist Bigamist, dismaritus, er hat zwei Frauen, uxores duas (1041). Sollte bei Apollodor das Irren und Hoffen des Menschen gezeigt werden, geht es bei Terenz um Lug und Trug. Ist die Kleinheit des Menschen bei Apollodor metaphysisch begründet, ist sie es bei Terenz moralisch. Hat der griechische Chremes Anlaß, mit seinen Bemühungen, die Tochter zu verheiraten, zufrieden zu sein, hat der römische Chremes allen Grund zu fluchen, überhaupt für die Tochter eingetreten zu sein. Mit einem Wort: Bietet der 'Epidikazomenos، Weltdeutung, ist der >Phormio in seinem von Terenz stammenden Finale auf die Stufe der Farce abgesunken. Ebenso resolut wie Cleostrata ist Nausistrata, ebenso kleinlaut wie Lysidamus ist Chremes. Nausistrata wünscht das, was ihm die Tränen in die Augen treibt, quod [...] oculi 
doleant (1053), Chremes gerät aus Angst ins Delirium, delirat miser / timore (997-998), er ist am Ende total erledigt: 'tot', mortuos (1015).

Es bedarf keiner Betonung, daß die Alten, Lysidamus in der Casinar und Chremes im >Phormior, nicht aus moralischen Gründen von den römischen Dichtern umgewertet, ja abgewertet werden, sondern lediglich wegen der damit verbundenen komischen Wirkung. Dies zeigen ganz deutlich die $>$ Bacchides` ( $(D i e$ beiden Schwestern Bacchis`) von Plautus. In ihnen agieren zwei Väter, von denen der eine, Nicobulus, strenge, der andere, Philoxenus, großzügigere Erziehungsprinzipien vertritt. Beide versuchen ihre Söhne vor den Hetären Bacchides zu bewahren, doch verfallen die Grauköpfe diesen schließlich selbst. Plautus hat im Gegensatz zu Menander, von dem das Original >Dis exapaton`( $(D e r$ Doppelbetrüger «) stammt, die Schluß-Szene in reichen Gesangspartien so umgestaltet, daß die Hetären die beiden Alten gehörig verspotten. Dabei wird, wie es plautinischer Art entspricht, die Metapher, daß die beiden Alten Schafe seien, fast zu Tode geritten. Bacchis I: 'Was ist hier los? Wer trieb diese Schafe her?' Nicobulus: 'Schafe nennen uns diese Verkommenen.' Bacchis II: 'Ihr Hirte schläft, während sie sich blökend von der Herde entfernt haben.' Bacchis I: 'Sie glänzen, scheinen beide gar nicht schlecht.' [1125:] Bacchis II: 'Geschoren sind sie beide ganz und gar.' Philoxenus: 'Sie scheinen uns zu verlachen!' [...] [1133:] Bacchis I: 'Die sollten zu uns hineingenötigt werden.' Bacchis II: 'Ich wüßte nicht, warum, da sie weder Milch noch Wolle haben. Laß sie so stehen. [1135:] Sie haben eingelöst, was sie wert waren, jegliche Frucht ging ihnen aus. Siehst du nicht, wie sie allein herumlaufen und frei schweifen? Ich glaube, sie sind vor Alter stumm: sie blöken nicht einmal, wenn sie sich von der Herde entfernt haben. Sie scheinen dumm, jedoch nicht schlecht.' [1140:] Bacchis II: 'Laß uns hineingehen, Schwester!' Nicobulus: 'Bleibt beide, auf der Stelle! Die Schafe wollen euch.' Bacchis II: 'Ein Wunder: die Schafe reden uns mit menschlicher Stimme an.'

BA. I: quid hoc est negoti nam, amabo?

quis has huc ovis adegit?

NI.: ovis nos vocant pessumae. BA. II: pastor harum dormit, quom haec eunt a pecu balitantes.

BA. I: at pol nitent, hau sordidae videntur ambae.

1125 BA. II: attonsae hae quidem ambae usque sunt. PH.: ut videntur deridere nos!

$[\ldots]$ 
1133 BA. I: cogantur quidem intro. BA. II : hau scio quid eo opus sit, quae nec lact' nec lanam ullam habent. sic sine astent.

1135 exsolvere quanti fuere, omnis fructus

iam illis decidit. non vides, ut palantes

solae, liberae

grassentur? quin aetate credo esse mutas:

1138a ne balant quidem, quom a pecu cetero apsunt. stultae atque hau malae videntur.

1140 BA. II: revortamur intro, soror. NI.: ilico ambae

1140 a manete: haec oves volunt vos.

BA. II : prodigium hoc quidemst: humana nos voce appellant oves.

Das Unerhörte ist nicht, daß die Hetären die biederen Alten verspotten, sondern daß diese den Spott völlig akzeptieren. Das hätte es in Athen kaum gegeben, in Rom aber war es ganz und gar lebensunwirkliches Treiben. Hieraus folgte als natürliche Konsequenz, daß man solche Konstellationen beliebig potenzieren konnte, bis vollends ein Spiel der reinen Phantasie entstand.

Die Abwertung an sich achtbarer Alter war ein beliebtes Motiv der römischen Komödie. Zur Verdeutlichung dessen bedürfte es keines weiteren Beispiels. Doch weil Micios Fall in Terenz' >Adelphen ('Die Brüder`) immer wieder mißdeutet worden ist, mag er hier neben Lysidamus, Chremes, Nicobulus und Philoxenus stehen. In diesem Stück, das nach Menanders gleichnamiger Vorlage gestaltet ist, vertreten die Brüder Demea und Micio ebenso wie Nicobulus und Philoxenus in den $>$ Bacchides unterschiedliche Erziehungsprinzipien: Demea gibt sich streng und starr, Micio liberal und verständnisvoll. Am Ende aber schlägt die Handlung so um, daß Micio bloßgestellt und damit sein Erziehungsprinzip widerlegt ist, andererseits Demea triumphiert und damit als Verfechter der richtigen Methode erscheint, obschon die ersten viereinhalb Akte den gegenteiligen Ausgang erwarten ließen. Bekanntlich hatte man schon im 18. Jahrhundert Anstoß an der Entwicklung der Charaktere genommen. So sagte Voltaire in seiner, Vie de Molière über Demea:

Le dénoûment des >Adelphes` n'a nulle vraisemblance: il n'est point dans la nature qu'un vieillard qui a été soixante ans, chagrin, sévère, et avare, devienne tout à coup gai, complaisant, et libéral.

Und zu Micio, dem am Ende Schlag auf Schlag versetzt wird, bemerkte Lessing in dem 100. Stück der $>$ Hamburgischen Dramaturgie : 
Solange der ehrliche Micio nur von seinem Vermögen dabei zusetzt, lassen wir uns den hämischen $\mathrm{Spaß}$ ziemlich gefallen. Aber nun kömmt es dem Verräter gar ein, den guten Hagestolze mit einem alten verlebten Mütterchen zu verkuppeln. Der bloße Einfall macht uns anfangs zu lachen; wenn wir aber endlich sehen, daß es Ernst damit wird, daß sich Micio wirklich die Schlinge über den Kopf werfen läßt, der er mit einer einzigen ernsthaften Wendung hätte ausweichen können: wahrlich, so wissen wir kaum mehr, auf wen wir ungehaltner sein sollen; ob auf den Demea oder auf den Micio. [...]

'Nein', sagt die Kritik; 'das ist zu viel! Der Dichter ist hier mit Recht zu tadeln. Das einzige, was man noch zu seiner Rechtfertigung sagen könnte, wäre dieses, daß er die nachteiligen Folgen einer übermäßigen Gutherzigkeit habe zeigen wollen. Doch Micio hat sich bis dahin so liebenswürdig bewiesen, er hat so viel Verstand, so viele Kenntnis der Welt gezeigt, daß diese seine letzte Ausschweifung wider alle Wahrscheinlichkeit ist und den feinern Zuschauer notwendig beleidigen muß. Wie gesagt also: der Dichter ist hier zu tadeln, auf alle Weise zu tadeln!'

Aber welcher Dichter? Terenz? oder Menander? oder beide?

Mit beiden Vätern zugleich ging Diderot hart ins Gericht, dessen Kritik Lessing im 86. Stück der >Hamburgischen Dramaturgie، übersetzt:

Die zwei kontrastierten Väter darin sind mit so gleicher Stärke gezeichnet, daß man dem feinsten Kunstrichter Trotz bieten kann, die Hauptperson zu nennen; ob es Micio oder ob es Demea sein soll? Fällt er sein Urteil vor dem letzten Auftritte, so dürfte er leicht mit Erstaunen wahrnehmen, daß der, den er ganzer fünf Aufzüge hindurch für einen verständigen Mann gehalten hat, nichts als ein Narr ist, und daß der, den er für einen Narren gehalten hat, wohl gar der verständige Mann sein könnte. Man sollte zu Anfange des fünften Aufzuges dieses Drama fast sagen, der Verfasser sei durch den beschwerlichen Kontrast gezwungen worden, seinen Zweck fahren zu lassen und das ganze Interesse des Stücks umzukehren. Was ist aber daraus geworden? Dieses, daß man gar nicht mehr weiß, für wen man sich interessieren soll. Vom Anfange her ist man für den Micio gegen den Demea gewesen, und am Ende ist man für keinen von beiden. Beinahe sollte man einen dritten Vater verlangen, der das Mittel zwischen diesen zwei Personen hielte und zeigte, worin sie beide fehlten.

Der Schluß war natürlich ironisch gemeint. Er zeigt glänzend, welche totale Verwirrung die römischen Komödiendichter mit der unbedenklichen Umwertung der Charaktere stifteten. Doch Lessing verstand in diesem Punkt keinen Spaß, wenn er hinzufügte:

Nicht ich! Ich verbitte mir ihn sehr, diesen dritten Vater; es sei in dem nämlichen Stücke, oder auch allein. Welcher Vater glaubt nicht zu wissen, wie ein Vater 
sein soll? Auf dem rechten Wege dünken wir uns alle: wir verlangen nur, dann und wann vor den Abwegen zu beiden Seiten gewarnet zu werden.

Die Philologen tun gut daran, sich diese Urteile von Dichtern zu vergegenwärtigen und vor allem die Konsequenzen aus ihnen zu ziehen. Daß Micio ebenso wie die bisher betrachteten Väter der römischen Komödie am Schluß 'abgewertet' wird, kann nicht zweifelhaft sein. Kompliziert wird das Problem nur dadurch, daß sein Pendant, Demea, nicht auch verspottet wird, so wie in den plautinischen ,Bacchides am Schluß beide Väter gleichermaßen bloßgestellt werden. Im Gegenteil: Demea erringt über Micio einen Triumph. Und in dieser Änderung glaubte man die Ursache für die gesamte terenzische Umdichtung sehen zu müssen, indem man meinte, Terenz habe es sich nicht leisten können, den Vertreter der Strenge in Rom unterliegen lassen zu können. Dies sei um so folgerichtiger, als Micio, der Vertreter der Liberalität, in Rom kaum Verständnis gefunden hätte. Abgesehen davon, daß man Terenz in diesem Fall den Vorwurf, bei der Auswahl des Stücks einen groben Mißgriff getan zu haben, nicht ersparen könnte, widerlegt sich diese Auffassung schon dadurch, daß Terenz mit wenigen Änderungen Demea zum Sieger hätte machen können, ohne Micio allzusehr bloßzustellen. Die völlig selbständige Gestaltung der Schluß-Szenen zeigt jedoch, daß das nicht in seiner Absicht lag. Er hat vielmehr durch eine Reihe von grotesken Einfällen Micio Schritt für Schritt planmäßig abgewertet und zu einer Witzfigur, die alles mit sich geschehen läßt, werden lassen. Micio war ganz eindeutig das - einzige - Ziel der Umdichtung. Am liebsten hätte Terenz wie Plautus beide Väter verspottet, doch war das von der Anlage des Stücks her nicht möglich. Während die Väter der >Bacchides in dem Sklaven Chrysalus einen allmächtigen Gegenspieler hatten, auf dessen alleinigen Sieg es ankam, gab es in dem menandrischen Stück einen solchen Kontrahenten nicht. Hier waren die beiden Alten zugleich auch ihre Gegenspieler: Sollte einer von ihnen unterliegen, avancierte der andere notwendig zum Sieger. Demeas Aufwertung war also nur das Mittel zum Zweck der Abwertung Micios. Bei Menander siegte Micio, der von Anfang an innerlich Überlegene, und unterlag Demea, der scheinbar Starke und Sichere. Sie waren Abbilder der Lebenserfahrung. Terenz aber fand Gefallen daran, den überlegenen Typ, an dessen Position kein Zweifel erlaubt schien, am Ende überraschend vom Podest zu stürzen, ihn 'hineinfallen' zu lassen. Terenz zielte einzig und allein auf die Komik des Handlungsumschlags, nicht auf die Korrektur von Prinzipien. Und dafür hatte ihm Plautus mit einer 
Reihe von Beispielen den Weg gewiesen. Da die >Adelphen sehr viel philosophischer und theoretischer angelegt sind als die $>$ Bacchides, verkannte man, daß Terenz' Ziel nicht philosophischer, sondern komischer Art war.

Ebenso ist Terenz im 'Heautontimorumenos` verfahren, in dem Menander mit dem alten Chremes einen Vertreter der Humanität par excellence auf die Bühne gestellt hatte, der in einer berühmten Sentenz bekannte, daß er ein Mensch sei und sich nichts Menschliches für fremd erachte: homo sum, bumani nil a me alienum puto (77). Gerade dieses Paradigma mußte Terenz besonders reizen. Während Chremes im Original erfolgreich bemüht ist, den Nachbarn wieder mit dessen Sohn zu versöhnen, wird er bei Terenz von seinem eigenen Sohn hintergangen. Wieder war es von hervorragender Wirkung, daß der Uberlegene, innerlich Sichere am Schluß selbst 'hineinfiel': Die Tiefe seines Sturzes bemaß sich nach der Höhe, die Menander seiner Position zuerkannt hatte. Wieder war Plautus Terenz vorangegangen. Die >Bacchides` schlossen mit der Feststellung, daß die Väter, die ihren Söhnen Fallen gestellt hätten, selbst hübsch 'gefangen' seien: lepide ipsi hi sunt capti, suis qui filiis fecere insidias (1207). Terenz schuf den, der anderen zu helfen weiß, selbst aber hineinfällt. Seine Gestaltung war um soviel feiner im Vergleich zu der plautinischen, als auch seine Vorlagen der >Adelphen und des >Heautontimorumenos feiner waren. Doch verrät schon ihre Auswahl einen ausgeprägten Kunstverstand in der Verfolgung eigener Vorstellungen.

Wenn auch in diesen Originalen Menanders die Darstellung bestimmter menschlicher Verhaltensweisen im Mittelpunkt stand, so gaben die Stücke dem Charakter der Neuen Komödie gemäß doch zugleich Weltdeutung. Micio und Chremes sind Menschen, die vor anderen in der Lage sind, ihren Lebensraum zu gestalten und Wirrnisse und Gefährdungen zu meistern. Und doch geraten bei Menander auch solche herausragenden Personen in Situationen, in denen sie vor aller Welt bloßgestellt und in ihren Lebensprinzipien widerlegt erscheinen. Daß sich diese Widersprüche später auflösen und nur als Irrtum der unwissenden Menschen erweisen, zeigt

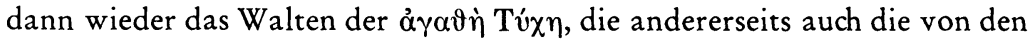
gesellschaftlichen Normen abweichenden Personen wie Demea mit sanfter Hand zur Erkenntnis führt. So ist die Neue Komödie in Athen immer zugleich Weltspiel, in Rom beliebig veränderbares Unterhaltungstheater. 
Dies läßt auch eine andere bevorzugte Figur erkennen: der gegen seinen alten Herrn intrigierende und selbst die schwierigsten Hindernisse überwindende Sklave, der zuweilen auch durch einen Sykophanten oder Parasiten vertreten wird. Auch diese beherrschende Figur ist in den Originalen fest in das von Tyche bestimmte Geschehen eingebunden. Phormio glaubt, mit seiner Intrige völlig selbstherrlich allen festgelegten Planungen entgegenzuarbeiten, ohne zu ahnen, daß er nur ausführt, was die Göttin vorbestimmt hat. Auch ein Phormio ist in die Tyche-Konzeption integriert. Ein schönes Beispiel stellt der plautinische >Pseudolus (`Der Lügenbold`) dar, dessen Hauptfigur der gleichnamige das Geschehen beherrschende Sklave ist. Dieser hat sich anheischig gemacht, möglichst auf Kosten seines alten Herrn Simo ein Mädchen für seinen jungen Herrn Calidorus zu schaffen, das in der Gewalt des Kupplers Ballio ist. Er wettet mit Simo um 20 Minen, daß es ihm gelingen werde, dem Kuppler das Mädchen zu entführen, ohne daß er freilich weiß, wie er es anfangen könnte. Da bietet sich ihm plötzlich die völlig unvorhersehbare Möglichkeit, mit Hilfe eines Briefs das Mädchen auszulösen. In einem Monolog sagt Pseudolus denn auch, daß die 'Gelegenheit', Opportunitas, also Tyche, deren Füllhorn er erwähnt, ihm überraschend geholfen habe. Und er stellt ausdrücklich fest, daß eines Menschen Verstand sich danach bemesse, wie er Fortuna (= Tyche) zu 'nutzen' verstehe. Das ist stimmig und läßt wieder die hellenistische Weltdeutung erkennen. Plautus hat den Sklaven jedoch schon vorher großsprecherisch tönen lassen, er habe einen festen Plan, consilium (575), obwohl das gar nicht der Fall sein kann. Denn für den römischen Komödiendichter ist der Sklave eine völlig autonome Figur, deren Handeln in kein höheres Walten eingebunden ist. Daher muß Plautus bei der Úbernahme des griechischen Monologs die im folgenden kursiv gesetzten Verse einschieben, um zu erklären, warum der erste, praktisch gar nicht existierende Plan nicht ausgeführt wird: 'Unsterbliche Götter, dieser Mensch hat mich durch sein Kommen gerettet. Auf seine Kosten hat er mich aus dem Irren wieder auf den Weg geführt. Selbst die Gelegenheit konnte mir nicht gelegener kommen als dieser Brief. Er kam in einem Füllhorn, in dem alles ist, was ich will: Listen, alle Betrügereien, Streiche, hier ist Geld und das Mädchen für den Herrn. Ich werde mich nun berühmt und allmächtig erweisen. Wie ich das einzelne ausfübren würde, um dem Kuppler das Mädchen zu entreißen, hatte ich schon alles festgesetzt und der Reibe nach vorbestimmt, abgegrenzt und fest umrissen, so wie ich es vorhatte, aber das wird nun so vor sich gehen. Hundert 
kluger Menschen Pläne vereitelt allein die Göttin, Fortuna. Und das ist wahr: wie einer Fortuna nutzt, so ragt er hervor, und alle nennen wir ihn weise. Wenn etwas gut ausgegangen ist, sprechen wir von einem klugen Mann, von einem dummen aber, wenn es schlecht ausgeht. Wir Toren wissen nicht, wie wir vergeblich sind, wenn wir etwas heftig wünschen, so als könnten wir beurteilen, was uns nützt. Sicheres lassen wir fahren, während wir Unsicheres erstreben. Und es passiert bei der Arbeit und im Schmerz, daß uns der Tod überkommt' (667-686):

di inmortales, conservavit me illic homo adventu suo. suo viatico redduxit me usque ex errore in viam. namque ipsa Opportunitas non potuit mi opportunius advenire quam haec allatast mi opportune epistula. nam haec allata cornu copia est, ubi inest quidquid volo: hic doli, hic fallaciae omnes, hic sunt sycophantiae, hic argentum, hic amica amanti erili filio. atque ego nunc me ut gloriosum faciam et copi pectore:

675 quo modo quidque agerem, ut lenoni surruperem mulierculam, iam instituta, ornata cuncta in ordine, animo ut volueram, certa, deformata habebam; sed profecto hoc sic erit: centum doctum hominum consilia sola haec devincit dea, Fortuna. atque hoc verum est: proinde ut quisque Fortuna utitur,

680 ita praecellet atque exinde sapere eum omnes dicimus. bene ubi quod scimus consilium accidisse, hominem catum eum esse declaramus, stultum autem illum quoi vortit male. stulti hau scimus frustra ut simus, quom quod cupienter dari petimus nobis, quasi quid in rem sit possimus noscere. certa mittimus dum incerta petimus; atque hoc evenit in labore atque in dolore, ut mors obrepat interim.

An dieser Stelle stehen die hellenistische Tyche-Konzeption und das Ignorieren ihrer Gültigkeit durch den römischen Komödiendichter unmittelbar nebeneinander. Der griechische Pseudolus ist wie die anderen Menschen im Irren, error (668), befangen, bis ihm Tyche einen (Aus)Weg zeigt. Nur dadurch unterscheidet er sich von anderen Menschen, daß er die Gelegenheit beim Schopfe packt, Fortuna utitur (679): darin besteht seine Weisheit, sapere (680), darin ist er ein kluger Mensch, bomo catus (681). Der römische Pseudolus ist erhaben über solche Hilfestellung, er bedarf Tyches nicht, er weiß alles vorher und besser, er ist ein Allerweltskerl, der sich selbst 'glorifiziert', gloriosum facit (674). Ihm steht es an, große Taten aus eigenem $\mathrm{zu}$ vollbringen, die noch nach ihm berühmt sind und fort- 
leben: magna me facinora decet ecficere / quae post mibi clara et diu clueant (590-591). Da dieser Typ aus der griechischen Weltordnung herausgetreten ist, kann sein Handeln und seine Bedeutung beliebig potenziert werden. Er pflegt deshalb Cantica anzustimmen, in denen er vor dem römischen Publikum seine Glorifizierung vorträgt. Während es sich dabei nur um Zusätze zu der Aktion der Vorlagen handelt, hat Plautus in anderen Fällen die Handlungen selbst in dieser Richtung verändert. So betrügt in dem Original der $>$ Bacchides`, dem 'Dis exapaton ( $>$ Der zweimal Betrügendes), der Sklave Chrysalus, wie schon der Titel sagt, seinen Herrn zweimal. Plautus ließ ihn dagegen den Alten gleich dreimal hereinlegen, um das Stück mit einer weiteren wirkungsvollen BetrugsSzene zu bereichern. Dementsprechend hatte Plautus seine liebe Not, in der Triumph-Arie, die Chrysalus anstimmt (925-978), den zweimaligen Betrug des Originals und den dreimaligen Betrug der eigenen Konzeption miteinander zu koordinieren. Dies war deshalb so schwierig, weil die Uberlistung des Alten in witziger Weise mit der Einnahme Troias verglichen wurde und jeder einzelne Betrug mit einer entsprechenden Stufe der Eroberung in Einklang gebracht werden mußte. Auch Pseudolus erfreut sich bei Plautus im Vergleich zum Original eines zusätzlichen Triumphs. Das griechische Stück ist so angelegt, daß der Sklave dem Kuppler Ballio zwar das Mädchen für seinen jungen Herrn raubt, es ihm aber später mit dem Geld bezahlt, das er in einer Wette mit seinem alten Herrn Simo gewonnen hat, der sich seinerseits schadlos halten kann, weil er eine Wette gegen Ballio gewinnt. Pseudolus hat also dadurch das Mädchen errungen, daß er gegen Ballio indirekt eine Wette gewonnen hat. Niemand hat sonst Geld verloren oder ist betrogen worden. Diese originelle Konzeption hat Plautus zweifach geändert, indem er Pseudolus dem Kuppler das Mädchen und diesen Simo die Wette nicht bezahlen ließ: Dadurch, daß Pseudolus Ballio das Mädchen nicht bezahlt, hat er nicht nur dieses, sondern auch Simos Geld gewonnen; und dadurch, daß Simo kein Geld von Ballio erhält, hat er mit seiner Wette Geld an Pseudolus verloren. Pseudolus hat zwei Dinge gewonnen und über zwei Gegner gesiegt: er ist zum Doppelsieger avanciert.

Damit demonstriert die römische Version des >Pseudolus` die beiden dargelegten Verfahrensweisen der römischen Komödiendichter: die Bloßstellung und Verspottung des pater familias und den absoluten Triumph des Sklaven. In Athen hielt sich das Spiel mit dem Komödienvater in den Grenzen, die eine liberal denkende Gesellschaft je nach dem Charakter 
und dem Verhalten desselben gestattete. Und die Intrige des Sklaven war stets dem angestrebten Ziel untergeordnet, ohne sich wie in Rom zu verselbständigen, ja zum Selbstzweck zu werden. Da das Widerspiel zwischen Hausherr und Sklave auch in der in Athen praktizierten gemäßigten Form für die römischen Verhältnisse absolut undenkbar war, konnte es in Rom selbst unverändert nicht übernommen werden, ohne den Charakter eines unwirklichen Spiels zu haben. Unter diesem Aspekt der Unwirklichkeit aber verlor es jede Verbindlichkeit und konnte nach Belieben ausgestaltet, und das bedeutete: gesteigert werden. Mit dem Sieger, der stets von neuem einen in der Wirklichkeit des Lebens unvorstellbaren Triumph erzielte, konnte sich das Wunschdenken eines großen Teils des römischen Publikums identifizieren; er konnte sich in eine Welt hineinträumen, die ihm auf das strengste verschlossen war. Auf der anderen Seite hatten die römischen Komödiendichter die zuweilen bittere Niederlage des Hausherrn mit einem derartigen Feuerwerk komischer Einfälle überlagert, daß auch der Teil des Publikums, der eine solche Wendung des Geschehens theoretisch nicht ohne weiteres als natürlich empfinden konnte, die Praxis der komischen Bühne akzeptierte. Nur unter diesem Aspekt ist der Erfolg des miles gloriosus in Rom zu verstehen, der sich hier in der Gesellschaft eines ganz anderen Renommées als in Athen erfreute. Plautus' geniale Darstellung dieser Figur ist bekannt, und auch Terenz war von ihr so angetan, daß er sie in die Handlung des menandrischen 'Eunuchus einbaute. Ebenso exotisch erschien den Römern die Person des schmarotzenden Parasiten. Sie mußte auf sie eo ipso komisch wirken. Plautus war mit ihr offenbar so erfolgreich gewesen, daß auch Terenz nicht auf sie verzichten mochte, obwohl sie seine Vorlagen nicht boten. So hat er sie ebenfalls dem Personal des 'Eunuchus hinzugesellt und im >Phormio den Titelhelden von einem Sykophanten in einen Parasiten umfunktioniert. Es war nur natürlich, daß die römische Gesellschaft auch kein Verständnis für die spätbürgerliche Figur der griechischen 'edlen' Hetäre, der $\dot{\varepsilon} \tau \alpha i \varrho \alpha \chi \emptyset \emptyset \sigma \tau \eta$, haben konnte und die Dichter mit ihr nach Belieben verfuhren. Am schlimmsten erging es Thais aus Menanders 'Eunuchus‘, einer der hervorragendsten Vertreterinnen attischer Humanität. Um eines bloßen komischen Schlußeffekts willen ließ Terenz ihr, der wie Micio Sicheren, der Umgebung innerlich Uberlegenen, die Schmach zuteil werden, daß sie $\mathrm{zw}$ ischen ihrem Liebhaber und einem lächerlichen miles gloriosus 'aufgeteilt' wurde! Es kam den römischen Komödiendichtern nicht so sehr auf die Personen als Symbole der Weltdeutung, als Träger von Ideen oder als 
Charaktere und Repräsentanten von Verhaltensweisen an als vielmehr auf eine sich stets nur an der komischen Wirkung des Augenblicks orientierende Handlung. Das aus der Bindung attischen Denkens herausgelöste Personal der griechischen Vorlagen konnte ihnen zur Erreichung dieses Ziels nur recht und billig sein. Die Neue Komödie war in Rom nicht wie in Athen ein Spiegel des Lebens, ein speculum vitae, sondern ein Gebilde der Phantasie.

So wie die Tragödie im Gegensatz zu Athen nicht der Ausdruck tragischer Weltdeutung war, sondern von ihren Anfängen an bis in die augusteische Zeit hinein der Erbauung diente, war die Komödie nicht der Ausdruck bürgerlicher Weltdeutung, sondern diente der Unterhaltung. Tragödie und Komödie waren in Rom atypische literarische Phänomene.

\section{Die Struktur des römischen Dramas}

\section{Die Tragödie}

Wenn es zutrifft, daß die Struktur eines literarischen Werks, die oixovouia, sich nach seinem Gehalt, der Weltdeutung und dem Menschenbild, bestimmt, muß aufgrund der totalen Andersartigkeit der Gehalte des griechischen und römischen Dramas auch ihre Struktur grundverschieden sein. Die griechische Tragödie zeigt die Auseinandersetzung des Menschen mit der Welt, wie sie ihm im Bereich des Transzendenten und der Gemeinschaft der Mitmenschen entgegentritt. Der tragische Mensch begreift die in der Welt auftretenden Gegensätze als solche und versucht in stets neuem Ringen, zwischen ihnen Position zu beziehen. Es versteht sich, daß die Darstellung des permanenten Räsonnements in der Tragödie feste Formen ausbildet wie Rede und Gegenrede, Wechselrede, Reflexion im Monolog und Kommentar auf höherer Ebene im Chor. Deshalb ist die Struktur der Tragödie nicht parataktisch wie die des Epos, sondern hypotaktisch, in ihren Teilen aufeinander bezogen. Hölderlin hat die Wechselwirkung von Gehalt und Struktur der griechischen Tragödie in den >Anmerkungen zum Oedipus` im Prinzip richtig erklärt:

Die Darstellung des Tragischen beruht vorzüglich darauf, daß das Ungeheure, wie der Gott und Mensch sich paart, und grenzenlos die Naturmacht und des Menschen Innerstes im Zorn Eins wird, dadurch sich begreift, daß das grenzenlose Eineswerden durch grenzenloses Scheiden sich reiniget. [...] 
Darum der immer widerstreitende Dialog, darum der Chor als Gegensatz gegen diesen. Darum das allzukeusche, allzumechanische und faktisch endigende Ineinandergreifen zwischen den verschiedenen Teilen, im Dialog, und zwischen dem Chor und Dialog und den großen Partien oder Dramaten, welche aus Chor und Dialog bestehen. Alles ist Rede gegen Rede die sich gegenseitig aufhebt.

Die unheimliche Konsequenz der Fragestellungen und Lösungsversuche bewirkt eine ungewöhnlich feste Grundstruktur der griechischen Tragödie. Deshalb spricht Hölderlin von Technik, $\mu \eta \chi \alpha v \eta$, von dem "gesetzlichen Kalkul“, von der „Schule“ und dem „Handwerksmäßigen“ in der Weise, daß die "Verfahrensart berechnet und gelehrt, und wenn sie gelernt ist, in der Ausübung immer zuverlässig wiederholt werden kann“. Schon Aristoteles hatte im 6.-8. Kapitel seiner >Poetik festgestellt, daß die Tragödie die Darstellung einer in sich geschlossenen und ganzen Handlung

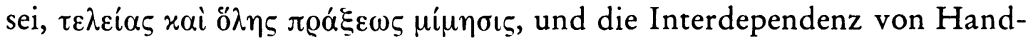
lung und Struktur hervorgehoben. Denn es müsse in der Tragödie, wie in den anderen nachahmenden Künsten die Einheit der Darstellung (Nachahmung) auf der Einheit des Gegenstands beruhe, der Stoff, da er Nachahmung von Handlung sei, die Darstellung einer einzigen, und zwar einer ganzen Handlung sein; ferner müßten die Teile der Geschehnisse so zusammengefügt sein, daß sich das Ganze verändere und durcheinandergerate, wenn irgendein Teil umgestellt oder weggenommen werde; denn was ohne sichtbare Folgen vorhanden sein oder fehlen könne, sei gar nicht ein Teil des Ganzen (1451a, 30-35):

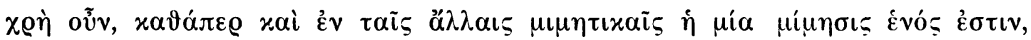

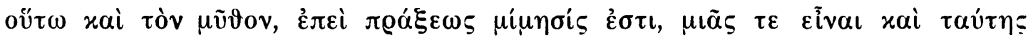

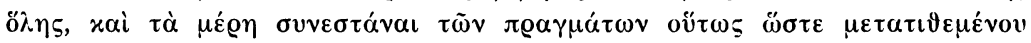

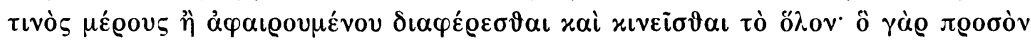

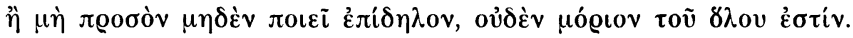

Es versteht sich, daß der Zerfall eines einheitlichen Weltbilds auch einen Zerfall der dramatischen Form bedingt, und so ist schon immer beobachtet worden, daß bei Euripides die traditionellen Bestandteile der Tragödie in steigendem Maße ein Eigenleben zu führen beginnen: Das Fehlen einer gedanklichen Mitte begünstigte die Verselbständigung der Einzelteile. Die an die Stelle des einen umfassenden Konflikts tretenden Einzelkonflikte konnten um die Einzelteile nicht mehr das eine umfassende Band legen. Die Auflösung der alten Polis hatte jedoch nicht nur den Verfall der Tragödie zur Folge, sondern auch den der Alten - politischen - Komödie. Die beiden letzten Stücke des bedeutendsten Vertreters, Aristophanes, >Plutos، 
(`Der Reichtumৎ) und >Ekklesiazusen` (`Die Weibervolksversammlung`), spiegeln mit der Auflösung der alten Form die inneren Veränderungen deutlich wider.

Es ist folgerichtig, daß für die römischen Dichter, die aufgrund ihres andersartigen Weltverständnisses die Gehalte und Ideen der griechischen Tragödien nicht übernehmen konnten, auch die originale Struktur dieses Genus unverbindlich sein mußte. Da das römische Drama in der tragischen Form auf Erbauung und die statische Darstellung menschlicher Verhaltensweisen zielte, nicht jedoch auf Diskussion und Auseinandersetzung wie die griechische Tragödie, steht es prinzipiell auf der Stufe des Epos, das ebenfalls nicht argumentiert, sondern darstellt. Gemäß diesem epischen Charakter ist die Struktur der römischen Tragödie nicht hypotaktisch, sondern parataktisch, sind ihre einzelnen Teile nicht einander untergeordnet, sondern gleichgeordnet: Die Tragödie ist in Rom wie die Komödie durch den Verzicht auf eine organisch sich entwickelnde Handlung gekennzeichnet.

Für die erhaltenen Dramen, die Komödien und Senecas Tragödien, ist die Auflösung des Dramenkörpers in Einzelszenen leicht nachweisbar, doch darf sie, nicht nur aus Gründen der Analogie, auch für die republikanische Tragödie angenommen werden. Jedenfalls ist es für die am ehesten römische Erscheinungsform derselben, die Praetexta, bezeichnend, daß sie nicht ein durchgängig dramatisches Geschehen, sondern aneinandergereihte Episoden zur Darstellung gebracht hat, wie die Rekonstruktionen - etwa die des $>$ Paullus von Accius - mit ziemlicher Wahrscheinlichkeit erkennen lassen. Wenn ferner eine Reihe von Episoden aus der römischen Geschichte oder Sage von denselben Dichtern ebenso im Epos wie in der Praetexta behandelt wurde, zeigt sich darin ebenfalls der epische Grundzug der römischen Tragödie, zugleich aber auch der uneigentliche Charakter der römischen Epik: Die Dichter argumentierten zwar nicht innerhalb ihrer Werke, aber sie argumentierten mit ihren Werken. Sie stellten das Geschehen nicht einfach dar, sondern sie wollten etwas mit dem dargestellten Geschehen aus der Sicht der römischen Heilsdeutung beweisen. Das hätte ein ursprünglicher epischer Dichter nicht getan, und so ist die Bezeichnung der römischen Tragödie als 'episch' nur formal zu verstehen.

Wenn in dem Verzicht auf eine organisch sich entwickelnde Handlung wiederum ein wesentlicher Unterschied zwischen griechischer und römischer Dramaturgie zu erkennen ist, bedarf der Begriff der Handlung der 
Präzisierung. Handlung im Sinne eines bewegten Bühnengeschehens war dem antiken Drama überhaupt fremd: In ihm wurde nicht gehandelt, sondern von etwas gehandelt, wie Thomas Mann in seinem >Versuch über das Theater unterschieden hat:

Das aber, was man heute unter 'Handlung' versteht, schloß das antike Drama bekanntlich gerade aus, verlegte es vor den Anfang des Dramas oder hinter die Bühne, und was es eigentlich vorführte, war die pathetische Szene, der lyrische Erguß, ein Handeln von etwas, mit einem Worte die Rede.

Obschon sich Thomas Mann vor allem auf die griechische Tragödie bezogen haben dürfte, kann bei dieser dennoch insofern von Handlung gesprochen werden, als die von der Argumentation bestimmten Szenen wie in der Komödie logisch miteinander verzahnt sind, sich auseinander entwickeln. Dies ist in der römischen Tragödie sowenig wie in der römischen Komödie der Fall. Wenn im folgenden auch bei Senecas Dramen die Tendenz zur Einzelszene dargelegt wird, so ist damit zugleich zu zeigen, welche Art von Einheit bei ihm an die Stelle der handlungsmäßigen und argumentativen Geschlossenheit der griechischen Dramen getreten ist. Ein herausragendes Beispiel für eine an äußerer Handlung arme, an innerer Entwicklung reiche Tragödie ist Sophokles', Oidipus<, bei der sich das entscheidende Geschehen schon vor Beginn des Stücks abspielt und die gleichwohl die 'zusammengesetzteste Handlung' hat, wie Schiller am 2. Oktober 1797 an Goethe schrieb:

Ich habe mich dieser Tage viel damit beschäftigt, einen Stoff zur Tragödie aufzufinden, der von der Art des >Oedipus Rex wäre und dem Dichter die nämlichen Vorteile verschaffte. Diese Vorteile sind unermeßlich, wenn ich auch nur des einzigen erwähne, daß man die zusammengesetzteste Handlung, welche der tragischen Form ganz widerstrebt, dabei zum Grunde legen kann, indem diese Handlung ja schon geschehen ist und mithin ganz jenseits der Tragödie fällt [...] Der >Oedipus ist gleichsam nur eine tragische Analysis. Alles ist schon da, und es wird nur herausgewickelt. Das kann in der einfachsten Handlung und in einem sehr kleinen Zeitmoment geschehen, wenn die Begebenheiten auch noch so kompliziert und von Umständen abhängig waren. Wie begünstiget das nicht den Poeten!

Über Senecas >Oedipus` hätte Schiller schwerlich dieses Urteil abgeben können. In Sophokles' Tragödie vollziehen sich zwei Abläufe: der der äußeren Handlung und der des Wissens und der Wahrheit. Obschon beide in engstem Zusammenhang stehen, kommt es hier nur auf die oixovouía 
des Stücks an, die in durchweg strenger Motivation und dramatischer Folgerichtigkeit durchgeführt ist: Szene folgt aus Szene. Anlaß der Handlung ist die Pest, deren Ursache Oidipus zu ergründen sucht. Er hat deshalb Kreon nach Delphi geschickt. Dieser kommt zurück und berichtet. Oidipus schickt nach Teirasias, der Kreons Nachricht verdeutlichen soll. Dabei beschuldigt Oidipus den inzwischen abwesenden Kreon. Als dieser davon hört, kehrt er erneut zurück, um Oidipus zur Rede zu stellen. Iokaste, Oidipus' Gattin, tritt auf, um den entstehenden Streit zu schlichten. Sie will Oidipus beruhigen, doch trägt sie nur zu größerer Beunruhigung bei. Mit dem Erscheinen des Mannes aus Korinth kommt der einzige Handlungsanstoß von außen, ereignet sich die Katastrophe. Die Positionen verkehren sich: Oidipus beruhigt sich, Iokaste gerät in größte Bedrängnis. Dann wird nach dem alten Hirten geschickt, um Klarheit zu erlangen. Wovon man sich Erlösung erhofft, macht die Katastrophe vollkommen.

Ganz anders ist Senecas ,Oedipusı strukturiert. In ihm stehen die einzelnen Szenen äußerlich gesehen nahezu unverbunden nebeneinander. Dem Stück fehlt der Motor, die treibende Kraft. Während der sophokleische Oidipus auf die Pest mit einer tatkräftigen Untersuchung reagiert, will der senecaische fliehen und sterben. Iocasta kann ihn nur mit Mühe zurückhalten. Dann kommt Creo, der jedoch nicht von Oedipus geschickt wurde. Creo erwähnt den verhängnisvollen Dreiweg, trigemina via (278), doch es ist, als höre Oedipus gar nicht zu! Sodann tritt Tiresia auf, ebenfalls nicht auf Oedipus' Veranlassung, sondern weil er von Apollos Orakel gehört hat - was aber gar nicht vorstellbar ist. Während der sophokleische Teiresias voll informiert ist, hat der senecaische keine Ahnung. Im Sinne einer verknüpfenden Dramaturgie hätte man erwartet, Oedipus ließe Tiresia holen, der aber wisse nichts. Doch kam es Seneca darauf nicht an. Nachdem diese Szene nicht weiterführt, hält Tiresia ein Extispicium ab, doch auch dieses führt zu keinem Ergebnis, so daß er beschließt, vor der Stadt eine Unterweltsbeschwörung ins Werk zu setzen. Wenn Creo davon in einer überlangen Rede später berichtet, wird deutlich, daß Tiresias ganzer Auftritt im Hinblick auf den Handlungsablauf höchst überflüssig war, insofern die Beschwörungsszene auf den ersten Creo-Auftritt hätte folgen können. $\mathrm{Da}$ Oedipus Creo nach seinem Bericht verdächtigt, ist das senecaische Stück nach über $Z_{w}$ eidritteln dort angelangt, wo das sophokleische am Beginn in der Teiresias-Szene steht. Bei Sophokles tauchte in dieser Begegnung die Wahrheit kurz auf, aber Oidi- 
pus hörte sie nicht, und so durfte sie auch der Zuschauer vergessen. Bei Seneca aber ist das Aussprechen der Wahrheit endgültig, bald darauf folgt die Katastrophe. Doch vor dieser ist ein tiefer Schnitt im dramatischen Gefüge - so tief, wie es attische Dramaturgie schwerlich geduldet hätte. Iocasta tritt auf, völlig unmotiviert; bei Sophokles wollte sie den Streit zwischen Oidipus und Kreon schlichten, der bei Seneca, durch ein Chorlied abgetrennt, schon zurückliegt. Auch nach hinten ist die Iocasta-Szene nicht verknüpft, insofern gar nicht auszumachen ist, wann sie eigentlich abtritt. Auf den Bericht des Korinthers reagiert sie nicht, während sie in der sophokleischen Szene eine erschütternde Rolle spielt.

Nicht weniger auffallend ist Oedipus' Verhalten. Bei Sophokles bohrte er von Szene zu Szene konsequent nach der Wahrheit, nutzte er jeweils sein Wissen aus der vorhergehenden Szene aus. Senecas Oedipus hätte schon bei der Creo-Erzählung das Richtige kombinieren können, wenigstens aber in der gewiesenen Richtung nachforschen müssen. Das unterbleibt. In der Iocasta-Szene versucht Seneca dann, die unterbrochene Untersuchung wieder in Gang zu bringen, indem er Oedipus sich selbst mehr oder weniger zufällig - tenue per vestigium (768) - an das erinnern läßt, auf was er vorher schon mehr als deutlich hingestoßen wurde. Denn wenn Oedipus selbst vom Dreiweg zu sprechen beginnt (772), geschieht das reichlich spät und zufällig, nachdem dieser schon V. 278 erwähnt worden war. Seneca legte auf eine folgerichtige Motivierung und dramaturgische Verknüpfung der Szenen keinen Wert.

Es dürfte somit deutlich geworden sein, daß bei dem griechischen Stück zu Recht von der 'zusammengesetztesten Handlung' gesprochen werden kann. In ihm geht es um das schrittweise Herausfinden der Wahrheit, um das konsequente Enucleiren des Verborgenen, das sich erst am Schluß nach dem Beschreiten mancher Irrwege zeigt. Der sophokleische `Oidipus< ist in seinem Geist und demzufolge auch in seiner Struktur der Ausdruck höchster Ratio. Ganz anders ist Senecas Stück. In ihm gibt es kein Ereignis der Wahrheit, sondern nur die Bestätigung eines von vornherein feststehenden Tatbestands: An die Stelle des Logos ist das Pathos getreten, das keine Entwicklung, sondern nur Steigerung kennt. Geist und Struktur des Stücks kennen kein Maß, sondern nur das Überbieten des schon Ausgesprochenen. Beliebigkeit hat den Platz der Notwendigkeit eingenommen. Insofern kann das Extispicium Tiresias völlig gleichberechtigt neben der Unterweltsbeschwörung stehen, indem gezeigt wird, mit welcher Beharrlichkeit das Fatum, dem Oedipus zu entfliehen sucht, näherrückt - so 
wie es von Anfang an feststeht. Dies ist das eine große Thema des senecaischen Stücks.

Sophokles' `Oidipus ist oft als Darstellung eines Gerichtsverfahrens bezeichnet worden. Es könnte daher den Anschein haben, daß seine strukturelle Verzahnung in der besonderen Fragestellung begründet sei. Daß es dennoch berechtigt ist, von einem grundsätzlichen Unterschied der griechischen und der römischen Dramaturgie zu sprechen, möge das Beispiel der >Medeia< zeigen, bei der man noch weniger von Handlung reden kann als beim ১Oidipus`. Schiller hat in einem Brief an Goethe vom 26. April 1799 unter Bezug auf den Stoff zu >Maria Stuart< von der 'Euripidischen Methode', welche in der 'vollständigsten Darstellung des Zustandes' bestehe, gesprochen:

Besonders scheint er sich zu der Euripidischen Methode, welche in der vollständigsten Darstellung des Zustandes besteht, zu qualifizieren, denn ich sehe eine Möglichkeit, den ganzen Gerichtsgang zugleich mit allem Politischen auf die Seite zu bringen, und die Tragödie mit der Verurteilung anzufangen.

Beim `Oidipus` würde man gern Schillers Formulierung von der 'zusammengesetztesten Handlung' für die sophokleische Fassung, die von der 'vollständigsten Darstellung des Zustandes' für die senecaische in Anspruch nehmen. Sollte bei der Gestaltung der >Medeia Euripides schon auf der Seite Senecas stehen? In der Tat ist die Handlung der euripideischen >Medeia‘, überspitzt ausgedrückt, eine einzige große Rede Medeias, zu der nacheinander verschiedene Personen treten: Kreon, Iason, Aigeus, abermals Iason, der Bote und wieder Iason. Die Monologe werden durch Dialoge unterbrochen. Von diesen Szenen ist keine für den äußeren Handlungsablauf dramaturgisch unentbehrlich. Die Iason-Szenen dienen der gegenseitigen Explizierung der unterschiedlichen Standpunkte, der Botenbericht hat traditionell eine mehr epische Funktion, Aigeus' Erscheinen ist insofern nicht notwendig, als Medeia auch ohne sein Asylangebot nicht auf ihre Rache verzichten würde, und die Verbannung Medeias durch Kreon brauchte nicht der König selbst zu überbringen, sondern könnte Medeia von Anfang an bekannt sein. Daß alle diese Szenen andererseits die Funktion haben, Medeias Auseinandersetzung mit ihrer Umgebung zur Darstellung zu bringen, bedarf keiner Betonung. Jeder an die Dramaturgie Senecas und seiner Nachfolger gewöhnte Zuschauer würde sich damit zufriedengeben. Uberraschenderweise hat Euripides jedoch ein Mittel gefunden, die so verschiedenen Szenen argumentativ zu verklammern 
und ihrer Abfolge bis zu einem gewissen Grade eine dramaturgische Notwendigkeit zu verleihen, indem er das Stück als Rache-Drama gestaltete und seiner Handlung eine bis in Einzelheiten ausgesponnene Intrige zugrundelegte. In diesem Zusammenhang ist die Kreon-Szene wichtig, in der Medeia ihre Intrige ins Werk zu setzen beginnt. Es ist im höchsten Maße auffallend, wie planvoll und überlegen sie Kreon belügt und hintergeht, wie sie die verschiedenen Wege der Rache durchspielt, $\pi 0 \lambda \lambda \dot{\alpha} \varsigma$ ódoús (376), wie sie gar bedenkt, was nach der Rache aus ihr wird (386ff.). Wenn sie sich selbst ermuntert, sie möge keine ihrer Kenntnisse

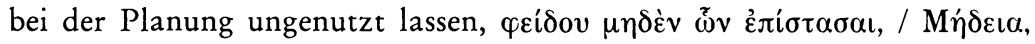

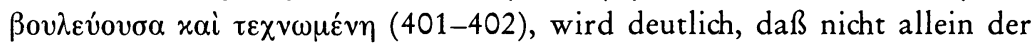
Schmerz die Triebfeder ihres Handelns ist, sondern Medeia eine Intrigantin beachtlichen Formats verkörpert. Sie bezieht auch Aigeus in ihr Spiel mit ein, da er ihr kaum Schutz angeboten hätte, wenn ihm ihre Pläne bekannt gewesen wären. Immerhin bewundert er ihre minutiöse Planung, $\pi \circ \lambda \lambda \dot{\eta} v \pi \varrho \mu \eta \eta{ }^{\prime} \alpha v(741)$. Die ganze zweite Iason-Szene ist dermaßen von Medeias Intrige bestimmt, daß diese nicht allein Ausdruck des Schmerzes zu sein scheint, sondern fast zum Selbstzweck zu werden droht. Die Art, wie genüßlich Medeia dem Boten zuhört oder sich in der letzten Szene an Iasons Schmerz weidet, erinnert schon an senecaische Gestalten, zeigt aber auch den Erfolg ihrer Intrige, indem sie unverhohlen der Freude über die Richtigkeit ihrer Kalkulation Ausdruck verleiht. Es fällt auf, daß Euripides nicht eine dramaturgische Verknüpfung der Szenen in der Weise gewählt hat, daß er $\mathrm{n}$ a $\mathrm{ch}$ der Kreon-Szene in Medeia den Gedanken an die Ermordung Kreons und Kreusas und $\mathrm{n}$ a $\mathrm{ch}$ der Iason-Szene den Plan zum Kindermord aufkommen ließ. Statt dessen wird die Handlung in einem erheblich äußerlicheren Sinne durch die sich fast über 1000 Verse von Kreons Auftritt (271) bis zu Kreons Tod (1230) erstreckende Intrige zusammengehalten. Für das moderne Empfinden wird Medeias Größe dadurch Eintrag getan, für den griechischen Kunstverstand war offenbar eine weitgehend von der Ratio bestimmte Handlungsführung unverzichtbar. Von Euripides führte ein direkter Weg zur Neuen Komödie.

Sehr viel einfacher ist Senecas >Medear strukturiert, in der das ganze Geschehen in noch größerem Maße auf die Heldin konzentriert ist. Außerlich kommt das schon darin zum Ausdruck, daß der Chor nicht mehr auf Medeas Seite steht und sich demgemäß nicht mehr aus Frauen zusammensetzt, sondern aus Männern, die das Geschehen aus neutraler Sicht kom- 
mentieren. Durch diesen mangelnden Rückhalt ist Senecas Medea von vornherein sehr viel einsamer als ihr griechisches Vorbild. Weiterhin fehlt die Aigeus-Szene. Senecas Medea hat nicht ein sicheres Asyl in der Hinterhand: Sie ist ganz auf sich gestellt und bringt sich unserer Sympathie dadurch nur näher. Ferner sind bei Euripides zu Beginn des Stücks die Kinder bei Medeia; sie hat die Möglichkeit, mit ihnen zu fliehen. Bei Seneca sind die Kinder von Anfang an bereits bei Iason: Medeas Verlassenheit und Einsamkeit ist vollkommen. Die Konzentration des Geschehens auf die Person Medeas zeigt sich auch in der Zurückdrängung alles Nur-Faktischen. So ist der Botenbericht von Kreons und Kreusas Tod von 103 Versen bei Euripides auf 12 Verse bei Seneca komprimiert. Bezeichnenderweise wird die Wirkung der Zauberei bei Euripides von dem neutralen Boten geschildert, bei Seneca hingegen als Teil von Medeas Wesen gedeutet, insofern diese in einer über 100 Verse langen Rede als Zauberin vorgeführt wird (740-848): Alles dient der totalen Explizierung ihres Inneren. Vor allem aber ist in dem römischen Stück die Intrige nicht so breit bis in alle Verästelungen hinein ausgesponnen wie in dem griechischen Vorbild. Daher fehlt die gesamte zweite Iason-Szene, die Medeia bei Euripides dazu dient, ihren Betrug zu inszenieren, während sie bei Seneca lediglich in der ersten Iason-Szene in wenigen Versen darum bittet, ihre Kinder noch einmal sehen zu dürfen (551-557). Die unterschiedliche Dramaturgie beider Stücke spiegelt auch schon die Creo-Szene wider. Bei Euripides spricht Kreon die Verbannung aus und gibt damit den Anlaß $\mathrm{zu}$ Medeias Intrige. Während es nahezu das alleinige Ziel der euripideischen Medeia ist, Kreon ihre Harmlosigkeit zu beweisen, diskutiert Senecas Medea offen über ihr crimen und verteidigt ihre scelera. Die Verbannung taucht keineswegs als neues Moment auf, sondern ist Medea längst, iamdudum (191), bekannt. Die Creo-Szene dient lediglich dazu, die 'inneren' Positionen Medeas und damit auch Creos und Iasons darzulegen. Die sich anschließenden Szenen offenbaren abermals die strukturelle Verschiedenheit in einer höchst aufschlußreichen Weise. Bei Euripides hält Medeia eine Rede (364-409), bei Seneca führt sie formal einen Dia$\log$ mit der Amme (380-430). Euripides' Medeia spricht den Chor an, rechtfertigt vor ihm ihr Tun, erwägt, was man über sie denken werde, diskutiert, wer sich später um sie kümmern werde, und bezieht schließlich sich und den Chor in die Frauengemeinschaft ein: $\pi \varepsilon \varphi v ́ x \alpha \mu \varepsilon v ~(407)$. In Senecas Szene reden sowohl die Amme als auch Medea für sich, ohne aufeinander einzugehen. Euripides' Medeia spricht - obschon in einer 
Einzelrede - aus der Gemeinschaft heraus im Hinblick auf die Gemeinschaft, Senecas Medea spricht - obschon in einem Dialog - aus der Einsamkeit heraus im Hinblick nur auf sich. Euripides' Medeia argumentiert von außen und nach außen, Senecas Medea argumentiert von innen und nach innen.

Der Konzentration auf die Person entspricht eine konsequente Vernachlässigung des Faktischen. Senecas Art, den Stoff seiner Dramen zu exponieren, mag das verdeutlichen. So läßt die Exposition des ১Oedipus، viele Fragen offen. Bei Sophokles gibt Oidipus in den Versen 1-13 eine allgemeine Exposition, indem er den Schauplatz und die Personen, sich eingeschlossen, vorstellt, während der Priester in den Versen 14-57 die spezielle Exposition im Hinblick auf die Pest anfügt. Bei Seneca tritt hingegen ein Mann auf, der in den Versen 1-5 ein Stimmungsbild und 6-11 eine Sentenz über die Königsherrschaft ausmalt, sodann sagt, sein Vater heiße Polybus, er sei geflohen und in ein Königreich 'geraten', incidi (14) - Rätsel über Rätsel. Aber die innere Situation, auf die es allein ankommt, ist deutlich: Ein Mann ist auf der Flucht vor dem Schicksal und sich selbst; dieser Mann hat auch eine Frau, deren Namen ebensowenig genannt ist, deren Haltung aber klar umrissen wird, indem sie fest dafür eintritt, jeder vom Schicksal bestimmten Situation standzuhalten. Es wird nicht deutlich, wer der Mann und die Frau sind, dafür aber, daß in stoischem Sinne der Mann sich falsch, die Frau richtig verhält.

In Euripides' Medeiar gibt die Amme in den ersten 19 Versen eine genaue Exposition: Fahrt der Argo, Mord an Pelias, Korinth als Schauplatz, neue Heirat Iasons, Medeias Verlassenheit als Folge. Wenn sie dann fortfährt, Medeia klage über die Eheeide, ßoọ $\mu \dot{\varepsilon} v$ ọ̋xovธ (21), und rufe

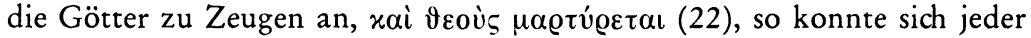
Zuschauer ein genaues Bild über die Handlungssituation machen. Seneca führte jedoch in seinem Stück mit dem ersten Vers Medeas ßoõv und ảvax $\alpha \lambda \varepsilon i v$ in seinem ganzen Pathos höchstselbst vor, indem er die gesamte Exposition kurzerhand strich. Zwar fallen im achten Vers die Namen Iason und Medea, aber es mußte völlig unklar sein, wer die neue Gattin, wer der Schwiegervater, wer die Kinder seien, denen Medea in den Versen 17 und 18, in die ihre Rede - ein einziger Racheruf von 18 Versen gipfelt, den Tod wünscht: coniugi letum novae / letumque socero et regiae stirpi date. Das gilt für den ganzen 55 Verse umfassenden Monolog. Der Zuhörer konnte - und sollte - nur realisieren, daß eine Frau in namenlosem Schmerz sprach und auf namenlose Rache sann: Das Pathos 
schwemmte alle rationalen Verknüpfungen der einzelnen Argumente mit sich fort.

Heiter und gelöst, aber ebenfalls nur auf Stimmung, nicht auf realistische Erfassung der Zusammenhänge angelegt ist der Prolog zur $>$ Phaedrar. Hippolytus singt ein Jagdlied allgemeinster Prägung, das auf jede andere ähnliche Situation übertragbar ist. Man kann Hippolytus' 84 Verse lange Arie nicht besser charakterisieren, als es W. H. Friedrich getan hat: „Er liefert zunächst, indem er die Jagdgenossen im Gelände verteilt, einen Abriß der attischen Landeskunde mit einer Fülle von tönenden Namen. Dann gibt er Anweisungen wegen der Hunde, indem er die wichtigsten Rassen nennt, und weist den einzelnen Jägern ihre Aufgaben zu. Er schließt mit einem Gebet an Diana, deren Wirkungsbereich er ausführlich würdigt, und eilt endgültig in den Wald.“

Die Betrachtung der Expositionen in der römischen Komödie wird bestätigen, daß die immer wiederholte Ansicht unzutreffend ist, Seneca habe den Stoff seiner Tragödien so mangelhaft exponiert, weil er seinen Hörern und Lesern allbekannt gewesen sei. Hier zeigt sich vielmehr ein grundlegender Unterschied in der Gewichtung, die Griechen und Römer der Darstellung faktischer Zusammenhänge gaben. Für fast alle von Euripides auf die Bühne gebrachten Stoffe galt, daß sie den Zuschauern zur Genüge bekannt waren, und doch exponierte er sie teilweise so pedantisch, daß Aristophanes seine Manier in den >Fröschen $<$ auf das Korn nahm. Andererseits haben die römischen Komödiendichter die komplizierten Handlungen ihrer Vorlagen so oberflächlich exponiert, daß sie den Zuschauern oft nicht durchschaubar sein konnten. Wie in anderen Genera der römischen Literatur kam es auch im Drama mehr auf den Ausdruck von Haltungen und Ideen als auf deren Voraussetzungen und Begründungen an.

Es ist hinreichend deutlich, daß die griechische Tragödie die folgerichtige Verknüpfung der einzelnen Szenen, die römische die pathetische Reihung derselben kennt. Der organischen Entfaltung der Handlung der griechischen Tragödie entspricht eine dynamische Entwicklung der Bestimmungen der Charaktere. Der statischen Struktur der römischen Tragödie entspricht die statische Darstellung ihrer Charaktere. Die einzelnen Szenen bringen für diese nicht so sehr neue Situationen, die ihr Handeln entscheidend beeinflußten, sondern dienen der Ausmalung und Ausgestaltung von Anfang an festgelegter Bestimmungen und Züge der Charaktere. Daher zeigen schon die ersten Szenen, oft die Prologe, die Personen fast in ihrer endgültigen Situation. Mit ihnen ereignet sich nicht etwas, sondern 
sie selbst sind das Ereignis, das dargestellt werden soll. Die römische Tragödie führt im Gegensatz zur griechischen nicht vor, wie Oidipus stürzt oder wie Medeia zur Kindermörderin wird, sondern demonstriert von Beginn an den gestürzten Oedipus und die Kindermörderin Medea.

Bei Sophokles tritt Oidipus reinsten Gewissens auf; er hat nicht den geringsten Anlaß zu der Annahme, er könne an der Pest schuld sein. Erst im Verlaufe der Handlung kommt er zu der Erkenntnis, daß die Gottheit ihn wegen seiner Taten als Befleckung des Landes, $\mu i \alpha \sigma \mu \alpha$, empfinde und daher die Pest geschickt habe. Bei Seneca kann Oedipus zwar feststellen, $\mathrm{da} ß$ er bisher vermieden habe, den Vater zu erschlagen und die Mutter zu heiraten, aber nach der stoischen Prädestinationslehre ist er schuldig von dem Augenblick an, wo er die betreffenden Orakel erhalten hat. Demgemäß ist er in seinem Bewußtsein schuldig, noch ehe er erfährt, daß er die vorausgesagten Taten bereits begangen hat. Während der sophokleische Oidipus zur Pest ein neutrales Verhältnis hat, bezieht sie der senecaische sofort auf sich: 'In dem Verderben der Stadt und den immer neu zu beklagenden Leichenzügen und dem Sterben des Volkes stehe ich unversehrt - ganz offensichtlich als Angeklagter Apollos. Konntest du hoffen, für solche Verbrechen werde ein gesundes Reich gegeben? I $c h$ habe den Himmel schädlich gemacht' (32-36):
inter ruinas urbis et semper novis
deflenda lacrimis funera ac populi struem
incolumis asto - scilicet Phoebi reus.
sperare poteras sceleribus tantis dari
regnum salubre? fecimus caelum nocens.

Oedipus spricht von seinen scelera, noch ehe er weiß, daß er sie vollbracht hat, er bekennt sich schuldig, noch ehe er weiß, daß er schuldig ist. Er spricht von seiner tödlichen Hand, letalis manus (77), noch ehe er weiß, $\mathrm{da}$ er den Vater erschlagen hat, und nennt seine Verfehlungen als Ursache für die Verpestung des Himmels, tabifica caeli vitia (79), noch ehe er weiß, daß er die Pest verursacht hat. Für Oedipus' Bewußtsein und Haltung trägt die gesamte Handlung des Stücks nichts bei. Während das Geschehen des sophokleischen 'Oidipus ein Ecce homo zeigt, indem der Mensch zu Beginn auf der höchsten Stufe und am Schluß im tiefsten Elend steht, zu Beginn strahlender Herrscher ist und am Schluß in die Verbannung zieht, ist der senecaische Oedipus von Anfang an elend und auf der Flucht. Während Sophokles' Oidipus eine Wandlung durchmacht, erfährt 
Senecas Oedipus nur eine Bestätigung. An die Stelle der Dynamik ist Statik getreten.

Während Oedipus sein Schicksal durch das Orakel kennt und desto leichter von der Realisierung in seinem Bewußtsein noch nicht vollbrachter Taten sprechen kann, entfällt bei anderen Personen dieser äußere Anstoß. Dennoch hat Seneca bei ihnen keineswegs die Entwicklung zu einer Entscheidung hin oder gar die Entfaltung ihres Wesens zeigen wollen. Vielmehr war für ihn die darzustellende Person stets eine konstante Größe, deren Umriß von Beginn an feststand und bei der es nur galt, die einzelnen Züge nach und nach zu einem vollständigen Porträt zusammenschießen zu lassen. Der vorgegebene, sozusagen für ihr Wesen verpflichtende Rahmen einer Person ist bei Medea besonders gut zu beobachten. Sie hat schon früher Schandtaten, scelera, begangen: Raub des Goldenen Vlieses, Beihilfe zu den Morden am Bruder, am Vater und an Pelias. Wenn sie überlegt, wie sie sich an Iason rächen könne, geht es ihr nicht um die Sache, um Iasons Person, sondern um ihre eigene Person: Sie muß sich mit einem scelus rächen, wie es ihrer angemessen ist. Der furchtbare Anlaß, der für die euripideische Medeia allein Gewicht hatte, verliert völlig an Bedeutung gegenüber der Größe 'Medea'. Es kommt nicht so sehr darauf an, daß Iason gestraft wird, als vielmehr darauf, wie Medea straft. Und so beruft sie sich konsequent auf ihre vergangenen scelera, um aus ihnen die Verpflichtung für die Gegenwart abzuleiten: scelera te hortentur tua / et cuncta redeant (129-130). Freilich kann der Fall eintreten, daß die gegenwärtige Situation wie bei Medea eine besondere Reaktion erfordert. Denn es ist ja unbestreitbar, daß ihre Lage noch nie so zugespitzt war. Und so kann sie sagen, daß ihr jetzt größere scelera 'anstünden': maiora iam me scelera [...] decent (50). Damit ist aber keine Entwicklung ihres Wesens, sondern lediglich eine quantitative Steigerung ihrer Handlungsgewohnheiten gemeint. Wenn es ihr gelingt, diesen den I-Punkt aufzusetzen, ist sie endlich ganz Medea. Dann füllt sie den von Anfang an vorgegebenen Rahmen aus. Dies bedeuten die beiden oft zitierten Wendungen, Medea wolle Medea werden, Medea fiam (171), und nach vollbrachter Tat: sie sei nun Medea, Medea nunc sum (910). Lediglich ihre Erfindungsgabe ist durch das Leid gewachsen, ihr Wesen hat sich nicht entwickelt: crevit ingenium malis (910). In diesem Zusammenhang erklären sich auch die vieldiskutierten Andeutungen der zukünftigen Taten Medeas im Prolog. Dort spricht sie offen aus, daß sie Creo und Creusa den Tod wünscht (17f.). Dann überlegt sie, wie sie Iason Schlimmeres 
wünschen könne: er möge leben und durch unbekannte Städte bedürftig, verbannt, in Furcht, verhaßt und unstet irren, schon bekannt, stets an fremde Türen klopfen; Medea möge er wieder zur Frau wünschen und das Schlimmste von allem - Kinder, die Vater und Mutter ähnlich seien. Und in diesem Augenblick, in dem Medea von Kindern spricht, ruft sie aus: geboren sei die Rache, denn sie habe geboren, d. h. sei Mutter von Kindern, an denen die Rache vollzogen werden könne (19-26):

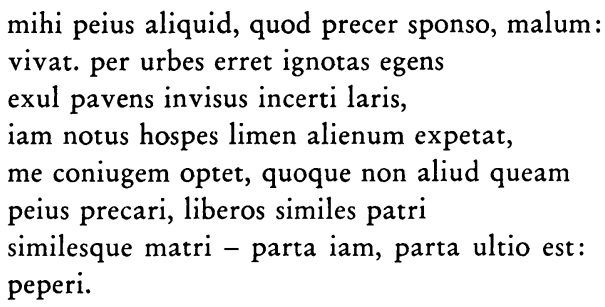

Das ist natürlich doppeldeutig formuliert, aber wenn Medea wenig später sagt, sie wolle den Weg der Rache durch den eigenen Leib hindurch suchen, per viscera ipsa quaere supplicio viam (40), spielt sie ebenfalls auf den Kindermord an, mit dem sie sich selbst trifft. Durch die situationsbedingte Doppeldeutigkeit lasse man sich nicht täuschen: Während die euripideische Medeia erst V.792 auf den Gedanken an den Kindermord verfällt, steht die senecaische Medea von Anfang an als potentielle Kindermörderin da. Senecas Medea wird durch kein Ereignis während des Stücks zu irgendeiner vorher undenkbaren Entscheidung, zu einer Entfaltung oder gar Veränderung ihres Wesens getrieben. Sie braucht lediglich ihre Erfindungsgabe, ihr ingenium, einzusetzen, um die neue Situation zu meistern. Sie ist von Anfang an die, die sie am Schluß ist. Eine Entwicklung kennt sie so wenig wie die anderen Gestalten der römischen Bühne.

Die Emanzipation der Person von der Handlung bewirkt, daß die Einzelrede in der römischen Tragödie eine besondere Bedeutung erlangt. Freilich ist es unverkennbar, welch fein nuanciertes Instrument die attische Tragödie mit der Umsetzung menschlichen Denkens und Fühlens in Rede und Gegenrede allen nachfolgenden Epochen in einzigartiger Weise bereitgestellt hatte. Nietzsche hat das in dem 80. Kapitel des zweiten Buchs der ,Fröhlichen Wissenschaft เ so gesehen: 
Die Griechen (oder wenigstens die Athener) hörten gerne gut reden: ja sie hatten einen gierigen Hang danach, der sie mehr als alles andere von den Nicht-Griechen unterscheidet. Und so verlangten sie selbst von der Leidenschaft auf der Bühne, daß sie gut rede, und ließen die Unnatürlichkeit des dramatischen Verses mit Wonne über sich ergehen [...] Nun haben wir uns alle, dank den Griechen, an diese Unnatur auf der Bühne gewöhnt [...] Es ist uns ein Bedürfnis geworden, welches wir aus der Wirklichkeit nicht befriedigen können: Menschen in den schwersten Lagen gut und ausführlich reden $\mathrm{zu}$ hören: es entzückt uns jetzt, wenn der tragische Held da noch Worte, Gründe, beredte Gebärden und im ganzen eine helle Geistigkeit findet, wo das Leben sich den Abgründen nähert, und der wirkliche Mensch meistens den Kopf und gewiß die schöne Sprache verliert. Diese Art Abweichung von der Natur ist vielleicht die angenehmste Mahlzeit für den Stolz des Menschen; ihretwegen überhaupt liebt er die Kunst, als den Ausdruck einer hohen, heldenhaften Unnatürlichkeit und Konvention [...] Der Athener ging ins Theater, um schöne Reden zu bören! Und um schöne Reden war es dem Sophokles zu tun! - man vergebe mir diese Ketzerei!

Noch ketzerischer war Grillparzer in dem 3556. Stück seines >Tagebuchs vom Herbst 1841, wenn er zu Aischylos anmerkte:

In den Wechselreden brauchen die Unterredenden die längste Zeit um sich über die einfachsten Verhältniße zu verständigen, und was der Zuseher bei der ersten Antwort begriffen hat, wird oft durch zehn Verse durch gefragt, bis die Redenden in's Klare kommen [...] Später beim Euripides, ja schon beim Sophokles, ist es jene Redseligkeit, die den Athenern, aus der Gewohnheit von öffentlichen Reden und Gerichtsverhandlungen, zum eigentlichen Labsal geworden war. Solche Geschwätzigkeit im guten Sinne kommt selbst in den Dialogen des Plato nicht selten vor.

Form und Funktion der tragischen Rede haben bei Seneca gegenüber der griechischen Tragödie einige entscheidende Modifikationen erfahren. Zunächst hat der Verzicht auf eine argumentative Weltdeutung in der römischen Tragödie bewirkt, daß deren Personen nicht nur ganz auf sich gestellt sind und nur auf sich bezogen empfinden und sprechen, sondern daß ihre Reden auch aus dem argumentativen Gesamtzusammenhang des Dramas herausgenommen sind und ein Eigenleben führen. Daher steht in der römischen Tragödie nicht nur Szene neben Szene unverbunden nebeneinander, sondern letztlich auch Rede neben Rede. Da es nicht mehr um den Widerstreit von Ideen geht, gibt es auch keine Agone mehr, ja nicht einmal echte Dialoge. Außerlich zeigt sich das darin, daß oft nicht feststellbar ist, wann Personen zu einer sprechenden Person hinzutreten oder an einem Gespräch nicht mehr teilnehmen. Bezeichnend ist dafür die 
Rolle Iocastas in Senecas >Oedipus«. Das Stück beginnt mit einem 81 Verse umfassenden Monolog von Oedipus, bei dem kein anderer Teilnehmer denkbar ist. Dann spricht plötzlich Iocasta, ohne daß man weiß, ob sie von Anfang an 'Zuhörerin' war oder erst später hinzuzudenken ist. Es ging Seneca nur um Oedipus: $\mathrm{Zu}$ dessen unstoischem Verhalten brauchte er als Regulativ die stoische Gegenposition, damit seine Haltung möglichst deutlich wurde. Iocasta ist keine 'lebendige' Person, kein organischer Bestandteil des Stücks, sondern nur die Verkörperung einer Idee. Sie erfüllt eine ganz bestimmte Funktion, und zwar in Hinsicht auf Oedipus' Argumentation. Von hieraus wird auch verständlich, daß sie bei ihrem schon betrachteten zweiten Auftritt von einem bestimmten Zeitpunkt an einfach vergessen werden kann, obschon es um das Äußrste geht, aus dem die griechische Iokaste die letzte Konsequenz zieht. Aber auch Dialoge sind oft im Grunde nur Monologe, die durch Zusatz-Argumente größeres Profil erhalten. So ist der Dialog mit dem Satelles in Senecas >Thyestes (204-219) nur eine Fortsetzung von Atreus' Monolog (176-204), auf die sofort wieder ein Monolog folgt (220-244). In dem Zwischenstück sollten durch die Einwürfe Atreus' sarkastische Maximen fortlaufend pointiert von der Normalansicht abgehoben werden. Nicht anders ist die Funktion der bei Seneca so beliebten Domina-Nutrix-Szenen in der >Phaedra<, im >Agamemnon< und in der >Medea<, wo jeweils nur die Position der Hauptheldin nach allen Richtungen hin abgesteckt wird. Am deutlichsten ist das in der >Medear, wo weder die beiden Szenen mit der Amme noch, wie schon dargelegt, die von diesen eingeschlossene Creo-Szene einen echten Dialog darstellen, sondern nur der Explizierung von Medeas Wesen dienen.

Weiterhin ist für die besondere Ausprägung der senecaischen Rede eine literarische Form wichtig geworden, die zuerst bei den Neoterikern begegnet und am ehesten der modernen Technik des 'inneren Monologs' vergleichbar ist. In jener Zeit, in der das Individuum durch die Entwicklung der politischen und gesellschaftlichen Verhältnisse auf sich selbst zurückgeworfen wurde, bildete sich in der Literatur eine Form aus, in der das Ich, ohne sich an ein fest umrissenes Gegenüber zu richten, über seine Situation reflektiert und dabei die verschiedensten Vorstellungen an sich vorüberziehen läßt. Diese zum ersten Male in Catulls Ariadne-Klage zu beobachtende Technik haben die römischen Elegiker geradezu virtuos ausgebildet. Seitdem gibt es in der römischen Literatur den von Person zu Person schweifenden, an keine bestimmte Situation gebundenen, von Zeit- 
stufe zu Zeitstufe springenden und die Gedanken assoziativ verbindenden 'inneren Monolog', den Vergil in den Reden Didos, Ovid in den sHeroides, vor allem aber Seneca in seinen Tragödien aufgenommen und weiterentwickelt haben. Das Rezitationsdrama ist literaturgeschichtlich gesehen die konsequente Fortsetzung dieser römischen Ausdrucksform.

Als dritte Komponente hat zur Ausbildung der senecaischen Rede die stoische Philosophie beigetragen, die das gesamte Weltgeschehen nur aus dem Blickwinkel des einzelnen Menschen heraus betrachtete. Für die von ihr geprägte Grundhaltung konnte nicht das Handlungsganze, sondern nur der jeweilige Handlungsausschnitt von Bedeutung sein, weil es immer nur auf die Reaktion des einzelnen ankam. Die stoische Psychologie hatte dabei eine Betrachtungsweise entwickelt, die auch die feinsten Regungen und Nuancen der menschlichen Seele erfassen und beschreiben konnte. Sie fiel in dieser literarischen Situation in Rom bei dem senecaischen Rezitationsdrama auf einen besonders fruchtbaren Boden.

Diese vielschichtigenVoraussetzungen haben bewirkt, daß die senecaische Rede eine literarische Form sui generis wurde, die in ihrer Modernität eine Nachwirkung ohnegleichen erlebt hat. Wenn Schiller in der unterdrückten Vorrede zu den >Räubern` die echte 'dramatische Manier' von der der französischen Tragödie absetzt, so ist mit der letzten zugleich die senecaische Manier und damit der Archetyp innerhalb der Entwicklung der europäischen Tragödie charakterisiert:

Wirklich ist dieses große Vorrecht der dramatischen Manier, die Seele gleichsam bei ihren verstohlensten Operationen zu ertappen, für den Franzosen durchaus verloren. Seine Menschen sind (wo nicht gar Historiographen und Heldendichter ihres eigenen hohen Selbsts) doch selten mehr als eiskalte Zuschauer ihrer Wut, oder altkluge Professore ihrer Leidenschaft.

Die senecaische Manier kann bis zu einem gewissen Grade der Monolog veranschaulichen, den im >Hercules Furens` ('Der rasende Herakles`) der aus dem Wahnsinn erwachende Hercules hält, wenn er die Leichen seiner von ihm getöteten Frau und Kinder erblickt (1138-1186). An dieser Stelle spricht sein griechisches Vorbild im $>$ Herakles 'Ah! Ich atme und sehe, was ich muß, [1090:] Himmel, Erde und die Strahlen der Sonne; ich bin in wogenden furchtbaren Wahnsinn gefallen und hole aus meiner Lunge unsteten heißen Atem herauf. Sieh, warum sitze ich wie ein Schiff festgebunden mit Stricken [1095:] um Brust und 
Arme an einen halbzerborstenen Stein und habe meinen Platz neben Leichen? Und die geflügelten Pfeile! Der Bogen aber liegt am Boden fortgeschleudert, der mich in meinen Armen [1100:] schützte, so wie ich ihn schützte. Kam ich wieder in den Hades, ein zweites Mal für Eurystheus? In den Hades? Woher? Aber ich sehe nicht Sisyphos' Fels und Pluton und nicht das Szepter der Demeter-Tochter. [1105:] Ich bin geschlagen. Wo bin ich und weiß nicht weiter? He, welcher Freund ist nah oder fern, der meinen Irrtum heilt? Denn das Gewohnte erkenne ich nicht' (1088-1108):

है $\alpha$.

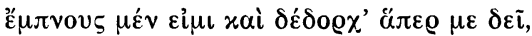

1090

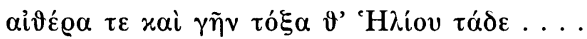

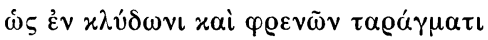

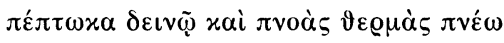

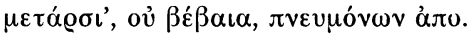

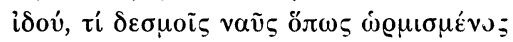

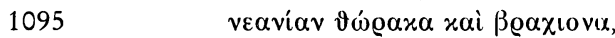

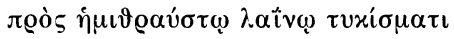

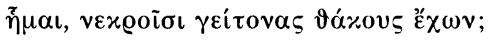

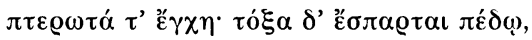

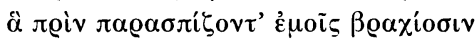

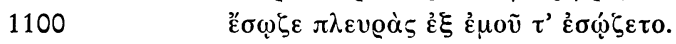

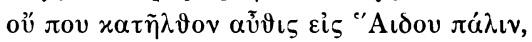

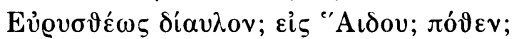

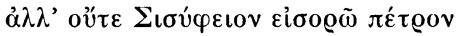

П1

1105

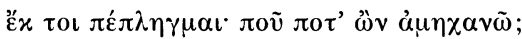

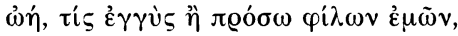

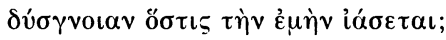

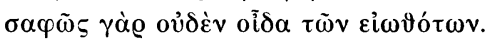

Demgegenüber äußert sich Senecas Hercules folgendermaßen: 'Welcher Ort, welche Gegend ist das, welcher Platz der Welt? Wo bin ich? Gegen Sonnenaufgang, gegen die Achse [1140:] der eisigen Bärin? Setzt hier die äußerste Küste am Hesperischen Meer dem Ozean die Grenze? Welche Luft atme ich? Welcher Boden ist unter dem Erschöpften? Ich bin gewiß wieder zurück - warum sehe ich zu Hause blutige Körper niedergestreckt? Hat der Geist noch nicht [1145:] die unterirdischen Bilder abgelegt? Irrt noch nach der Rückkehr vor meinen Augen die Totenschar? Ich bekenne mit Scham: ich habe Furcht. Irgendein, ein großes Unglück ahnt mein 
Geist. Wo bist du, Vater? Wo ist meine auf die Kinderschar [1150:] stolze Gattin? Warum entbehrt meine linke Seite des Löwenfells? Wohin ist mein Schutz, der zugleich ein weiches Polster für Hercules' Schlaf war? Wo sind die Pfeile? Wo ist der Bogen? Wer konnte mir, solange ich lebe, die Waffen nehmen? Wer hat solche Beute gemacht [1155:] und schreckte nicht selbst vor Hercules' Schlaf zurück? Ich habe Lust, meinen Besieger zu sehen, wirklich Lust. Erscheine, Verkörperung der Virtus, für den mein Vater den Himmel verließ, um ihn als neuen Helden zu erschaffen, bei dessen Zeugung die Nacht länger anhielt als die unsrige - welch Verbrechen sehe ich? [1160:] Die Kinder liegen in blutigem Mord hingerafft, ermordet die Gattin. Welcher Lycus herrscht als König? Wer wagte es, nach Hercules' Rückkehr solche Verbrechen in Theben zu begehen? Der du die Gegend des Ismenus, die attischen Fluren, [1165:] des dardanischen Pelops Reich, das auf beiden Seiten vom Meer bespült wird, bewohnst, komm zu Hilfe, melde den Urheber des wilden Mordes! Mein Zorn richte sich gegen alle: Feind ist mir, wer mir nicht den Feind nennt. Sieger über den Alciden, verbirgst du dich? Tritt vor, ob du das trotzige Gespann [1170:] des blutigen Thrakers, Geryones' Herde oder die Herren von Libyen rächen willst, der Kampf wird nicht verzögert. Da stehe ich nackt; ja mit meinen Waffen magst du den Waffenlosen angreifen. Warum meiden Theseus und der Vater meinen Anblick? Warum verbergen sie ihr Gesicht? [1175:] Laßt das Weinen! Sprich, wer die Meinen alle zusammen getötet hat - was schweigst du, Vater? So sage es du, Theseus, aber mit deiner bekannten Zuverlässigkeit! Beide bedecken schweigend ihr schamerfülltes Antlitz und vergießen heimlich Tränen. Wessen müßte man sich bei solchem furchtbaren Geschehen [1180:] schämen? Hat der übermütige Herrscher über die argivische Stadt, hat ein feindliches Heer des sterbenden Lycus uns mit solcher Niederlage überfallen? Bei dem Ruhm meiner Taten bitte ich dich, Vater, bei dem mir immer [1185:] günstigen Schutz deines Namens, sprich: Wer hat das Haus heimgesucht? Wem lag ich als Beute da?'

Quis hic locus, quae regio, quae mundi plaga?

ubi sum? sub ortu solis, an sub cardine

1140 glacialis ursae? numquid Hesperii maris extrema tellus hunc dat Oceano modum? quas trahimus auras? quod solum fesso subest? certe redimus - unde prostrata ad domum video cruenta corpora? an nondum exuit 
simulacra mens inferna? post reditus quoque oberrat oculis turba feralis meis? pudet fateri: paveo; nescio quod mihi, nescio quod animus grande praesagit malum. ubi es, parens? ubi illa natorum grege animosa coniunx? cur latus laevum vacat spolio leonis? quonam abit tegimen meum idemque somno mollis Herculeo torus? ubi tela? ubi arcus? arma quis vivo mihi detrahere potuit? spolia quis tanta abstulit ipsumque quis non Herculis somnum horruit? libet meum videre victorem, libet. exurge, virtus, quem novum caelo pater genuit relicto, cuius in fetu stetit nox longior quam nostra - quod cerno nefas? nati cruenta caede confecti iacent, perempta coniunx. quis Lycus regnum obtinet? quis tanta Thebis scelera moliri ausus est Hercule reverso? quisquis Ismeni loca, Actaea quisquis arva, qui gemino mari pulsata Pelopis regna Dardanii colis, succurre, saevae cladis auctorem indica. ruat ira in omnes: hostis est quisquis mihi non monstrat hostem. victor Alcidae, lates? procede, seu tu vindicas currus truces Thracis cruenti sive Geryonae pecus Libyaeve dominos, nulla pugnandi mora est. en nudus asto; vel meis armis licet petas inermem. cur meos Theseus fugit paterque vultus? ora cur condunt sua? differte fletus; qui meos dederit neci omnes simul, profare - quid, genitor, siles? at tu ede, Theseu, sed tua, Theseu, fide. uterque tacitus ora pudibunda obtegit furtimque lacrimas fundit. in tantis malis 1180 quid est pudendum? numquid Argivae impotens dominator urbis, numquid infestum Lyci pereuntis agmen clade nos tanta obruit? per te meorum facinorum laudem precor, genitor, tuique nominis semper mihi numen secundum, fare. quis fudit domum? cui praeda iacui? 
Der griechische Herakles hält eine knappe Rede, deren Gedanken sich folgerichtig in vier Schritten entwickeln: 1. physische Verfassung: 'Ich bin wieder bei Besinnung, atme aber noch schwer' (1088-1093). 2. Außere Lage: 'Ich sitze gefesselt neben Leichen, waffenlos' (1094-1100). 3. Folgerung bezüglich des Orts: 'Sollte ich wieder im Hades sein? Doch dem Anschein nach trifft das nicht zu' (1101-1104). 4. Folgerung bezüglich der Situation: 'Was tue ich? $\alpha \mu \eta \chi \alpha v \tilde{\omega}$ ' (1105-1108). Herakles stellt wenige berechtigte Fragen: Warum er gefesselt sei? Ob er wieder im Hades sei? Wo er dann sei? Welcher Freund ihm helfe? Im Grunde ist das eine einzige und zudem angemessene Frage. Während der griechische Herakles mühsam aus der Ohnmacht erwacht, ist der römische Hercules auf der Stelle hellwach und entlädt sich sofort eines wahren Feuerwerks von Fragen. Wenn man Leos oben gegebenem Text folgt, sind es nicht weniger als 28 Fragen, davon 17 in den ersten 18 Versen. Da seine Lage nicht anders als die seines Vorbilds ist, muß seine Geisteshaltung eine andere sein. Dies zu berücksichtigen ist deshalb wichtig, weil es ein alter Fehler ist, die Vielzahl der Fragen für den Ausdruck leerer, seelenloser Rhetorik zu halten. Vor allem sollte man in diesem Zusammenhang mit dem Begriff 'kalter' Gelehrsamkeit vorsichtig sein, etwa wenn Hercules gleich zu Anfang die verschiedenen Möglichkeiten umschreibt, ob er sich im Osten, Norden oder Westen befinde? Lessing hätte jedenfalls einen solchen Vorwurf nicht zugelassen, wenn er gegen die Kritik des französischen Jesuitenpaters Pierre Brumoy an den Versen 944-952, in denen Hercules von dem Tierkreiszeichen des Löwen spricht, in seiner Abhandlung >Von den lateinischen Trauerspielen welche unter dem Namen des Seneca bekannt sind bemerkt:

Mit [...] wenig Grunde tadelt Brumoy diejenigen Stellen, in welchen Herkules raset. „Herkules, sagt er, bildet sich ein den himmlischen Löwen, den er in dem Nemeäischen Walde überwunden, zu sehen, wie er eben bereit ist, die Zeichen des Herbstes und des Winters zu überspringen, um den Stier zu zerreissen, welcher ein Zeichen des Frühlings ist. Das ist wahrhaftig eine gelehrte Raserey!“ - Wie artig der Jesuit spottet. Aber warum ist sie denn gelehrt? Ohne Zweifel darum, weil ein Jesuitenschüler nicht ganz und gar ein Ignorante seyn muß, wenn er wissen will, daß Herkules einen Löwen umgebracht habe. Aber was für eine Gelehrsamkeit braucht denn Herkules, dieses von sich selbst zu wissen? Oder steckt etwa die Gelehrsamkeit in der Kenntniß der Zeichen des Thierkreisses? Wenn das ist, so werden ziemlich alle Bauern gelehrt seyn. - -

Es ist nicht zu bestreiten, daß Hercules mehr als mancher andere weiß, es ist auf der anderen Seite aber ganz natürlich, daß er gerade auf den 
Löwen Bezug nimmt, da das Sternbild mit dem von ihm getöteten Nemeischen Löwen in Verbindung gebracht wurde (daß das erst eine spätere Zeit tat, ist eine senecaische Pointe, auf die es hier nicht ankommt). Von kalter Gelehrsamkeit könnte man nur sprechen, wenn Hercules ein beliebiges Sternbild, nicht aber sein 'persönliches' genannt hätte: primus en nos ter labor (944). Ebenso verhält es sich zu Anfang des Monologs. Hercules hat ein besonderes Recht, die verschiedenen Himmelsrichtungen aufzuzählen, da er ja durch die ganze Welt gezogen ist, um die Ungeheuer aller Gegenden zu erlegen. Es handelt sich in beiden Fällen darum, daß die unbelebte Natur, die Welt, sogar das Weltall von dem subjektiven Empfinden des einzelnen durchsetzt wird, ja nur im Hinblick auf den einzelnen eine Funktion, sozusagen Leben erhält. Darum fährt Hercules auch nicht fort zu fragen: 'Welche Luft ist das? Welcher Boden ist das?' Sondern er fragt: 'Welche Luft atme ich? Welcher Boden trägt den Erschöpften?' Er bringt sein Atmen und sein Erschöpftsein sogleich in die Fragen mit ein. Er bezieht seine Umwelt auf sich, nicht sich auf seine Umwelt.

Die senecaischen Helden nehmen keine Person so wichtig wie die eigene. Insofern sind sie ohne Unterlaß beschäftigt, sich zu beschreiben und zu preisen, die beiden Funktionen also zu erfüllen, die Schiller meint, wenn er von 'Historiographen und Heldendichtern ihres eigenen hohen Selbsts' spricht. So beschreibt Hercules da, wo der griechische Herakles nur den Bogen nennt, auch seine 'Rüstung', das Löwenfell, und fügt hinzu, daß es ihn nicht nur schütze, sondern ihm auch als angenehmes Schlafpolster zu dienen pflege (1150-1152). Der griechische Herakles hat einen konkreten Anlaß, vom Bogen zu sprechen, weil er ihn auf dem Boden liegen sieht. Hercules hingegen kann nicht von seinen Waffen sprechen, ohne auch seines Wahrzeichens Erwähnung zu tun (es fehlt nur die Keule) - wie ein Historiograph seiner Person. So läßt er auch einfließen, daß bei der Erzeugung eines so gewaltigen Helden, wie er es ist, die Nacht anhalten mußte, damit Iupiter das Werk überhaupt vollbringen konnte (1157 bis 1159) - nicht aber, damit er seine voluptas verlängerte, wie es die Tradition wollte! Ansonsten hat Hercules in der betrüblichen Situation natürlich wenig Veranlassung, sich herauszustellen. Doch hat er das schon vorher gebührend getan. Während der griechische Herakles bei der Rückkehr aus der Unterwelt in der ersten Hälfte des Stücks sofort von seiner Gattin Megara in ein sachliches Gespräch gezogen wird und ausdrücklich beschließt, ehe er in das Geschehen eingreift, den Göttern für die glückliche 
Rückkehr zu danken (606-609), hält der römische Hercules eine ausführliche, ja geradezu panegyrische Rede auf seine Leistung: $\mathrm{Er}$ ist nicht nur weit davon entfernt, den Göttern zu danken, er erhebt sich im Gegenteil über sie. Nach dem Sonnengott Phoebus, nach Iupiter und Neptun wendet er sich Iuno und dem Herrscher der Unterwelt zu: 'Mich zu bestrafen und mir Mühe zu schaffen, dazu ist die Erde nicht groß genug für Iunos Haß: ich sah den Ort, der allen unzugänglich und Phoebus unbekannt ist und den ein minder guter Himmel einem schrecklichen 'Iupiter' zugestanden hat; und wenn mir der Ort des dritten Loses gefiele, hätte ich ihn beherrschen können: das Chaos der ewigen Nacht und Schlimmeres als die Nacht, die traurigen Götter und den Tod sah ich; den Tod verachtend kehrte ich zurück - was gibt es noch? Ich habe die Unteren gesehen und zugänglich gemacht' (604-613):

605

in poenas meas

610 atque in labores non satis terrae patent
Iunonis odio: vidi inaccessa omnibus,
ignota Phoebo quaeque deterior polus
obscura diro spatia concessit Iovi;
et, si placerent tertiae sortis loca,
regnare potui: noctis aeternae chaos
et nocte quiddam gravius et tristes deos
et fata vidi, morte contempta redi -
quid restat aliud? vidi et ostendi inferos.

So hat auch Hercules in echt senecaischer Weise als 'Heldendichter seines eigenen hohen Selbsts' die rechte Einstellung zu sich. Freilich ist die Situation des aus dem Wahnsinn erwachenden Hercules eine andere, aber auch hier ist er nicht fähig, das Geschehen angemessen zu betrachten oder selbstlos zu empfinden, so wie bei wahrem Mitleid der Bemitleidete wichtiger als der Mitleidende ist. Der griechische Herakles fühlt echten Schmerz, als er vom Tod der Kinder hört. Sein erstes Wort lautet: 'Weh mir! Was

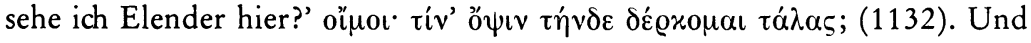
seine zweite Reaktion lautet: 'Weh! Denn eine Wolke von Jammer um-

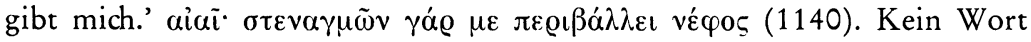
von Rache, vielmehr wünscht er sich selbst den Tod. Der römische Hercules hingegen empfindet nicht Schmerz, sondern Wut, ira (1167). Er ist nicht fähig, unreflektiert zu leiden oder gar mitzuleiden, sondern nur zu fragen, was es für ihn bedeute, daß ihm dieses Leid zugefügt wurde. Er hat keinen anderen Bezugspunkt als seine Person, er ist wie alle seneca- 
ischen Helden grenzenlos monoman. Der griechische Herakles weiß nicht, was er davon halten soll, daß sein Bogen auf der Erde liegt, der römische Hercules kann nur sofort schließen, daß er besiegt ist, obschon er unbesiegbar ist. Und damit hat er recht. Denn hier erfüllt sich, was Iuno im Prolog vorhergesagt hatte: Keiner sei dem Alciden gewachsen außer er sich selbst; daher möge er mit sich selbst Krieg führen, quaeris Alcidae parem? / nemo est nisi ipse: bella iam secum gerat (84-85). Er möge sich selbst besiegen, se vincat (116). Gemäß Iunos Einschätzung laufen auch zweimal Hercules' ichbezogene Folgerungen ab. Aus der Tatsache, daß er waffenlos ist, folgert er, daß es einen stärkeren Helden gebe, eine personifizierte virtus (1157), bei deren Zeugung durch Iupiter die Nacht noch länger gedauert haben müsse als bei der seinigen; und aus dem weiteren Faktum, daß es sich bei den Leichen um die Seinen handelt, schließt er zunächst wieder auf einen Besieger seiner Person, victor Alcidae (1168), dann aber auf einen Rächer seiner früheren Taten. Beide Male bezieht er in die Beurteilung der Gegenwart die e ig e n e - glorreiche - Vergangenheit mit ein. Das ist dieselbe Haltung wie die schon betrachtete Medeas, die aus ihren vergangenen scelera eine Verpflichtung für die Art der gegenwärtigen ableitet (129-134). Die senecaischen Helden erkennen für ihr Handeln keine außerhalb ihrer Person liegende Instanz an. Verpflichtend für sie sind nur sie selbst.

Hercules reagiert erzürnt. Bezeichnenderweise begegnet aber nicht das Adjektiv iratus oder ein grammatisches Aquivalent, sondern das Substantiv ira (1167). Im Sinne der stoischen Psychologie, aber auch der Neigung der Römer, solche Abstracta zu Leitbegriffen zu erheben, handelt es sich um eine Konstante, über die der Träger nicht ohne weiteres bestimmen kann, sondern die im Innern der Person ihr Eigenleben behauptet. So beschreibt Hercules wenig später mehrere solcher Konstanten, die er im Grunde nicht regieren kann, von denen er im Gegenteil regiert wird: Durch seinen Wahnsinn, furor, sei sein Schamgefühl, pudor, noch nicht soweit erloschen, daß er alle Völker durch seinen ruchlosen Anblick vertreiben möchte. Er fordert, daß Theseus ihm die Waffen zurückgebe. Wenn sein Geist geheilt sei, möge man ihm die Geschosse bringen, wenn dagegen der Wahnsinn, furor, andauere, möge der Vater zurücktreten: er werde schon einen Weg zum Tode finden (1240-1245):

non sic furore cessit extinctus pudor, populos ut omnes impio aspectu fugem. arma, arma, Theseu, flagito propere mihi 
subtracta reddi - sana si mens est mihi, referte manibus tela; si remanet furor, pater, recede: mortis inveniam viam.

Hercules hat keinen Einfluß darauf, wann seine mens wieder sana wird und wie lange der furor andauert. Er nimmt das ganz ruhig als selbstverständlich hin. Gemäß der Funktion dieser Konstanten treten die senecaischen Gestalten aus sich heraus, um sich gleichsam von einem außerhalb ihrer Person liegenden Standpunkt zu betrachten und $\mathrm{zu}$ analysieren. Soweit es um ihr Außeres geht, sind sie 'Historiographen', soweit es um ihre Leistungen geht, 'Heldendichter ihres eigenen hohen Selbsts', und soweit es um ihr Inneres geht, 'eiskalte Zuschauer ihrer Wut, oder altkluge Professore ihrer Leidenschaft'.

Eine Meisterin in der Beschreibung ihrer Psyche, eine 'Professorin ihrer Leidenschaft' ist Medea, die die psychologischen Konstanten ihres Innern bei der Tötung ihrer Kinder geradezu als Partner empfindet, so daß sie mit ihnen während der einzelnen Stadien der furchtbaren Handlung ohne weiteres $Z$ wiesprache halten kann. Aus der großen Zahl der Apostrophen sind drei besonders lehrreich. Medea spricht nicht nur den Zorn, ihre ira, wie etwas außerhalb ihrer Person Liegendes an, sie ordnet sich ihm sogar unter, wenn sie ausruft, sie wolle ihm folgen, wohin er sie führe: ira, qua ducis, sequor (953). In welchem Maße Seneca mit dieser Konzeption in einer allgemeinen römischen Tradition steht, zeigt das zweifellos als Vorbild anzusehende Bekenntnis der Medea Ovids aus den >Heroides quo feret ira, sequar $(12,209)$. Andererseits lehren zwei weitere Apostrophen, $\mathrm{da} ß$ es sich eher um ein 'partnerschaftliches' Verhältnis handelt. Medea genießt ihren Schmerz und fordert ihn auf, sich geeigneten Stoff zu suchen, quaere materiam, dolor (914); und beim Tod des zweiten Kinds ruft sie aus, der Schmerz möge nicht eilen und das Verbrechen ausführlich genießen, perfruere lento scelere, ne propera, dolor (1016). In diesem $\mathrm{Zu}-$ sammenhang gewinnt Schillers Wort von den 'eiskalten Zuschauern ihrer Wut' an Bedeutung, wenn man 'eiskalt' im Sinne von gelassen, kontrolliert, versteht.

Angesichts des Umstands, daß es solchermaßen schwerfällt, ohne weiteres von der Einheit einer Person im herkömmlichen Sinne zu sprechen, wird es einsichtig, daß nicht einmal die einzelne Rede die kleinste organische Einheit senecaischer Stücke darstellt. Diese Personen, die unaufhörlich damit beschäftigt sind, das Geschehen nur aus ihrer Sicht zu deuten 
und ihr Inneres nach allen Richtungen hin zu durchforschen, die nicht bereit sind, auch nur den unbedeutendsten auf sie bezüglichen Gedanken der Mitteilung für unwert zu erachten, sprechen nicht eine zielstrebige, an der Sache orientierte Sprache, sondern nähern sich auf Umwegen, keine Regung oder Anregung auslassend, ihrem Ziel. Nicht nur die Personen führen ein Eigenleben, sondern auch ihre Gedanken innerhalb der Reden. Nichts wäre verfehlter, als hierin den Einfluß oder gar die Folge der Rhetorik zu sehen. Vielmehr ist bei Seneca aufgrund seiner eigentümlichen Personenauffassung nur weitergeführt, was von Anfang an im römischen Drama zu beobachten ist: daß seine Personen, denen keine Nebensächlichkeit für die anderen Gesprächsteilnehmer unwichtig ist, wenn sie ihnen nur selbst wichtig erscheint, sich eines kommentierenden, 'glossematischen' Stils befleißigen. Bei den senecaischen Personen ist der Stil nicht anders Selbstzweck als schon bei den plautinischen und terenzischen, wie noch zu zeigen sein wird.

Obschon die römische Tragödie im offiziellen Bereich als panegyrischaitiologisches Erbauungsschauspiel begonnen hatte und aufgrund der politischen Verhältnisse mehr und mehr das Individuum in den Mittelpunkt rückte, ist ihre Struktur offenbar stets gleich geblieben. Ihre Einheit lag nicht in der unmittelbaren organischen Tektonik, sondern auf einer abstrakten, übergeordneten Ebene: bei der frühen Form in der Heilsideologie der Allgemeinheit, bei der späten in der Psychologie des Individuums.

\section{Die Komödie}

Die Neue Komödie zeichnet sich, soweit sie uns kenntlich ist, durch die Beachtung strengster Formen aus. Ihre Struktur ist wie die der älteren Tragödie der Ausdruck ihrer konsequenten Weltdeutung. Hatte bei Euripides die zunehmende Einsicht, daß statt einer planvollen Ordnung der Zufall, Tyche, die Welt regiert, zu einer Auflösung der Formen, ja schließlich der Tragödie selbst geführt, so war eine neue Tyche-Konzeption die entscheidende Voraussetzung für das Entstehen der Neuen Komödie. Solange Tyches Walten unter dem Aspekt des reinen Zufalls und der blinden Beliebigkeit gesehen wurde, war ein konsequentes Weltverständnis nicht möglich. Sobald aber Tyches Wirken als 'gut' verstanden wurde und das oberste Prinzip die $\alpha \gamma \alpha \vartheta \dagger ่$ Túx $\eta$ war, sobald, wie bei der Neuen Ko- 
mödie, Tyche bevollmächtigt erschien, alles ordentlich zu entscheiden und

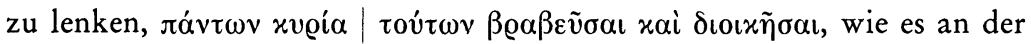
schon betrachteten Menander-Stelle heißt, sobald sie also letztlich alles zum Guten fügte, entstand wieder ein 'geordnetes' Weltbild. Wenn das oberste Prinzip als so überlegen und zielstrebig verstanden wurde wie in der Neuen Komödie, dann mußte deren Dramaturgie um so viel planvoller und konsequenter als die der Tragödie sein, um wieviel das Weltbild der Komödie planvoller und konsequenter als das der Tragödie ist. Dies ist in der Tat der Fall: Die Struktur der griechischen Neuen Komödie ist in den erhaltenen Stücken Menanders von einer nicht gekannten und nie wieder erreichten, wohl aber auch kaum erstrebten Stringenz. Sie bildet Planung und Fehlplanung der Menschen, Verständnis und Mißverständnis, Betrug und Aufdeckung, Aufeinander-Einwirken und Aneinander-Vorbeireden beispielhaft $a b$, wodurch die Handlungen, ehe sie ihr Ziel erreichen, immer wieder in falsche Richtungen getrieben werden.

Sowenig die römischen Dichter das Weltbild der griechischen Tragödie übernehmen konnten, sosehr war auch das Weltbild der Neuen Komödie von dem römischen Denken im dritten und zweiten Jahrhundert verschieden. Damit konnte aber auch die Nachbildung der Struktur der Originale kaum sinnvoll sein. Das die einzelnen Szenen der Vorlagen einigende Band verlor in Rom an Gültigkeit und gab jede einzelne Szene den Bearbeitern zu beliebiger Verwendung frei. In der römischen Komödie ist die Herauslösung der Einzelszene aus dem Strukturganzen ebenso deutlich zu beobachten wie in der römischen Tragödie. Ihre Dichter haben Szenen der Vorlagen aufgeschwemmt oder gekürzt, umgestellt, ausgelassen oder gar eigene Szenen eingeschoben, so daß sich bei der streng kalkulierten Struktur der Originale für die nachrechnende Ratio Unstimmigkeiten und Widersprüche in Menge ergaben. Während sich in der griechischen Komödie die Aussage durch das vollständige Handlungsgefüge explizierte, hatte der römische Dichter nicht so sehr eine Gesamtwirkung im Auge als vielmehr den Effekt einzelner Szenen, so daß die Wirkung eines Stücks vor allem auf der Reihung einer Anzahl besonders gelungener Szenen beruhte. Dies wird deutlich, wenn man die von den römischen Dichtern eingeschobenen Passagen betrachtet, wie etwa die Hetärenschau des Kupplers Ballio im >Pseudolus،. Während das Original in der Szene I 2 nur den Appell des Kupplers an sein Hausgesinde kannte, gehörig zu arbeiten, gefiel Plautus diese Ansprache so sehr, daß er gleich noch einen um- 
fangreichen Appell an die Hetären des Etablissements anfügte und von zwei der Hauptpersonen kommentieren ließ. Es mußte auf das römische Publikum des Jahres 191 v. Chr. in seiner Fremdheit äußerst belustigend wirken, wenn der Kuppler in der Haltung eines römischen Praetors den Hetären folgendes Edikt (edictio, 172) erließ: 'Ihr, die ihr in Pracht, Dekadenz und Vergnügen euer Leben mit vornehmen Herren verbringt, stadtbekannte Freundinnen, heute will ich es wissen und erproben, welche nur für ihren Kopf, welche für ihren Bauch sorgt und welche nur auf ihr Geld, welche auf ihren Schlaf achtet; wen ich freilassen und wen ich verkaufen muß, werde ich heute noch erfahren. Strengt euch gefälligst an, $\mathrm{daß}$ ich heute viele Geschenke von den Liebhabern bekomme; denn wenn ich heute nicht Vorrat für das ganze Jahr erhalte, biete ich euch morgen öffentlich dem Volke an. Ihr wißt, s'ist mein Geburtstag heute: wo sind nun die, denen ihr Auglein, Leben, Liebreiz seid, Busenherz und Honigpuppen? Macht, daß sie in Kompaniestärke präsentebeladen hier vor dem Hause antanzen!' (173-181):

vos quae in munditiis, mollitiis deliciisque aetatulam agitis, viris cum summis, inclutae amicae, nunc ego scibo atque hodie experiar

175 quae capiti, quae ventri operam det, quaeq'suae rei, quaeque somno studeat;

quam libertam fore mihi credam et quam venalem hodie experiar. facite hodie ut mihi munera multa huc ab amatoribus conveniant. nam nisi mihi penus annuos hodie convenit, cras poplo prostituam vos. natalem scitis mi esse diem hunc: ubi isti sunt quibus vos oculi estis, 180 quibus vitae, quibus deliciae estis, quibus savia, mammia, mellillae? maniplatim mihi munerigeruli facite ante aedis iam hic adsint.

Daß durch die Einfügung der Partie eine Reihe von Unstimmigkeiten auftrat, kümmerte Plautus wenig: Ihm kam es vor allem auf den wortschwelgerischen und musikalischen Effekt und die witzige Wirkung der über 60 Verse langen Hetärenschau an. Ebenso hat Terenz in den >Adelphen، ('Die Brüder`) durch die Einarbeitung einer Partie aus Diphilos' Synapothneskontes، (`Die gemeinsam Sterbenden`) eine wirkungsvolle Szene geschaffen, indem er die Entführung des Mädchens Bacchis, über die das Original lediglich berichtete, in allen Einzelheiten vorführte. Während bei Plautus nur die Phantasie der Zuschauer angesprochen wurde, wird ihnen bei Terenz ein turbulentes Geschehen mit Schlägereien und Beschimpfungen geboten, das von der Feinheit der menandrischen Vorlage weit entfernt ist. Wie bei der plautinischen Szene war die Einfügung nicht 
ohne Unstimmigkeiten möglich, doch sie setzte für den Augenblick dem Geschehen ein effektvolles Glanzlicht auf, das das zarte attische Gewebe der Vorlage zu verbrennen drohte.

Der Tendenz zur Ausgestaltung der Einzelszene entspricht auf der anderen Seite eine zuweilen erhebliche Vernachlässigung der verschiedenen Handlungsstränge der Originale. Die neugefundenen Fragmente des menandrischen 'Dis exapaton ( $>$ Doppelbetrüger`) lehren, daß Plautus in seiner Nachgestaltung, den $>$ Bacchides`, zwei Szenen zwischen Vater und Sohn, Nicobulus und Mnesilochus, gestrichen hat, um das Geschehen ganz auf die Haupthandlung zu konzentrieren. In diesem Falle war Plautus so geschickt vorgegangen, daß man die Auslassungen bisher nicht bemerkt hatte; doch gibt es viele Partien in den römischen Komödien, bei denen es evident ist, daß die Verkürzung der originalen Handlung zu auffälligen Unklarheiten im Faktischen geführt hat. Dies ist insbesondere bei den sorgfältigen Expositionen der voraussetzungsreichen Handlungen der attischen Stücke zu beobachten. Nicht nur, daß der griechische Zuschauer in anderer Weise als der römische gewohnt war, die Stimmigkeit des Faktischen als unabdingbar zu betrachten: Für die Absicht der Dichter war es überdies entscheidend, daß der Zuschauer jede einzelne Wendung des Geschehens verstehen und vor allem beurteilen konnte, weil er nur so imstande war, das Spiel der Personen als Ausdruck der Weltdeutung der Stücke zu begreifen. Er sollte sich nicht mit den Personen identifizieren, sondern von einer höheren Warte aus in ihnen gleichsam sich selbst von außen her beobachten und verstehen. Daher wurden in den griechischen

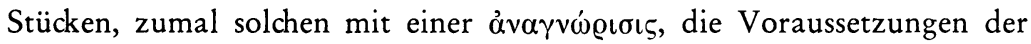
Handlung meist in einem Prolog am Beginn oder nach einer der ersten Szenen sorgfältig exponiert. Aufgrund ihrer ganz anderen Zielsetzung entfiel diese Notwendigkeit für die römischen Dichter. Die Exposition des nach einem Sklaven benannten 'Stichus von Plautus ist hierfür typisch. In den ersten beiden Szenen werden die Schwestern Panegyris und Pamphila vorgestellt, die ihr Vater Antipho erneut verheiraten will, weil ihre Männer seit drei Jahren auf Reisen sind. Breit werden in dem Gespräch die Charaktere der Schwestern und ihr Verhältnis zum Vater entwickelt, mangelhaft hingegen der Zusammenhang des Geschehens. Statt daß der berechtigte Grund für das Handeln des Vaters angegeben wird, erhält der Zuschauer ein negatives Bild von ihm: 'Das, Schwester, martert mich, daß unser Vater, der in einzigartiger Weise vor allen Bürgern als rechtschaffen gilt, nun nach eines unrechtschaffenen Mannes Art verfährt, da 
er uns in Abwesenheit unserer Männer ohne unsere Schuld solches Unrecht antut und uns von ihnen trennen will' (11-17):

$$
\begin{aligned}
& \text { hoc, soror, crucior } \\
& \text { patrem tuom meumque adeo, unice qui unus } \\
& \text { civibus ex omnibus probus perhibetur, } \\
& \text { eum nunc inprobi viri officio uti, } \\
& \text { viris qui tantas apsentibus nostris } \\
& \text { facit iniurias inmerito } \\
& \text { nosque ab eis abducere volt. }
\end{aligned}
$$

In einem wirkungsvollen Canticum erscheint der Vater eindrücklich als inprobus vir, der gegen die Schwiegersöhne und Töchter inmerito verfährt. Erst sehr viel später wird dem Zuschauer mitgeteilt, daß die jungen Männer ihr Vermögen durchgebracht hatten und deshalb zwischen ihnen und dem Alten eine Spannung, inimicitia (409), bestand. Antipho konnte ihnen also mit Recht mißtrauen und sie auszubooten versuchen. Doch vermochte der Zuschauer das Geschehen nicht adäquat zu beurteilen. Plautus kam es nicht so sehr auf den Zusammenhang der Handlung als vielmehr auf das Auskosten der einzelnen Situation an; alles, was nicht unmittelbar dazugehörte, schnitt er kurzerhand weg. Nicht anders ist er im 'Curculio ('Der Kornwurm) verfahren, in dem er auf die Wiedergabe des originalen Prologs verzichtet hat. Dadurch erfuhren die Zuschauer erst spät und nur bei größter Aufmerksamkeit, daß das Stück den ungewöhnlichen Schauplatz Epidaurus hatte (341). Auch wurde das entscheidende Faktum, daß das in der Gewalt eines Bordellbesitzers befindliche Mädchen Planesium freie Bürgerin war, ebenso mangelhaft exponiert wie die Person des Offiziers Therapontigonus in Curculios Erzählung II 3. Wenn man daraus jedoch, wie F. Leo, schließt, ein entsprechender plautinischer Prolog sei in der Uberlieferung verloren gegangen, verkennt man die eigentliche Zielsetzung der römischen Komödiendichter.

$\mathrm{Daß}$ es falsch wäre, die gegenüber den griechischen Originalen unvollständigen Expositionen auf das Bestreben zurückzuführen, die Spannung der Zuschauer zu erhöhen, zeigt das Verfahren, durch das Terenz die Prologe aller seiner Vorlagen ersetzt hat. Es läßt sich noch nachweisen, daß er in jedem seiner sechs Stücke bemüht gewesen war, die durch die Eliminierung der Prologe entstandenen Lücken in den Voraussetzungen durch Einschübe größerer und kleinerer Informationen innerhalb der Stücke auszugleichen, wo immer es möglich war. Es ist auffallend, daß er diese Informationen jeweils an der frühest möglichen Stelle gab - früher 
jedenfalls, als es für das unmittelbare Verständnis der Handlung nötig gewesen wäre. Das gilt etwa für den exponierenden Einschub, den man in dem Monolog des Sklaven Davus in der >Andriar I 3 (>Das Mädchen von Androsı) erkannt hat: Der Zuschauer bekommt mit der Andeutung, Glycerium bezeichne sich als Bürgerin, einen Wink, der ihn davor bewahrt, hinsichtlich des Ausgangs der Handlung falsche Schlüsse zu ziehen. Der ganze Einschub ist keinewegs, wie man geglaubt hat, für das Verständnis der folgenden Szene notwendig, sondern höchstens die einzelne Nachricht, daß Glycerium in anderen Umständen sei; und auch das hätte leicht in der folgenden Szene I 4 dem originalen Text hinzugefügt werden können. In der >Hecyra ‘ ('Schwiegermutter ) hat Terenz die Vorgeschichte an vier verschiedenen Stellen kunstvoll exponiert, obschon eine generelle Aufklärung am Ende des Stücks zum Verständnis des Hintergrunds genügt hätte. Keine andere Funktion hat die Exposition der Bürgerschaft Pamphilas durch Thais in ihren ersten Außerungen im 'Eunuchus‘, obgleich das die anwesenden Personen gar nicht wissen durften. Terenz war bemüht, die Exposition der Vorgeschichte und der Zusammenhänge früher als nötig, ja so früh wie möglich zu geben. Es kann daher nicht sein Bestreben gewesen sein, mit der Eliminierung der Prologe die Spannung des Zuschauers zu erhöhen und dessen Handlungsverständnis sich auf einer unmittelbareren Ebene als der des griechischen Zuschauers vollziehen zu lassen. Vielmehr dürften es künstlerische Gründe gewesen sein, die ihn veranlaßten, auf die überlangen, undramatischen Prologerzählungen der Originale zu verzichten. Er muß so empfunden haben, wie es Goethe am 22. April 1797 in einem Brief an Schiller formuliert hat:

Aber eben deshalb, dünkt mich, macht die Exposition dem Dramatiker viel zu schaffen, weil man von ihm ein ewiges Fortschreiten fordert, und ich würde das den besten dramatischen Stoff nennen, wo die Exposition schon ein Teil der Entwicklung ist.

Freilich war es Terenz nicht immer möglich, mit der Methode, die Stücke aus sich selbst heraus zu exponieren, Unklarheiten auszuschließen. Doch da die römischen Dichter nicht in gleichem Maße wie die griechischen auf eine exakte Exposition und Verknüpfung der Fakten Wert legten und auch die römischen Zuschauer daran keinen Anstoß nahmen, es also nichts ausmachte, wenn Personen auftraten, von denen man nicht gleich wußte, wer sie waren, oder sich eine Handlung entwickelte, bei der man nicht vermuten konnte, worauf sie hinauslaufe, kann kein Zweifel sein, daß 
Terenz mit der Eliminierung der Prologe nicht das Ziel verfolgte, die Spannung des Zuschauers zu steigern, sondern seine Art der Exposition der griechischen für völlig gleichwertig erachtete. Das römische Interesse an der einzelnen Szene statt an der Geschlossenheit und Einheit der Handlung kam ihm dabei zustatten.

Es liegt auf der Hand, daß die Betonung der Einzelszene erhebliche Konsequenzen für die Gesamtstruktur haben mußte. Insbesondere hat Plautus in diesem Punkt seine eigenen Ziele bedenkenlos verfolgt. So gestaltete er im >Poenulus، ('Der Punier`) den Auftritt I 2 als umfangreiche 'Toilettenszene' der beiden Hetären Adelphasium und Anterastilis, indem er entweder Ansätze des Originals mit seiner weiterspinnenden Phantasie aufgeschwemmt oder ein anderes Stück zum Vorbild genommen hat. Eingerahmt wird diese Szene jeweils durch ein Gespräch zwischen Adelphasiums Liebhaber Agorastocles und seinem Sklaven Milphio. Während das Original erst in der I 3 entsprechenden Szene die Darlegung der Intrige brachte, mit deren Hilfe man sich Adelphasiums versichern wollte, hat Plautus den Plan schon in I 1 entwickeln lassen. Wahrscheinlich hatte er den Eindruck, daß wegen der auf 200 Verse ausgedehnten 'Toilettenszene' das Stück zu spät in Gang gekommen wäre, wenn die Intrige erst in I 3 eingefädelt würde. Damit hat er jedoch gleich zwei Szenen isoliert, zu 'Einzelszenen' gemacht: Nicht nur ist die 'Toilettenszene' Selbstzweck geworden, sondern es ist auch die sinnvolle Verknüpfung von I 1 zu I 2 und I 3 verloren gegangen. Die originale Szenenfolge war offenbar so: Agorastocles sprach zu Milphio von seiner Liebe, dann schritt die Geliebte vorüber zum Tempel, und auf die neuerliche Bewußtwerdung der Liebe hin kam es zur Verabredung der Intrige. Bei Plautus aber wird das Ergebnis der ersten Szene nicht für die beiden Lauscher in der 'Toilettenszene' fruchtbar gemacht. Vor allem aber klappt I 3 durch die Antizipation der Intrige in die Szene I 1 bedenklich nach: sie ist funktionslos geworden. In der Struktur ist an die Stelle der organischen Dynamik des Originals Statik getreten.

Diese Besonderheit plautinischer Dramaturgie spiegelt die eigentümliche Konzeption seiner Personen wider. Es wird von Anfang an kein Zweifel daran gelassen, wer der Sieger, wer der Verlierer ist. Nachdem die Handlung des $>$ Poenulus erst 40 Verse fortgeschritten ist, prophezeit Milphio, er werde seinem Herrn noch heute den ganzen Kuppler mit seinem gesamten Anhang (also auch Adelphasium) 'schenken': totum lenonem tibi cum tota familia / dabo hodie dono (168-169). Der Plan, con- 
silium, steht am Anfang zwar erst im Rohbau, er ist rude (189), und sein Erfinder muß ihn noch ausfeilen, expolivero (188), aber sein Gelingen steht schon zu Beginn unbezweifelbar fest.

Es ist daher konsequent, daß Plautus versucht hat, den tatsächlich errungenen Erfolg schon so früh wie möglich eintreten zu lassen, auch wenn dabei der organische Aufbau des Originals Schaden nahm. In der $>$ Mostellaria ( Gespensterkomödie`) versucht der Sklave Tranio seinem alten Herrn Theopropides weiszumachen, sein Sohn habe während seiner Abwesenheit das Haus des Nachbarn Simo gekauft. In einem genial gelenkten Gespräch kann Tranio Theopropides zu dieser Uberzeugung bringen, ohne daß Simo merkt, worum es geht. Während sie in das Haus treten, um es zu besichtigen, naht ein anderer Sklave, durch den später der Schwindel auffliegen wird. Dann kommen Theopropides und Tranio aus dem Haus: Der Herr ist überzeugt, der Sklave feiert seinen Triumph. Plautus hat es im Gegensatz zum Original >Phasma`(`Das Gespenst<), das wahrscheinlich von Philemon stammt, nicht unterlassen können, den Triumph Tranios schon in die Szene mit Theopropides und Simo (III 2) vorzuverlegen. Wo der griechische Sklave vorsichtig zu Werke geht, da schon ein einziges Wort den gewagten Betrug gefährden mußte, stimmt der römische Sklave ungeniert und in gesundem Selbstvertrauen Siegeslieder auf seinen Erfolg an, indem er sich mit den größten Feldherren, Alexander und Agathokles, vergleicht. Plautus hat den Triumph in einem Maße antizipiert, daß die entsprechende Szene des Originals, in die der Triumph gehört, völlig leer geworden ist und als Doppelung nachklappt. Der alte Herausgeber der plautinischen Komödien aus dem 16. Jahrhundert Joachim Kammermeister (Camerarius) hatte daher diesen Auftritt unmittelbar hinter die erste Triumph-Szene gestellt, wo man sie lange Zeit beließ und sie die noch heute übliche Zählung III 3 erhielt, obschon sie in den vierten Akt gehört.

In letzter Konsequenz ist diese plautinische Manier im >Pseudolus $\mathrm{zu}$ erkennen, wo sich der intrigierende Sklave seines Siegs so sicher ist, daß er schon im ersten Akt als Herr der Lage, ja als Sieger vorgeführt wird, obwohl er noch nicht den leisesten Anhaltspunkt für einen erfolgversprechenden Plan hat. Deshalb sagt bereits in Pseudolus' erstem Gespräch mit seinem Herrn Simo dieser zu seinem Nachbarn, er möge Pseudolus' königliche Haltung beachten: statum vide hominis, Callipho, quam basilicum! (458), und Pseudolus bemerkt dazu, ein Sklave, der ein gutes Gewissen habe, könne seinem Herrn gegenüber stolz, superbus, sein (461). Sodann 
eröffnet er in einem Dialog von 18 Versen seinem Herrn, daß er das benötigte Geld ihm selbst noch am gleichen Tage abjagen werde (504-521), obwohl er unmittelbar darauf einen anderen Plan entwickelt. Man konnte sich diese 'Doppelung' nur mit der Annahme einer Kontamination zweier Vorlagen durch Plautus erklären, doch ist die Lösung des Problems viel einfacher: Plautus hielt es für besonders wirkungsvoll - was zweifellos auch zutrifft -, daß der Sklave seinem Herrn in frechster Uberheblichkeit entgegentritt und seine Niederlage dreist in das Gesicht sagt. Noch ärger ist Plautus verfahren, wenn er Pseudolus kurze Zeit später, während sich absolut nichts Neues ereignet hat, einen Triumph-Gesang anstimmen läßt, so daß der Zuschauer annehmen mußte, Pseudolus habe einen aussichtsreichen Plan: 'O Iupiter, wie mir alles, was ich betreibe, hübsch und glücklich ausgeht: [575:] in meiner Brust ist ein Plan verborgen, bei dem ich weder Zweifel noch Furcht zu haben brauche. Das ist Torheit, eine große Tat einem furchtsamen Herz anzuvertrauen. Denn alle Dinge laufen so, wie man sie anpackt, welche Bedeutung man ihnen beimißt. Daher habe ich schon rechtzeitig in meiner Brust Truppen derart bereit gestellt - [580:] doppelte und dreifache Listen und Schliche -, daß ich, wo ich auch Feinde treffe, (auf meiner Vorfahren Tüchtigkeit vertrauend, auf meinen Fleiß und meine Schelmerei) leicht siege und durch meinen Verrat die Gegner leicht der Beute beraube. Nun werde ich meinem und eurem gemeinsamen Feind Ballio [585:] hübsch eins ballern: Gebt acht! Diesen Ort will ich belagern, daß er heute noch fällt. Meine Legionen werde ich herführen; wenn die Eroberung glückt, werde ich meinen Bürgern die Sache leicht machen; darauf werde ich sofort mein Heer geradewegs gegen diese alte Stadt führen: dort will ich mich und alle Streitgenossen mit Beute beladen und beschweren, daß meine Gegner wissen, ich sei ihnen zu Furcht und Flucht geboren. [590:] Ich bin von der Art: mir steht es an, große Taten $z u$ vollbringen, die noch nach mir lange berühmt sein werden' (574-591):

pro Iuppiter, ut mihi quidquid ago lepide omnia prospereque eveniunt:

575 neque quod dubitem neque quod timeam meo in pectore conditumst consilium.

576-7 nam ea stultitiast, facinus magnum timido cordi credere; nam omnes res perinde sunt ut agas, ut eas magni facias; nam ego in meo pectore prius ita paravi copias, 
580 duplicis, triplices dolos, perfidias, ut, ubiquomque hostibus congrediar (maiorum meum fretus virtute dicam, mea industria et malitia fraudulenta), facile ut vincam, facile ut spoliem meos perduellis meis perfidiis. nunc inimicum ego hunc communem meum atque vostrorum omnium

585 Ballionem exballistabo lepide: date operam modo;

585 a hoc ego oppidum admoenire ut hodie capiatur volo. atque hoc meas legiones adducam; si hoc expugno facilem hanc rem meis civibus faciam, post ad oppidum hoc vetus continuo meum exercitum protinus obducam: ind' me et simul participes omnis meos praeda onerabo atque opplebo, metum et fugam perduellibus meis me ut sciant natum. eo sum genere gnatus: magna me facinora decet ecficere quae post mihi clara et diu clueant.

Die Arie ist an dieser Stelle um so befremdlicher, als Pseudolus erst in der darauffolgenden Szene die Idee zu seinem Plan kommt. Wenn der griechische Pseudolus in der schon betrachteten Szene II 3 folgerichtig seiner Freude Ausdruck gibt, muß der römische erst einmal einschieben, daß er den 'früheren Plan' fallengelassen habe, damit der Widerspruch nicht allzu deutlich hervortritt.

Die Argumentation der Originale ist, soweit sichtbar, konsequent, vom Logos bestimmt, die Argumentation der römischen Nachbildungen, da wo sie selbständig ist, of inkonsequent, vom Pathos bestimmt. Der konsequenten Argumentation der Originale entspricht eine organische Handlungsverknüpfung, eine dynamische Handlungsentwicklung; der inkonsequenten Argumentation der römischen Nachbildungen entspricht eine unorganische Auflösung der Handlung in Einzelszenen, eine im Grunde statische Handlungsführung. Derselbe Unterschied gilt für die Auffassung der Personen. Während die Darstellung einer Charakterentwicklung auch den griechischen Dichtern fremd ist, machen ihre Personen doch insofern eine Entwicklung durch, als sie von den stets wechselnden Gegebenheiten der Handlung bestimmt werden und in Situationen geraten, die sie nicht voraussehen konnten. Die Auffassung der römischen Personen ist dagegen durchaus statisch. Plautus' Lieblinge, die Sklaven, triumphieren unabhän- 
gig von dem Stand der Handlung am Anfang ebenso wie am Ende, und seine Väter sind, wenn er es auf sie abgesehen hat, am Anfang ebenso läppisch wie am Ende. Auch bei der unvermuteten Abwertung herausragender Personen am Schluß der Stücke durch Terenz handelt es sich nicht um konsequent angelegte Charakterstudien, sondern um ganz punktuelle, nur auf das jeweilige Handlungsstadium bezogene Darstellungen eines überraschenden Geschehens. Nur so ist es zu erklären, daß man bei der Betrachtung der Hetäre Thais aus dem ,Eunuchus oder Micios aus den Adelphen immer wieder zu divergierenden Ergebnissen kommt. Ohne Frage ist das terenzische Verfahren durch den Verzicht auf die metaphysische Komponente begünstigt worden: Wenn Thais in die Situation kam, daß ein Mitspieler ihre ganzen Pläne vereitelt zu haben schien (conturbasti mibi / rationes omnis, 868-869), und der erziehungsbewußte Micio vor die Tatsache gestellt wurde, daß sein Sohn ihn mit der Entführung einer Hetäre und dem folgenreichen Verhältnis zu einer Bürgerin offenbar hintergangen hatte, dann wollte Menander zeigen, wie Tyche letztlich alles in Ordnung brachte; für Terenz aber waren Personen, denen solches widerfahren konnte, Objekte, denen alles widerfahren konnte. Bei der mangelnden Absicht einer Weltdeutung wurden sie zum Freiwild seiner auf den komischen Effekt zielenden Phantasie. Wenn bei Plautus in entsprechenden Fällen die Abruptheit des Ubergangs nicht ganz so deutlich erscheint, so liegt das an der Art, über seine Opfer die Schale des Spotts $\mathrm{z} \mathrm{u}$ je der $\mathrm{Z}$ e i t auszugießen, nicht aber in dem Bestreben, die Personen konsequent zu zeichnen, deren Kern mit oberflächlichen Witzen kaum zu erfassen ist. Auch der in mancher Hinsicht feiner vorgehende Terenz hat es unterlassen, durch kleine Einschübe oder behutsame Änderungen, die ohne weiteres möglich gewesen wären, Micios oder Chremes' Position aus dem >Heautontimorumenos« von vornherein so zu umreißen, daß der spätere Fall, wenn auch keineswegs vorausschaubar, so doch 'psychologisch' glaubhaft war: Terenz störte es ebensowenig wie die Zuschauer, daß die Aspekte der einzelnen Szenen noch keine g a n z e Person ergaben, wenn nur eine komische Handlung zustande kam. Bei ihm stehen im Grunde genommen zwei Aspekte einer Gestalt unverbunden nebeneinander. Eine Entwicklung kennen auch seine Personen nicht.

Der Verzicht auf die Darstellung einer Entwicklung der Personen bedeutet nicht ein Desinteresse an ihnen überhaupt. Im Gegenteil haben sich die römischen Dichter ihrer Personen mit einer Liebe angenommen, daß sie darüber das Ganze aus den Augen zu verlieren drohten. E. Fraenkel 
hat im Hinblick auf die plautinischen Parasiten und parasitären Sklaven treffend bemerkt, „die gefräßigen Lieblinge des Plautus, die Chrysalus und Ergasilus mit ihrer ganzen Sippe (hätten) auch als dichterische Gestalten in den Dramen fast so verheerend gehaust wie ihre Urbilder in Küche und Keller".

Es versteht sich, daß die unterschiedliche Personenauffassung besonders deutlich in den Reden zu beobachten ist. Während man jedoch bisher in nahezu allen Fällen auf die Ergebnisse der analytischen Forschung angewiesen war, haben kürzlich bekanntgewordene Fragmente aus dem Vorbild der plautinischen $>$ Bacchides`, etwa 50 - nicht immer vollständige Verse aus dem $>$ Dis exapaton Menanders, den direkten Vergleich zwischen einem griechischen und einem römischen Komödien-Monolog ermöglicht. Der junge Athener Mnesilochus - bei Menander: Sostratos hat auf Samos die Hetäre Bacchis kennengelernt und seinen Freund Pistoclerus in Athen beauftragt, diese dort während seiner Abwesenheit ausfindig zu machen. Als er heimkehrt, erfährt er, daß sein Freund sich in Bacchis verliebt habe, ohne zu wissen, daß es sich um die gleichnamige Schwester von ihr handelt. Enttäuscht beschließt er, das Geld, das sein Sklave Chrysalus dem Vater abgelistet hat, diesem zurückzuerstatten: 'Sie wird ihn besitzen; den Sostratos hast du nur so vorwegvernascht. Sie wird es leugnen, das ist mir klar - denn sie ist unverschämt -, und alle Götter werden dazukommen ... Schlecht möge es der Schlechten ergehen - fort, Sostratos, vielleicht wird sie dich überreden. Ihr Sklave ... bin ich ganz; sie aber soll mich nur, wenn ich leer bin und nichts habe, überreden! Ich werde das ganze Geld dem Vater zurückgeben; sie wird schon aufhören, mich zu überreden, wenn sie merkt, daß sie, wie das Sprichwort sagt, einem Toten eine Geschichte erzählt. Aber jetzt muß ich zu ihm gehen. Doch da sehe ich ihn schon':

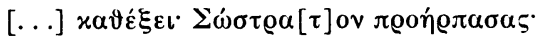

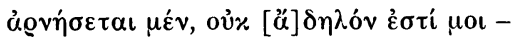

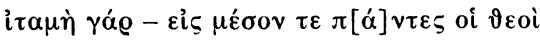

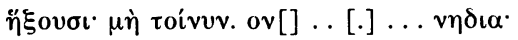

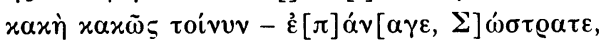

$$
\begin{aligned}
& \text { ¿ } \sigma \omega \varsigma \sigma \varepsilon \pi \varepsilon i \sigma \varepsilon \iota \cdot \delta o v \lambda \circ[3-4] \text {. [...] } \varrho \alpha . . . .
\end{aligned}
$$

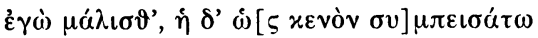

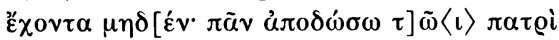

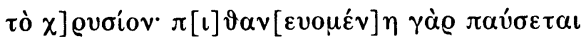

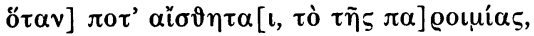




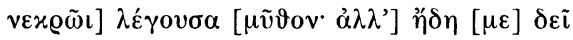

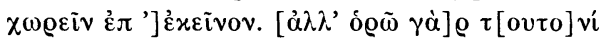

Erheblich länger ist die Rede, die der römische Mnesilochus in derselben Situation hält: '[500:] Wen ich für meinen größeren Feind halten soll, den Freund oder Bacchis, ist noch sehr unklar. Hat sie ihn vorgezogen? Mag sie ihn haben. Bestens. Das wird sie wahrlich tun zum Schaden von - mir; niemals möge mir einer an meinen Schwur glauben, [505:] wenn ich sie nicht auf jede Weise und ganz klar - liebe. Ich werde bewirken, daß sie nicht sagen wird, sie habe einen zum Verspotten gefunden. Ich werde jetzt nach Hause gehen und - etwas dem Vater stehlen. Ich treibe sie soweit, daß zum Bettler wird - mein Vater. Aber bin ich noch ganz bei Trost, [510:] der ich auf diese Weise von zukünftigen Dingen spreche? Ich bin verliebt, glaube ich, ja weiß ich sicher. Ehe sie auch nur um eine Flaumfeder von meinem Gelde schwerer wird, will ich an Betteln selbst den Bettler übertreffen. [515:] Solange sie lebt, wird sie mich nicht verlachen. Denn ich habe beschlossen, dem Vater das ganze Geld zurückzugeben. Dann wird sie mir, der ich leer bin und nichts habe, schmeicheln, wenn ihr Schmeicheln nicht mehr nützt, als wenn sie einem Toten am Grabe eine Geschichte erzählt. [520:] In der Tat steht es bei mir fest, dem Vater das Geld zurückzugeben. Zugleich werde ich ihn bitten, daß er nicht meinetwegen Chrysalus etwas tut oder ihm zürnt, weil er ihn meinetwegen mit dem Geld hintergangen hat; denn es ist recht und billig, daß ich für ihn sorge, der ihm meinetwegen eine Lüge gesagt hat':

inimiciorem nunc utrum credam magis sodalemne esse an Bacchidem incertum admodumst. illum exoptavit potius? habeat. optumest. ne illa illud hercle cum malo fecit - meo; nam mihi divini numquam quisquam creduat, ni ego illam exemplis plurumis planeque - amo. ego faxo hau dicet nactam quem derideat. nam iam domum ibo atque - aliquid surrupiam patri. adeo ego illam cogam usque ut mendicet - meus pater. sed satine ego animum mente sincera gero, qui ad hunc modum haec hic quae futura fabulor? amo hercle opino, ut pote quod pro certo sciam. verum quam illa umquam de mea pecunia ramenta fiat plumea propensior, mendicum malim mendicando vincere. 
515

numquam edepol viva me inridebit. nam mihi decretumst renumerare iam omne aurum patri. igitur mi inani atque inopi subblandibitur tum quom mihi nihilo pluris referet, quam si ad sepulcrum mortuo narret logos. profecto stabilest me patri aurum reddere. eadem exorabo Chrysalo caussa mea pater ne noceat neu quid ei suscenseat, mea caussa de auro quod eum ludificatus est; nam illi aequomst me consulere, qui caussa mea mendacium ei dixit.

Daß Plautus größeres Interesse an der Ausgestaltung der individuellen Rede als Menander hatte, geht schon daraus hervor, daß sein Monolog von doppelter Länge ist. Plautus hat das menandrische Vorbild im großen und ganzen in den Versen 500-502 und 512-519 nachgebildet, jedoch die Partie 503-511 sowie den Schluß 520-525 völlig neu hinzugefügt. Durch diese Zusätze hat er dem Monolog sowohl eine ganz andere Richtung als auch eine ganz andere Struktur gegeben. Bei Menander ist die Argumentation eindeutig: Sostratos stellt fest, Bacchis habe mit ihm nur gespielt, auch wenn sie es leugnen werde; das möge sie büßen. Dann erwägt er, ob sie ihn dennoch überreden könne und er Knecht würde; doch werde sie schon aufhören, wenn er kein Geld mehr hätte. Er schwankt nur einmal, aber es steht für ihn fest, daß Bacchis sich schlecht und unverschämt,

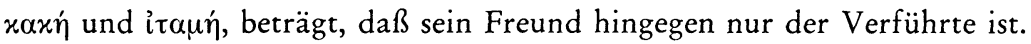
So sagt er wenig später an einer von Plautus nicht übersetzten Stelle, er

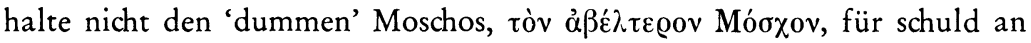
dem geschehenen Unrecht, sondern jene, die unverschämteste von allen:

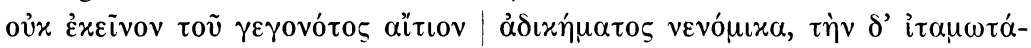

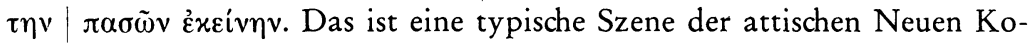
mödie. Der Spieler zieht mit aller Bestimmtheit aus einer mißdeuteten Situation eine Folgerung, die ihn noch weiter in die Irre führt. Erst in einer der nächsten Szenen erfährt er über seinen Irrtum Aufklärung. Dem Weltbild der Neuen Komödie entsprechend bewegt sich die Handlung zwischen Schein und Wahrheit, Irren und Aufklärung. Nichts davon bei Plautus. Er hat sozusagen überhaupt keine Linie. Die Antithese Bacchis-Pistoclerus wird sogleich aufgelöst, indem beide als in demselben Maße 'feindlich' eingestuft werden (500-502). Sodann folgt der plautinische Einschub, in dem alle Positionen relativiert werden und der Zuschauer 
vollends den Faden, an den er sich halten könnte, verliert. Zu dem menandrischen Teil des Monologs, bei dem Vers 512 an 502 nahtlos anschließt und an der Distanzierung von Bacchis kein Zweifel bleibt, paßt die plautinische Partie nur in einem sehr äußerlichen Sinne. Durch die viermal hintereinander wiederholte Technik, daß der Sprecher am Versende eine Wendung gebraucht, die den erwarteten Gedankenablauf unvermutet in sein Gegenteil verkehrt, wird deutlich zu erkennen gegeben, daß der Sprechende im Grunde nicht so denkt, wie er spricht. Freilich ist Plautus weit davon entfernt, eine psychologische Studie zu geben. Vielmehr zeigt die

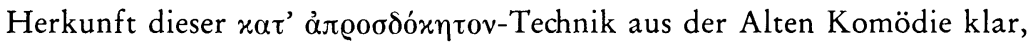
welcher Aussagewert ihr beizumessen ist. Ein schönes Beispiel bietet Plautus selbst in der Los-Szene der ,Casina‘, in der der alte Lysidamus die Sklavin Casina für seinen Gutsverwalter Olympio gewinnen möchte, um sich selbst ihrer ungestört erfreuen zu können, während seine gewitzte Ehefrau Cleostrata sie einem Reitknecht ihres Sohns verheiraten will. Dabei kommt es zu folgendem komischen Dialog, in dem sich Lysidamus mehrmals bezeichnenderweise 'verspricht': Lysidamus: 'Ich glaubte, bei dir, liebe Frau, durchsetzen zu können, daß Casina $\mathrm{mir}$ vermählt würde; und ich glaube das noch.' Cleostrata: 'D ir vermählt würde?' Lysidamus: ' Ja, $\mathrm{m}$ i $\mathrm{r}$ - ah, das wollte ich nicht sagen: während ich ' $\mathrm{m}$ ir' sagen wollte, sagte ich 'diesem', und während ich sie so sehr $\mathrm{mir}$ wünsche - ach, ich fasele laufend falsch daher.' Cleostrata: 'Weiß Gott, du machst es wirklich falsch.' Lysidamus: 'D i e s e m - nein, $\mathrm{mir}$ - weh, kaum finde ich den rechten Weg.' Cleostrata: 'Du vertust dich ziemlich oft.' Lysidamus: 'So geht das, wenn man etwas sehr ersehnt' (364-370):

LY. atqui ego censui aps te posse hoc me impetrare, uxor mea, Casina ut uxor $\mathrm{m}$ ih i daretur; et nunc etiam censeo.

CL. $t$ ib i daretur illa? LY. mihi enim - ah, non id volui dicere: dum 'mihi' volui, 'h u ic' dixi, atque adeo mihi dum

$$
\text { cupio - perperam }
$$

iam dudum hercle fabulor. CL. pol tu quidem, atque etiam facis.

LY. hu ic - immo hercle mihi - vah! tandem redii vix veram in viam.

CL. per pol saepe peccas. LY. ita fit, ubi quid tanto opere expetas.

Der griechische Sostratos ist wie die meisten Jünglinge Menanders ernsthaft mit seinen Problemen befaßt und auf seine Entscheidung konzentriert. Mnesilochus ist hingegen von Plautus zu einer komischen Figur gemacht worden, deren lapsus linguae die Zuschauer zum Lachen bringen 
sollen. Sostratos beschließt, sich von Bacchis abzuwenden: Mnesilochus ver-

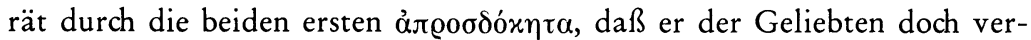
fallen bleibt und seine Entscheidung nicht ernst gemeint sein kann. Sostratos kündigt an, er werde dem Vater das Geld zurückgeben: Mnesilochus

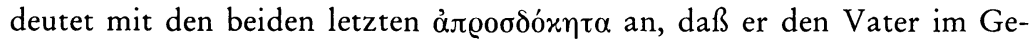
genteil noch um weiteres Geld betrügen werde. Der römische Jüngling widerruft damit praktisch beide Punkte des Beschlusses seines griechischen Pendants. Gleichwohl fährt er dann mit Vers 512 im menandrischen Sinne fort, indem er tut, als hätte er nie etwas anderes durchblicken lassen. Der mangelnden Konsequenz einer Entscheidung entspricht die mangelnde Einheit der Struktur des Monologs. Plautus gefällt sich statt dessen in der Ausmalung der Gedanken des Jünglings nach allen Seiten hin, aber es kommt keine Einheit des Charakters zustande. Er häuft Einzelzug auf Einzelzug, ohne doch ein Ganzes zu erzielen. Auch die Betrachtung einer Rede lehrt, daß in der griechischen Komödie Dynamik herrscht, in der römischen Statik. Plautus tritt in seinen Einschüben auf der Stelle.

Wie später bei Seneca beschäftigen sich auch schon die Personen der römischen Komödie hauptsächlich mit sich selbst und ihren eigenen Problemen. Das zeigt klar der plautinische Einschub in Mnesilochus' Monolog. Und auch in dem römischen Schluß bewahrt der Jüngling seinen persönlichen Blickwinkel, indem er nicht weniger als dreimal betont, Chrysalus habe seinetwegen, mea causa, den Vater hintergangen. So wie es dem römischen Komödiensklaven 'ansteht', etwas Bestimmtes zu tun, steht es auch Mnesilochus an, aequom est, für den einzutreten, der ihn unterstützt. Bei der liebevollen Versenkung der römischen Komödiendichter in das Innere ihrer Personen machte es nichts aus, wenn diese dabei zu einem Wissen gelangten, über das sie eigentlich nicht verfügen durften. Terenz hat das oft bei der Eliminierung der Prologe seiner Vorlagen praktiziert, um den dadurch entstehenden Mangel an Information auszugleichen. Der großzügige Begriff von der Einheit einer Person, den die römischen Dichter hatten, begünstigte ein solches Verfahren. Auch Plautus' Personen operieren immer wieder mit Möglichkeiten, die sich erst aus dem weiteren Verlauf der Stücke ergeben. Bei Mnesilochus war die Antizipation späteren Wissens jedoch so offenkundig, daß Plautus sich gezwungen sah, durch einen direkten Hinweis das Merkwürdige der Situation zu entschärfen, indem er den Jüngling sagen ließ, ob er denn bei Trost sei, daß er von $\mathrm{Z}$ u k ü $\mathrm{n} \mathrm{t}$ ig e $\mathrm{m}$ schwatze, sed satine ego animum mente sincera gero, / qui ad bunc modum haec bic quae fut ura 
fabulor? (509-510). Der Kern der plautinischen Person zerfließt damit vollends.

Wie Senecas Personen ist Mnesilochus in der Lage, gleichsam aus sich herauszutreten und seine Gesinnung und seine Entscheidungen zu kommentieren. Bereits in seinem ersten Monolog, in dem er sein künftiges Handeln absteckt, ist er bemüht, sein Verhalten exakt zu definieren. Wie Pseudolus (decet) oder er selbst in der schon betrachteten Partie (aequom est) mißt er es dort an einem abstrakten Begriff (oportet) und betont, daß das auch die Umwelt tun werde, da sein Handeln nicht verborgen bleibe (bau celabis). Wie Medea oder Hercules ist er in der Lage, sich von außen zu betrachten und zu beschreiben, wenn er, zumal mit senecaischer Selbstapostrophe, in typisch plautinischen Wendungen auseinandersetzt: 'Nun, Mnesilochus, wird die Probe erprobt, nun die Entscheidung entschieden, ob du bist, wie sich es gehört oder nicht, schlecht oder gut, wie du willst, gerecht oder ungerecht, freigebig oder knauserig, gefällig oder ungefällig. Hüte dich, daß du dich vom Sklaven im Wohltun übertreffen läßt. Wie du auch sein wirst, daran mahne ich dich, wird nicht verborgen bleiben' (399-403):
nunc, Mnesiloche, specimen specitur, nunc certamen cernitur sisne necne ut esse oportet, malus, bonus quoivis modi, iustus iniustus, malignus largus, comincommodus. cave sis te superare servom siris faciundo bene. utut eris, moneo, hau celabis.

Er ist im Schillerschen Sinne durchaus 'Historiograph seines eigenen Selbsts'. Und wie die tragischen Personen sind die Liebhaber der Komödie auch schon 'Professore ihrer Leidenschaft', etwa wenn Philolaches in der >Mostellariar I 2 oder Lysiteles im 'Trinummus، II 1 in Arien, die Plautus stark erweitert hat, ihre Liebe analysieren oder gar der alte verliebte Lysidamus in der 'Casinar eine Beobachtung, coniectura (224), hinsichtlich seines eigenen durch die Liebe veränderten Betragens macht. Vor allem aber sind die komischen Personen ebenso wie die tragischen bereits, um noch einmal Schillers Formulierung zu gebrauchen, 'Heldendichter ihres eigenen hohen Selbsts', indem sie zu ihrem persönlichen Ruhme kräftig in die Tasten greifen. Hierher gehören insbesondere die SelbstGlorifizierungen der Sklaven, die sich nicht genug tun können, in militärischen Metaphern ihre noch von der Nachwelt zu bewundernden Taten 
zu beschreiben. Auf derselben Stufe stehen die umfangreichen Elogien, in denen Parasiten ihre geistigen Fertigkeiten besingen. Selbst der gemäßigte Terenz hatte an ihnen solchen Gefallen gefunden, daß er entgegen der Konzeption seiner Vorlagen die Parasiten Gnatho im 'Eunuchus und Phormio in dem gleichnamigen Stück jeweils mit einem Preislied auf die Parasitenkunst auftreten ließ. Dem ausgeprägten römischen Interesse für die eigene Person gemäß erkennen schon die Gestalten der römischen Komödie niemanden außer sich an, verwenden sie im Bezug auf die eigene Person am liebsten den Superlativ. Niemand, der so tapfer, niemand, der so klug wäre wie sie; aber auch niemand, der solches Leid hätte wie sie: 'Die da sind, die da sein werden, die da waren und die künftig kommen werden - ich allein übertreffe sie alle leicht, der elendeste Mensch zu leben', qui sunt, qui erunt quique fuerunt quique futuri sunt posthac, I solus ego omnibus antideo facile, miserrumus hominum ut vivam (>Persa< 777-778). Und da es sich um Komödien handelt: Niemand, der so töricht wäre wie sie, wenn sie merken, daß sie hereingelegt worden sind: 'Wen auch immer es gibt, wen es gab und wen es künftig geben wird, Toren, Dumme, Einfaltspinsel, Pilze, Stumpfsinnige, Tölpel, Hohlköpfe - ich allein übertreffe sie alle leicht an Dummheit und törichtem Benehmen', quiquomque ubi sunt, qui fuerunt quique futuri sunt posthac / stulti, stolidi, fatui, fungi, bardi, blenni, buccones, / solus ego omnis longe antideo stultitia et moribus indoctis (>Bacchides< 1087-1089). Die Personen der römischen Komödie kennen ebenso wie die der Tragödie kein Maß in ihrem Stolz, in ihrem Leid, in ihrer Freude oder ihrem Ärger. Vor allem kennen sie keinen Konkurrenten, auch sie sind in einer erstaunlichen Weise monoman.

Der statische Charakter der römischen Komödie äußert sich wie der der römischen Tragödie in dreifacher Hinsicht: Bei der Struktur der Stücke in der Verselbständigung der Einzelszene, bei der Personengestaltung in der bloßen Anhäufung von Einzelzügen, bei der Rede im Selbstzweck der einzelnen Formulierung. Die ersten beiden Eigenarten finden ihren Ausdruck vor allem in der charakteristischen Ausprägung der Rede. Überall dort, wo sich längere oder kürzere Einschübe der römischen Dichter feststellen lassen, dienen sie nicht sosehr der Weiterführung der Handlung als vielmehr der Ausmalung von Situationen. Umfangreiche Partien, in denen die römischen Dichter auf der Stelle treten und sich in immer neuen Variationen und Assoziationen gefallen, sind etwa der Hetären-Appell 
des Kupplers Ballio im >Pseudolus I 2, die Toiletten-Szene der Hetären Adelphasium und Anterastilis im >Poenulus I 2, die Auftritte der Parasiten Phormio und Gnatho im >Phormior II 2 und >Eunuchus، II 2 sowie natürlich die Triumph-Arien und Glorifizierungen der Sklaven. Auch solche längeren Reden sind nicht auf ein bestimmtes Ziel hin ausgerichtet, sondern zerfließen letztlich in der Anhäufung von Pointen. Man darf überspitzt sagen: Eine kürzere Passage der römischen Komödiendichter dient der Einfügung einer Pointe, eine längere der Einfügung einer Summe von Pointen. Dies ist ein grundlegender Unterschied zwischen griechischer und römischer Rede. Treffender als E. Fraenkel in seinem Buch >Plautinisches im Plautus kann man Plautus' Redeweise nicht charakterisieren (413 f.):

Der Dialog des Plautus begnügt sich nicht mit der Funktion des Mittlers, er ist sehr stark Selbstzweck. Nicht die Worte nur und ihre Fügungen, auch die Gedanken selbst machen sich in weitem Umfange ganz unabhängig von dem Grundgehalt und der Aktion der Szene und führen ein Sonderleben. Auch wo die eigentlichen Skurrilitäten fehlen, entstehen durch die Art, in der von dem Hauptgedanken auf kleinen Umwegen abgebogen wird, immerfort Sonderspannungen, dem Hörer werden Rätsel aufgegeben, die sich im Folgenden lösen, unvermutete Aspekte bekannter Dinge tauchen auf, der Dichter schießt plötzlich einen Pfeil in die Luft und holt irgend einen glänzenden Vogel herunter. Es ist als sollte man niemals zur Ruhe kommen, sich nicht in die Sphäre einer besonderen Stimmung einschließen dürfen. Die Rede hat etwas unaufhörlich Prickelndes; alles das, was man allenfalls als rhetorische Figuren bezeichnen könnte, macht nur einen geringen Teil dieser Wirkung aus.

Ebensowenig wie der plautinische oder terenzische ist der senecaische Stil rhetorisch im schulmäßigen Sinne. Vielmehr zeigt sich bei diesen Dichtern ein ausgeprägtes Interesse an der Rede in ihren kleinsten Bestandteilen. Ihre Personen sind stets bemüht, nichts ungesagt sein zu lassen, auch das Nebensächlichste für bedenkenswert und mitteilungswürdig zu halten, und bereit, sich noch in die äußerste Assoziation zu verlieren. K. Büchner hat im Hinblick auf Terenz von dem 'Glossematischen' seines Stils gesprochen - eine Charakteristik, die ebenso auf Plautus und Seneca zutrifft. Nicht auf Handlungsstrukturen sind diese Dichter aus, sondern auf das Glossieren als konstante Begleitung der Handlung. In der Komödie überwiegt naturgemäß die bloße Pointe, aber auch der tragische Stil ist in einer oft als unangemessen empfundenen Weise von Pointen bestimmt. Wie die tragischen Personen sind auch schon die komischen vor- 
nehmlich damit beschäftigt, das eigene Verhalten zu beobachten und zu beschreiben, nicht einfach etwas zu sagen, sondern stets auch die Bedeutung des Gesagten zu bedenken. Ihr Stil ist dementsprechend kommentierend. Die Personen des römischen Dramas sind nicht nur Darsteller, sondern auch 'Historiographen ihres eigenen Selbsts'.

\section{Ausblick :}

\section{Die Einheit des römischen Dramas}

Wenn das römische Drama nicht die Einheit der Handlungsstruktur, nicht die Einheit der Person, ja nicht einmal die Einheit der Rede kennt, ist die Frage gestattet, worin seine Einheit dann liege, oder ob eine solche gar nicht vorhanden sei. Wenn es im römischen Drama keine argumentative Verknüpfung der einzelnen Szenen gibt, bedeutet das noch nicht, daß es in ihm keine Argumentation gebe. Auch das römische Drama argumentiert - jedoch nicht in der Weise, daß Argumente aus Argumenten entwickelt oder Argumente gegeneinander abgewogen würden. Die Argumentation des römischen Dramas ist, wenn man so sagen darf, nicht dynamisch, sondern statisch. Bestimmte Thesen oder Verhaltensweisen werden nicht im Entstehen gezeigt, sondern als von Anfang an fertige Muster demonstriert, ja zuweilen eingehämmert. Die griechischen Stücke gleichen einem strömenden Gewässer, bei dem auch die bewegteste Oberfläche der richtungweisenden, in stets neuen Bahnen verlaufenden Tiefe geordnet folgt, die römischen Stücke dagegen einem stehenden Gewässer, bei dem die Oberfläche ganz nach Belieben einmal ruhig verharren, ein andermal in ungeordneter Bewegung durcheinandergeraten kann, die Tiefe jedoch stets unverändert bleibt. Im römischen Drama ist wie in der römischen Dichtung überhaupt zuallererst nach der den einzelnen Szenen zugrundeliegenden Idee, nach dem die konkreten Geschehnisse zusammenhaltenden abstrakten Band zu fragen. Selbst die klassische Dichtung wie Vergils -Aeneis kennt keine organische Tektonik, sondern die gedankliche Einheit römischer Kunstwerke. Der Leser darf sich nicht einfach dem Gang des konkreten Geschehens anvertrauen wie bei Homer, sondern ist aufgerufen, bei jeder einzelnen, vom Dichter beliebig herausgegriffenen scheinbar konkreten Szene die Bedeutung derselben mitzubedenken: Ohne deren Kenntnis ist er nicht imstande, jene zu verstehen. Ein grundlegen- 
der Unterschied zwischen griechischer und römischer Epik und Geschichtsschreibung liegt darin, daß diese Genera bei den Griechen einen literarischen Eigenwert hatten, bei den Römern aber von vornherein einen argumentativen, über sich selbst hinausweisenden Charakter. Die Römer schufen zu Beginn nicht autonome Literatur, sondern wollten mit der Literatur etwas 'beweisen', sei es - wie Naevius oder Fabius Pictor - den Griechen, sei es sich selbst. Es wurde schon dargelegt, wie der unverhältnismäßig hohe Anteil des Troia-Stoffs in der römischen Tragödie sich daraus erklärt, daß die Römer ihre troische Abstammung als politisches Argument gegenüber dem Osten verwandten. Andererseits bedeuteten diese Stoffe für das Selbstverständnis der Römer ein Stück Selbstdarstellung, einen Beitrag zu ihrer Heilsgeschichte. Für die aitiologischen Themen der frühen Tragödien ist das ebenso einsichtig wie für die panegyrischen Tendenzen der Praetexten. Noch Varius verfolgte mit seinem Festspiel 'Thyestes` einen außerhalb des Stücks liegenden Zweck. Dasselbe gilt in einem ganz anderen Sinne sowohl von den Rezitationsdramen der Kaiserzeit, soweit sie der Oppositionsliteratur zuzurechnen sind, als auch von Senecas Tragödien, die die Bedingungen des Individuums abstecken. Alle diese Stücke wollen nicht eine Argumentation entwickeln, sondern sollen als $\mathrm{G}$ a n z e s wirken. Dieses Ganze, ihre Idee, steht von vornherein fest. Ihr ist alles untergeordnet. Nicht die einzelne Szene, nicht die Summe der einzelnen Szenen führt zum Ganzen, sondern jede einzelne Szene verkörpert bereits das Ganze. Deshalb stehen die einzelnen Szenen nicht zueinander in Verbindung, sondern nur in Bezug zu der Idee des Stücks. Deshalb kann jede einzelne Szene ohne Rücksicht auf die vorhergehenden oder folgenden Szenen beliebig ausgestaltet und umgestellt werden, da sie nur der Idee des ganzen Stücks verantwortlich ist. Wenn der römische Dramatiker seine Aufmerksamkeit auf die Einzelszene konzentriert, meint er damit immer zugleich das Ganze. Dementsprechend kennen die Personen des römischen Dramas keine Entwicklung. Sie stehen bereits von Anfang an als fertige Muster da. Die plautinischen Sklaven sind schon zu Beginn die Sieger, die Väter und Kuppler die Verlierer. Daher kann der Sklave schon am Anfang des Stücks eine Triumph-Arie anstimmen, auch wenn die Handlung dafür keinen Anlaß bietet. Denn es geht bei ihm nur um die Idee des triumphierenden Sklaven, nicht aber darum zu zeigen, wie es zu diesem Triumph kommt. Ebenso ist schon zu Beginn des Stücks Senecas Oedipus der Gestürzte, Verfolgte, Medea die Kindermörderin. Die römischen Dramen kennen weder Organik noch Ơkonomie. 
Der abstrakten Idee gegenüber verliert alles Konkrete an Bedeutung. Die Exposition des Faktischen ist ebenso zweitrangig wie die Abgrenzung des Ortlichen. Oft hat man den Eindruck, daß das römische Drama im luftleeren Raum spielt. In der Komödie gehen griechische und römische Ortlichkeiten munter durcheinander, und in Senecas Tragödien ist der Schauplatz zuweilen überhaupt nicht zu fixieren. Terenz ist in seinem Stil schon wesentlich ungegenständlicher als Plautus, weniger konkret, er ist auf dem Weg zu Seneca. Grillparzer konnte zu Recht sagen:

Kann ich nicht genug Lateinisch, oder sind die Exemplare des Terentius so mangelhaft, vieles verstehe ich in diesen Komödien nicht. Aus dem Sinn erraten kann ich es so gut als die Kommentatoren, daß aber das römische Volk so gewandt gewesen sein sollte, um derlei dunkle Andeutungen im Vorüberrollen der Rede zu verstehen, bleibt mir immer rätselhaft.

Die Einheit des griechischen Dramas liegt im Logos, die des römischen im Pathos. Wenn der einzelne Baustein nicht von der Umgebung gestützt wird, sondern beliebig vergrößert werden kann, da er das Ganze verkörpert, ist es natürlich, daß er so repräsentativ wie möglich ausgestaltet werden muß. Dem Pathos ist als bestimmendem Element damit keine Grenze mehr gesetzt. Diesen Prozeß spiegelt die Sprache des römischen Dramas in ihrer Abundanz und Exuberanz folgerichtig wider. Das aus Menanders >Dis exapaton « überlieferte Stückchen, das Mnesilochus' Mono$\log$ vorhergeht, zeigt den Unterschied zu den griechischen Vorbildern ebenso deutlich wie der besprochene Monolog selbst. Wo Menander vov-

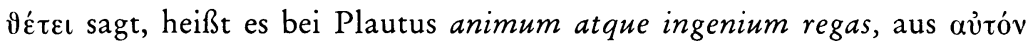

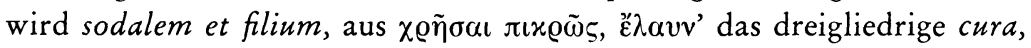

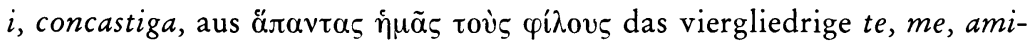
cum atque alios ('Bacchides، 494-498). Cassandras Warnung aus Ennius' >Alexander erhebt sich in den Alliterationen am Beginn und den Antithesen am Schluß zu eindrücklichem Pathos: 'Mutter, beste aller Frauen, ich bin von Weissagungen getrieben worden, und Apollo schlägt mich nicht wider Willen - durch Prophezeiungen mit Wahnsinn. Ich meide die gleichaltrigen Mädchen und schäme mich meiner Tat vor meinem Vater, dem besten Manne. Mutter, du jammerst mich, meinetwegen empfinde ich Verdruß. Die besten Kinder hast du Priamus geboren - außer mir; das schmerzt mich: daß ich schade, sie nützen, daß ich nicht gehorche, sie willfährig sind!'

mater optumarum multo mulier melior mulierum, missa sum superstitiosis hariolationibus, 
neque me Apollo fatis fandis dementem invitam ciet. virgines vereor aequalis, patris mei meum factum pudet optumi viri. mea mater, tui me miseret, mei piget.

optumam progeniem Priamo peperisti extra me; hoc dolet: med obesse, illos prodesse, me obstare, illos obsequi!

Cicero, der diese Verse in seiner Schrift $>$ De divinatione 1, 66 zitiert, unterbrach sich an dieser Stelle und rief aus: o poema tenerum et moratum atque molle, welch zarte, charaktervolle und dahinströmende Dichtung! Höchstes Pathos spricht aus Andromaches überbordender Klage in Ennius' gleichnamigem Stück: 'O Vater, Vaterland, Priamus' Haus, du Tempel, geschlossen von tönender Angel; ich sah dich, als unsere Macht noch stand, königlich mit deinen Kassettendecken, Gold und Elfenbein. Dies alles sah ich in Flammen aufgehen, Priamus sterben, Iupiters Altar von Blut entweiht werden':

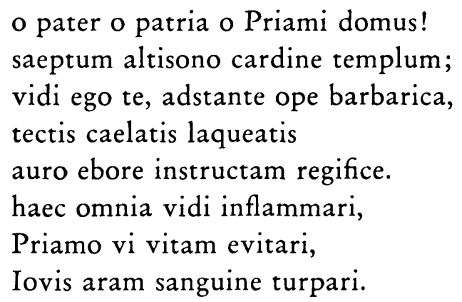

Auch bei der Zitierung dieser Verse in den >Tusculanae Disputationes 3, 44-45 unterbricht sich Cicero nach dem fünften Vers mit dem Ausruf O poetam egregium, welch herrlicher Dichter! Und er sagt vom Ganzen, es sei ein einzigartiges Gedicht; es drücke sowohl in den Gedanken als auch in den Worten und im Rhythmus die Trauer aus, praeclarum carmen; est enim et rebus et verbis et modis lugubre.

Beidemal hebt Cicero den Duktus und den Rhythmus der Verse hervor. Mit Recht kann man angesichts des Auskostens der Formulierungen und des Schwelgens in Klangmalereien bei großen Teilen der republikanischen Tragödie und Komödie von einer alle logischen Brüche überdeckenden, alle verstandesmäßigen Bedenken fortschwemmenden Wortmusik sprechen. Überdies wurden etwa zwei Drittel dieser Stücke - jedenfalls der Komödien, wohl aber ebenso der Tragödien der republikanischen Zeit im Gegensatz zu den griechischen Vorlagen zu Musikbegleitung rezitiert oder gar gesungen. Man verwandelte die attischen Sprechdramen in Singspiele, die auf einer ganz anderen Ebene von den Dichtern konzipiert 
und von den Zuschauern rezipiert wurden. Scheint im römischen Drama ein Monolog oder eine Szene in eine Summe von einzelnen Gedanken und Einfällen zu zerfallen, so werden diese auf der Ebene des Klangs und der Musik wieder zu einer die verschiedenen Elemente zusammenstimmenden Einheit verschmolzen. Auch senecaische Monologe und Chorlieder, die wohl ohne Musikbegleitung vorgetragen wurden, haben in ihrer von Paradoxien und Pointen geprägten Klangfülle eine auf dieser Ebene bestrickende Einheit.

Während die Einheit des griechischen Dramas in seiner vom Logos bestimmten Dynamik liegt, läßt zwar die Statik des römischen Dramas die Stücke in Einzelszenen auseinanderfließen und die einzelnen Teile zum Selbstzweck werden, doch sind diese auf der Ebene des Pathos, mit dem die Ideen und Haltungen verkörpert, demonstriert, nicht jedoch entwikkelt werden, wieder zu einem mehr die Sinne und das Gefühl als den Verstand ansprechenden Einheit zusammengeschlossen. Was W. Schadewaldt über eine dramaturgische Neuerung von Terenz im Vergleich zur griechischen Komödie gesagt hat, gilt im allgemeinen Sinne vom ganzen römischen Drama:

Bestätigt es sich, daß Terenz eine Prologrede beseitigte, so machte er zugleich dem Gefühl des Zuschauers, indem er ihn unwissender ließ, den Seelenton innerlichen Leidens vernehmbarer: was die Menschen auf der Bühne tun und fühlen, tut und fühlt der Hörer mit ihnen, und was sie sagen, scheint aus innerer Tiefe zu kommen und ist ihm mehr zu Herzen gesagt.

'Gefühl', 'Seelenton', 'Leiden', 'innere Tiefe', 'zu Herzen sagen' - dieser einheitliche Grundzug der römischen Komödien und Tragödien hat seine Wirkung auf das europäische Drama nicht verfehlt.

$\mathrm{Nachbemerkung:Die} \mathrm{vorstehenden} \mathrm{Uberlegungen} \mathrm{stellen} \mathrm{den} \mathrm{Versuch}$ dar, die vielfältigen Erscheinungsformen des römischen Dramas - der Tragödie und der Komödie - aus einer gemeinsamen Wurzel zu erklären. Dem Charakter einer Typologie gemäß war eine unbedingte Konzentration auf die wesentlichen Züge des römischen Dramas erforderlich. Die selbstverständliche Tatsache, daß in nahezu jedem Punkt eine Reihe von Gegenbeispielen beigebracht werden kann und der Potentialis 'richtiger' als der Indikativ wäre, sollte nicht zu dem Verzicht auf solche Versuche führen. Entsprechend der Vorläufigkeit der Darlegungen wurde auf eine Auseinandersetzung mit der gelehrten Literatur verzichtet, obschon der kundige Leser bemerken konnte, wieviel ihr verdankt wird. Durch die 
90 Eckard Lefèvre: Versuch einer Typologie des römischen Dramas

Ausführlichkeit der anderen Abhandlungen mag dieses Verfahren ein wenig gerechtfertigt werden. Einzelnachweise werden für die Tragödie gegeben in: Die römische Tragödie oder die Überwindung der Tragik durch die Ideologie (noch nicht erschienen), für die Komödie in: "Die römische Komödie“, Neues Handbuch der Literaturwissenschaft, Bd. III: Die römische Literatur, hrsg. v. M. Fuhrmann, Frankfurt 1974, S. 33-62. Der Verf. weiß sich vielen Gesprächen mit Gustav Adolf Seeck, Kiel, verpflichtet sowie seinem unten folgenden Beitrag über Senecas Tragödien. 